Helmut König, Manfred Sicking (Hg.)

D e r I r a k - Kri e g und die

Zukunft Europas

[transcript] 
Helmut König, Manfred Sicking (Hg.)

Der Irak-Krieg und die Zukunft Europas 

Helmut König, Manfred Sicking (Hg.)

Der Irak-Krieg und die Zukunft Europas

[transcript $]$ 


\section{(9)(1) $\Theta \Theta$}

Dieses Werk ist lizenziert unter der Creative Commons Attribution-NonCommercial-NoDerivs 4.0 Lizenz (BY-NC-ND). Diese Lizenz erlaubt die private Nutzung, gestattet aber keine Bearbeitung und keine kommerzielle Nutzung. Weitere Informationen finden Sie unter https://creativecommons.org/licenses/by-nc-nd/4.o/deed.de/. Um Genehmigungen für Adaptionen, Übersetzungen, Derivate oder Wiederverwendung zu kommerziellen Zwecken einzuholen, wenden Sie sich bitte an rights@transcript-verlag.de

\section{(C) 2004 transcript Verlag, Bielefeld}

Die Verwertung der Texte und Bilder ist ohne Zustimmung des Verlages urheberrechtswidrig und strafbar. Das gilt auch für Vervielfältigungen, Übersetzungen, Mikroverfilmungen und für die Verarbeitung mit elektronischen Systemen.

\section{Bibliografische Information der Deutschen Nationalbibliothek}

Die Deutsche Nationalbibliothek verzeichnet diese Publikation in der Deutschen Nationalbibliografie; detaillierte bibliografische Daten sind im Internet über http://dnb.d-nb.de abrufbar.

Umschlaggestaltung und Innenlayout: Kordula Röckenhaus, Bielefeld Satz: digitron $\mathrm{GmbH}$, Bielefeld

Druck: Majuskel Medienproduktion GmbH, Wetzlar

Print-ISBN 978-3-89942-209-2

PDF-ISBN 978-3-8394-0209-2

Gedruckt auf alterungsbeständigem Papier mit chlorfrei gebleichtem Zellstoff. Besuchen Sie uns im Internet: http://www.transcript-verlag.de Bitte fordern Sie unser Gesamtverzeichnis und andere Broschüren an unter: info@transcript-verlag.de 


\section{Inhalt}

Helmut König, Manfred Sicking

Einleitung $\ldots \ldots \ldots \ldots \ldots \ldots \ldots$

ERnSt-OtTo CZEMPiel

Europa und die USA im Streit . . . . . . . . . . . . . . 2I

Christian Tomuschat

Das Völkerrecht und die Rolle der Vereinten Nationen . . . . . 43

August Pradetto

Die NATO im Geflecht internationaler Organisationen . . . . . 67

HeRfRIED MÜNKLER

Was ist neu an den neuen Kriegen? . . . . . . . . . . IOI

JÜRGEN KOCKA

Wo liegst du, Europa? Europäische Identität als Konstrukt . . . II7 
Emanuel Richter

Die Europäische Verfassung als »demokratisches Projekt« . . . I43

GUdRUN KRÄMER

Von Normen und Werten:

Religion, Recht und Politik im modernen Islam . . . . . . . . I7I

Zu den Herausgebern und Autoren . . . . . . . . . . I9I 


\section{Einleitung}

\section{Helmut König, Manfred Sicking}

I.

Die weltpolitischen Konsequenzen des Krieges, den die USA und ihre >Koalition der Willigen < im März/April 2003 gegen den Irak geführt haben, sind noch nicht im Einzelnen abzusehen. Aber eine Folge ist bereits sichtbar: Von niemandem erwartet, ist eine intensive öffentliche Debatte über die internationale Ordnung und die zukünftige Rolle Europas in Gang gekommen. Der IrakKrieg ist zum Katalysator einer breiten Diskussion über europäische Erneuerung und europäische Identität geworden. An ihr beteiligen sich nicht nur die jeweiligen (außen-)politischen Experten der Parteien, der Wissenschaft und der Medien, sondern darüber hinaus und vor allem eine Reihe namhafter europäischer Intellektueller.

Das ist überraschend und neu. Erst jetzt, zu Beginn des 2I. Jahrhunderts und in der Situation tiefer Ratlosigkeit angesichts eines nach dem Zweiten Weltkrieg beispiellosen weltpolitischen Alleingangs durch die USA, beginnen die Intellektuellen damit, 
Europa zu entdecken und zu ihrem eigenen Thema zu machen. Die großen Intellektuellen des i9. und 20. Jahrhunderts dagegen haben sich, von wenigen Ausnahmen abgesehen, für Europa nicht interessiert. (Vgl. Lepenies I99I) Zu den Ausnahmen zählen im 20. Jahrhundert einige mittel- und osteuropäische Intellektuelle, für die die Zugehörigkeit zu (West-)Europa zum Inbegriff von Freiheit und Unabhängigkeit wurde und die deswegen Mitteleuropäische Meditationen verfassten. (Vgl. Konrád 1985) Große Resonanzen hat das nicht hervorgerufen.

»Es ist beschämend, aber in der Summe kann gesagt werden, dass die deutschen Intellektuellen weniger für Europa geleistet haben als jeder andere Berufsstand: Europa hat sie gelangweilt.« (Harpprecht 2002: 20)

Es gibt keinen Grund, diese Aussage auf die deutschen Intellektuellen einzuschränken.

Im mainstream der intellektuellen Debatten der letzten 200 Jahre lagen Themen, die wenig mit Europa zu tun hatten. Die rechten Intellektuellen beschäftigten sich überwiegend mit Staat und Nation, und die linken Intellektuellen kümmerten sich um menschheitliche Fragen. Europa als analytischer Begriff oder als politisch-kulturelle Idee hatte in einer geistigen Welt, die von den Polen Nationalstaat und Menschheit geprägt war, keinen Ort, allenfalls einen negativen. Europa wurde

»als ein mehr oder minder deutlich ausgeprägter Gegenentwurf zu den je eigenen politischen Perspektiven wahrgenommen: im einen Fall als eine die Bestimmtheit von Staat und Nation aufweichende Größe, im anderen Fall als ein universalen Menschheitsperspektiven entgegenstehendes Machtkonglomerat, das als Ausgangspunkt von Kolonialismus und Imperialismus, als Ort innerer Kriege und Bürgerkriege den Visionen einer friedlichen Menschheitsordnung eher entgegenstand als sie beförderte.« (Münkler I996: 97) 
Ende Mai 2003 ergriff eine Reihe namhafter Intellektueller die Initiative und eröffnete in verschiedenen großen europäischen Zeitungen eine Debatte über die Identität und Zukunft Europas nach den Verwerfungen des Irak-Krieges. Jürgen Habermas und Jacques Derrida beklagen in ihrem gemeinsamen Beitrag selbstkritisch das Versagen der Intellektuellen, die es bislang nicht geschafft hätten, das Thema Europa auf die öffentliche Agenda zu setzen, und fordern dazu auf, eine »attraktive, ja ansteckende >Vision für ein künftiges Europa« zu entwerfen (Derrida/Habermas 2003). Vielleicht markiert der Irak-Krieg tatsächlich den Beginn eines europaweit geführten Diskurses, die Geburtsstunde einer europäischen Öffentlichkeit, den historischen Augenblick, in dem Europa damit beginnt, jenen gemeinsamen Erfahrungs-, Erinnerungs- und Kommunikationsraum auszubilden, dessen Fehlen häufig beklagt und als entscheidendes Hindernis einer vertieften europäischen Integration ausgemacht wurde. (Vgl. Kielmannsegg 1996)

\section{II.}

Zur Eröffnung der Pariser Weltausstellung des Jahres I867 schrieb der damals in Frankreich verfemte Victor Hugo eine »majestätische Vision« über die Zukunft Europas im 20. Jahrhundert. Die europäische »Nation«, so meinte Hugo, wird »edel, reich, verständig, friedfertig und der übrigen Menschheit gegenüber herzlich gesinnt« sein, sie wird sich

»über den Ruhm der kegelförmigen Geschosse wundern, und sie wird einen General kaum von einem Schlächter unterscheiden können; [...] eine Schlacht zwischen Italienern und Deutschen, zwischen Engländern und Russen, zwischen Preußen und Franzosen wird ihr so vorkommen wie uns eine Schlacht zwischen Pikarden und Burgundern. Die Vergeu- 
dung von Menschenblut wird ihr unnütz erscheinen. [...] Jede Grausamkeit wird sie beschämen und entrüsten. Der Anblick eines Schafotts wird ihr eine Beleidigung sein. [...] Man wird nirgends die Freizügigkeit behindern. Die Grenzflüsse werden Pulsadern sein. Eine Brücke zerstören wird so unmöglich sein wie eine Enthauptung. [...] Überall wird das Eisen in Schwertform verschwinden, um als Pflugschar wiederzuerscheinen. Im 20. Jh. wird [diese Nation] sich Europa nennen, in späteren, noch mehr verwandelten Jahrhunderten wird sie Menschheit heißen. [...] Die Verbrüderung des Kontinents - das ist die Zukunft.« (Zitiert nach Foerster I963: 222f.)

Die Vision wurde nicht aufgegriffen, sie setzte keine Debatte in Gang. Und in fast allen Punkten hat sich Hugo geirrt: Das 20. Jahrhundert ist nicht das Jahrhundert Europas und der Zivilisation geworden, sondern das Jahrhundert der Katastrophen. Ihre Haupthöllen heißen: Erster Weltkrieg, Zweiter Weltkrieg, Holocaust, Gulag, Hiroshima. Es gibt kein Jahrhundert, das dem 20. an Schrecken und Terror gleichkommt. Dass >Europa $<$ darauf eine Antwort, dass >Europa< überhaupt eine große Idee sein könnte, - diese Vorstellung blieb auch in der zweiten Hälfte des 20. Jahrhunderts auf einige weitblickende Politiker begrenzt, die bei den tonangebenden Intellektuellen nicht auf Unterstützung rechnen konnten.

Europa ist bis heute im Kern ein Projekt geblieben, das funktionalen Gesichtspunkten und Interessen gehorcht und der Herstellung eines großen Wirtschafts- und Währungsgebiets gedient hat. Den marktschaffenden Entscheidungen wurden keine vergleichbar weitreichenden Maßnahmen für ein politisches, kulturelles und soziales Europa zur Seite gestellt. Wie kein Ereignis zuvor konfrontiert der Irak-Krieg die Europäer nun mit der Tatsache, dass sich europäische Politik nicht darin erschöpfen kann, den Austausch von Gütern, Kapital, Personen und Dienstlei- 
stungen zu organisieren, und dass sich Wirtschaftsmacht nicht automatisch in (welt-)politische Macht übersetzt.

\section{III.}

Die Liste der berechtigten Gravamina gegenüber den USA ist lang. Die amerikanische Weltpolitik nach Clinton und im Vorfeld, im Verlauf sowie nach dem Ende des dritten Golf-Krieges ist hoch fragwürdig. Massenvernichtungswaffen im Irak wurden bislang nicht gefunden, die Verbindungen zum Terrornetzwerk Al Qaida konnten nicht nachgewiesen werden. Die angeblichen Behauptungen und Berichte der Geheimdienste über irakische Pläne zur Uranbeschaffung und eine Irak-Afrika-Connection werden zunehmend unglaubwürdiger und changieren zwischen Tragödie und Komödie. Das hat nun auch in den USA und den Ländern der Kriegskoalition zu heftigen Diskussionen über gezielte Falschinformationen der Öffentlichkeit vor dem Kriegsbeschluss geführt. An ihrem Ende könnte eine völlige Neubewertung des Krieges gegen den Irak stehen und die eine oder andere Regierung ins Strudeln geraten. Der Verdacht der gezielten Täuschung und Irreführung in der Informationspolitik wiegt in Demokratien schwer.

Die USA haben mit imperialem Gestus die Verfahren der kooperativen Politik im Raum des internationalen Systems verlassen, die sie selber über Jahrzehnte hinweg maßgeblich mit aufgebaut haben. Seit dem Amtsantritt von Bush hat die amerikanische Außenpolitik unübersehbar militarisierte, unilaterale und hegemoniale Züge angenommen. Wichtige internationale Übereinkünfte gehen erstmals seit I945 nicht mehr von den USA aus und kommen überhaupt nur noch gegen deren Willen zustande. 
Die Geringschätzung internationaler Kooperationen, Institutionen und Regime, die generelle Geringschätzung von soft power als Mittel für Konfliktregelungen ist dem amerikanischen Selbstbild nie fremd gewesen. Nach dem Ende des Kalten Krieges hat sie durch die hegemoniale Stellung der USA gewaltigen Auftrieb erhalten. Hegemoniale Haltungen in Verbindung mit heilsgeschichtlichem Sendungsbewusstsein im Dienste von Fortschritt, Freiheit und Demokratie entkoppeln den Gebrauch der politischen Macht von rechtlichen Bindungen und den Prinzipien der Reziprozität, wie sie in der liberalen Staatsphilosophie seit dem ausgehenden I8. Jahrhundert entworfen wurden und nach und nach Eingang in die politische Praxis gefunden haben. Ein Hegemon begreift sich als absolut souverän, als Gebieter über den Ausnahmezustand. Er entbindet sich von den Einschränkungen, die rechtliche und vertragliche Regelungen ihm auferlegen. Für den Hegemon gilt der Satz aus dem Buch Hiob des Alten Testaments, den Thomas Hobbes 165I über das Frontispiz seines Leviathan schrieb: Non est potestas super terram quae comparetur ei. Tatsächlich gibt es keine Macht der Erde, die mit seiner Macht gleichgesetzt werden könnte. $\mathrm{Zu}$ supranationalen Institutionen und Regelungen hat der Hegemon ein instrumentelles und interessenbestimmtes Verhältnis. Solange sie der Durchsetzung der eigenen Interessen unmittelbar dienlich sind, werden sie anerkannt, sonst nicht.

In den USA ist gegenwärtig diese instrumentalisierende Lesart des Völkerrechts und der internationalen Kooperationen tonangebend. Das wird nicht dazu führen, dass die USA aus der UNO austreten, obwohl auch das der eine oder andere amerikanische Politiker gelegentlich in Erwägung zieht. Aber vorherrschend ist ein im Wesentlichen taktisches Verhältnis zu diesen Institutionen - und offensichtlich auch zu Europa. Wenn es den eigenen Interessen nützt, werden Formen und Verfahren beiseite geschoben. Das ist der Kern der Unterscheidung, die Robert 
Kagan so unverblümt und treffend ausgedrückt hat: Die Amerikaner leben in der Hobbes-Welt der Realpolitik, in der ein Vertrag wenig gilt und die Macht alles ist, die Europäer hingegen träumen mit Kant vom Ewigen Frieden. (Vgl. Kagan 2003)

Der Preis für die Rückkehr zum Paradigma der Staatstheorie von Hobbes ist hoch, auch für den Hegemon USA. Das mit ihr verknüpfte Messen mit zweierlei Maß führt zum Verlust an Glaubwürdigkeit, zur Demütigung von Freunden und Feinden und vor allem zu einer gravierenden Unterschätzung der politischen Konsequenzen, die mit Glaubwürdigkeitsverlusten und Demütigungen einhergehen. Die USA brechen das Völkerrecht und wollen zugleich als Verkündiger des Rechts und der Rechtsstaatlichkeit in der arabischen Welt anerkannt werden. Sie fordern die Einhaltung des ius in bello und verwehren den Inhaftierten auf ihrem Stützpunkt Guantanamo Bay den Status als Kriegsgefangene. Sie entwickeln Pläne für die strafrechtliche Ahndung der Makrokriminalität im Irak und bekämpfen zugleich den Internationalen Strafgerichtshof, weil sie meinen, ihre Bürger vor jedweder Anklage durch dieses Gericht schützen zu müssen.

Ungleichbehandlungen werden von den Gedemütigten nicht vergessen. Im kollektiven Gedächtnis der arabischen Welt haben sich Bilder eingegraben, an deren Entstehung die USA großen Anteil hatten. Zweifellos beruhen diese Bilder in vielen Fällen auf Verzerrungen und Klischees, sie täuschen über die selbstverschuldeten Blockaden der islamischen Welt hinweg und verschleiern die wirklichen Probleme. Aber zugleich können sie sich von den vielen Beispielen nähren, in denen die USA auf der Seite von Gewaltherrschaften, auch der von Saddam Hussein, standen. Immer wieder haben die USA Militärdiktaturen unterstützt und beim Sturz von Demokratien geholfen, von der Niederschlagung der Unabhängigkeits- und Demokratie-Bewegung auf den Philippinen über die Ermordung des ersten gewählten 
kongolesischen Präsidenten Patrice Lumumba bis zu den (verdeckten) Interventionen im Iran I953, in der Dominikanischen Republik I968 oder in Chile 1974.

\section{IV.}

So wird es wieder nur eine Frage der Zeit sein, bis Zynismus, Doppelzüngigkeit und Unfähigkeit der amerikanischen Politik erneut ans Tageslicht kommen. Es hat ja schon begonnen. Die Schwierigkeiten der Besatzungsmächte im Irak nehmen täglich zu. Nichts von den anvisierten Zielen, die erreicht werden sollten, ist bislang zu sehen. Im Gegenteil: Es mangelt an der Gewährleistung von Sicherheit und physischer Subsistenz, die Wasserversorgung funktioniert nicht, das Erziehungswesen kommt nicht in Gang, zu schweigen vom Aufbau einer Zivilgesellschaft mit unabhängigen Medien und Verbänden oder der Entwicklung eines politischen Systems mit politischen Parteien, demokratisch legitimierten Parlamenten und Regierungen, mit einer funktionierenden Verwaltung und unabhängiger Justiz.

Zur Beschädigung der normativen Autorität, die die USA nicht wahrhaben wollten, kommt nun die Beschädigung ihrer faktischen Autorität, die sie nicht mehr ignorieren können. Schmerzlich wird ihnen bewusst, dass die Kosten weitaus höher sind als kalkuliert und dass die Erfolgsaussichten für eine rasche Realisierung ihrer Ziele schwinden. Mittlerweile ist nicht einmal mehr sicher, ob der Krieg wirklich gewonnen ist oder sein offiziell verkündetes Ende nur der Beginn eines neuen Krieges ist. Das amerikanische Militär spricht offen vom Guerillakrieg, dem es sich ausgesetzt sieht, und weckt damit die Erinnerung an das tief sitzende Trauma des Vietnamkriegs.

Schneller als gedacht ist damit der amerikanischen Überheblichkeit der Boden entzogen worden. Nicht einmal auf ihrem 
nach Kagan ureigenen Gebiet, dem Hobbesschen Staatsziel der Sicherheitsproduktion, scheinen die USA erfolgreich $\mathrm{zu}$ sein. Und auf die Dauer wird sich die amerikanische Bevölkerung nicht mit dem immer häufiger zitierten Satz von Roosevelt beruhigen lassen, dass es schwieriger ist, den Frieden zu gewinnen als Feinde im Kriege zu besiegen. $\mathrm{Zu}$ sehr ist diese Formel dazu angetan, die eigenen Fehler und das eigene Versagen zu kaschieren.

\section{V.}

Die Weltgeschichte ist kein Weltgericht, und europäische Genugtuung und Schadenfreude über Schwächen, Ohnmacht und Fehler von anderen machen eigene Unfähigkeiten auf die Dauer nicht wett. Wer für die Zukunft Europas auf diese Logik baut, betreibt die Renaissance der europäischen Identität aus dem Geist des Ressentiments und der vordergründigen Abgrenzung gegen die USA. Das ist gewiss verlockend. Denn noch immer gibt es nichts Besseres für die innere Einigung und Integration als einen gemeinsamen äußeren Gegner. Nichts eint so sehr, nichts lässt so leicht die internen Differenzen vergessen wie die Gemeinsamkeit eines Antipoden.

Aber es ist noch keine europäische Außen- und Sicherheitspolitik, beim Scheitern des amerikanischen Hegemons im Irak oder im Nahen Osten zuzusehen. Der Irak-Krieg zeigte das Scheitern der gemeinsamen europäischen Außen- und Sicherheitspolitik, - das heißt nicht, dass die amerikanische Außenpolitik gelingen muss. Und umgekehrt ist ein mögliches Scheitern der Amerikaner im Irak keine Garantieurkunde für die Qualitäten Europas. Für europäische Überheblichkeit gibt es ohnedies keinen Grund. Die Liste der Fälle, in denen Europa (und die UNO) nach I945 kläglich versagt haben, ist nicht kürzer als die 
entsprechende Liste der USA, - von den Schandtaten auf dem europäischen Kontinent in der ersten Hälfte des 20. Jahrhunderts $\mathrm{zu}$ schweigen. An erster Stelle steht die deprimierende Tatenlosigkeit im Balkankonflikt, die das Terrain für die Massenmorde in Srebrenica ebnete. Diese Erfahrung ist es, die im Hintergrund der Haltungen vieler osteuropäischer Politiker und Intellektueller wie Adam Michnik oder Václav Havel steht, die beim Kampf gegen Menschenrechtsverbrechen und Despoten eher den USA vertrauen als den Europäern und der UNO.

Die Ohnmacht des Völkerrechts und die immer wieder unter Beweis gestellte Tatenlosigkeit der UNO unter Einschluss der Europäer gegenüber tyrannischen Regimen und Völkermorden ist ein Skandal: gestern in Ruanda, heute im Kongo. Die Europäer favorisieren den Einsatz von soft power, von Verhandlungen, gesellschaftlichen Beziehungen, ökonomischen Kooperationen, internationalen Regimen. Aber der Einsatz von soft power ist nicht immer gut, der Einsatz von Gewalt nicht immer schlecht. Die Anzahl der Toten im Irak, die auf den Wirtschaftsboykott zurückgehen, übersteigt die Toten des Krieges um ein Vielfaches. Auch die Europäer haben mit Despoten kooperiert, und auch das Stillhalten gegenüber Tyranneien ist eine politische Entscheidung. Ein europäisches Bewusstsein für die Paradoxien und Ambivalenzen politischen Handelns und Übungen zur Steigerung der politischen Urteilskraft sind dringend erforderlich. Es sollte mit einigen Naivitäten aufräumen und mindestens die Unterscheidung zwischen Verantwortungs- und Gesinnungsethik und das Problem der Divergenz von Mitteln und Zwecken in der Politik in Erinnerung rufen.

Und ob die Europäer wenigstens in Sachen nation- und statebuilding wirklich besser sind, ist keineswegs ausgemacht und erst noch unter Beweis zu stellen. Sicher: Die Erfolgsquote der USA auf diesem Gebiet ist nicht sehr hoch. In den I6 Fällen, in denen amerikanische Regierungen in den letzten einhundert 
Jahren nach Militärinterventionen versucht haben, einen demokratischen Staat aufzubauen, waren sie nur zweimal erfolgreich, nämlich in der Bundesrepublik und in Japan. Und im Falle des Irak werden die Voraussetzungen als besonders schlecht eingeschätzt. (Vgl. Pei/Kasper 2003)

Ob die UNO im Kosovo viel mehr erreichen wird als die USA in anderen Fällen erreicht haben, darf durchaus bezweifelt werden. Vier Jahre nach dem Ende des Krieges ist dort die Lage in einigen Bereichen kaum besser als heute, einige Monate nach dem Ende des dritten Golfkrieges im Irak. Auch in Bosnien oder Afghanistan kann bislang von mehr als sehr bescheidenen Ansätzen eines funktionierenden Staats- und Gemeinwesens keine Rede sein.

Und Enzensberger hatte schon Recht: Etwas mehr Freude über das Ende des despotischen Regimes im Zweistromland wäre angebracht gewesen, etwas mehr Erschrecken über das Ausmaß der Tyrannei und des Mordens und über die eigene Gleichgültigkeit ihnen gegenüber ebenso. (Vgl. Enzensberger 2003) Die Kriegs- und Menschenrechtsverbrechen des irakischen Tyrannen und seiner Helfer sind keine quantité négligeable: Giftgasangriffe auf Halabdscha im Jahre I988, Einsatz chemischer Waffen im ersten Golfkrieg gegen den Iran, Verfolgung und Ermordung irakischer Kurden und Schiiten, jahrelanger Gebrauch von Terror bei der Verfolgung der Regimegegner, scheußlichste Foltermethoden (Ausstechen von Augen, Elektroschocks und Säurebäder, Durchbohren der Handflächen mit Elektrobohrern), Massenmorde, die in die Tausende gehen, Sippenhaft, Zwangsvertreibungen. Anerkannte Menschenrechtsorganisationen wie Human Rights Watch und Amnesty International haben darüber seit Jahren berichtet.

Die Beiträge des vorliegenden Buches gehen auf eine Vortragsreihe zurück, die anlässlich der Verleihung des Internationalen 
Karlspreises zu Aachen an Valéry Giscard d'Estaing im Mai 2003 veranstaltet wurde. Die Beiträge des Buches bieten eine Bestandsaufnahme und greifen einige Aspekte, Elemente und Themen auf - beileibe nicht alle -, die für die Zukunft Europas nach dem Irak-Krieg zentral sind.

Ernst-Otto Czempiel zeigt, wie tief der Riss zwischen Europa und den USA geht und worauf er zurückzuführen ist. Christian Tomuschat untersucht die ablehnende Haltung, die die USA zum Völkerrecht und zu den Vereinten Nationen in der Irak-Krise eingenommen haben, und lotet die Perspektiven für eine Veränderung dieser Haltung aus. August Pradetto analysiert die Auswirkungen für die NATO, die seit ihrer Gründung I949 eine wichtige transatlantische Klammer war und im Konflikt um den Irak-Krieg völlig an den Rand gedrängt worden ist. Herfried Münkler zeigt, dass der überlegene Sieg der >Koalition der Willigen im Irak-Krieg und die sich abzeichnenden Guerillakämpfe die zwei Seiten der neuen Kriege sind, die das 2I. Jahrhundert prägen werden. Jürgen Kocka legt dar, dass sich die Idee einer europäischen Identität zwar auf eine Reihe von Vorarbeiten und Traditionen stützen kann, aber im Kern und unvermeidlich eine Konstruktion, eine politische Konstruktion ist. Emanuel Richter unterzieht den Entwurf für eine europäische Verfassung einer demokratietheoretisch ausgerichteten Lektüre und fragt nach dem Erscheinungsbild der >Weltmacht Europa<, das dort formuliert wird. Und schließlich - last but not least - analysiert Gudrun Krämer das Verhältnis des Islam zur Moderne, das seit den Thesen von Huntington und den Ereignissen des II. September 200I zu Recht zu einem zentralen Bezugspunkt der weltpolitischen Zukunftsdiskussionen geworden ist.

Die Beiträge sind Wortmeldungen in einer Debatte, die gerade erst angefangen hat, und sie sind zugleich Interventionen in politische Verwerfungen und Entwicklungen, von denen noch niemand genau weiß, wohin sie gehen werden und wohin sie 
gehen sollen. Es ist selbstverständlich, dass jeder Mitarbeiter dieses Buches für seine Ausführungen und Positionen selbst verantwortlich ist.

Die Herausgeber danken Sabine Schielke für die redaktionelle Bearbeitung der Manuskripte und dem Kulturwissenschaftlichen Institut Essen sowie dem Außen-Institut der RheinischWestfälischen Technischen Hochschule Aachen für die Unterstützung bei der Publikation dieses Buches.

\section{Literatur}

Derrida, Jacques/Habermas, Jürgen (2003): »Unsere Erneuerung. Nach dem Krieg: Die Wiedergeburt Europas«, in: Frankfurter Allgemeine Zeitung vom 31.05.2003.

Enzensberger, Hans Magnus (2003): »Blinder Frieden. Eine Nachschrift zum Irak-Krieg«, in: Frankfurter Allgemeine Zeitung vom 15.04 .2003 .

Foerster, Rolf Hellmut (Hg.) (1963): Die Idee Europa 1300 - 1946. Quellen zur Geschichte der politischen Einigung, München.

Harpprecht, Klaus (2002): »Keine Festouvertüre für den Euro aber ein Glückstag«, in: Neue Gesellschaft/Frankfurter Hefte, Heft I/2.

Kagan, Robert (2003): Macht und Ohnmacht. Amerika und Europa in der neuen Weltordnung, Berlin.

Kielmansegg, Peter Graf (1996): »Integration und Demokratie«, in: Markus Jachtenfuchs/Beate Kohler-Koch (Hg.): Europäische Integration, Opladen.

Konrád, György (1985): Antipolitik. Mitteleuropäische Meditationen, Frankfurt a.M.

Lepenies, Wolf (I99I): »Aufstieg und Fall der Intellektuellen in Europa«, in: Neue Rundschau, Heft I. 
Münkler, Herfried (1996): Reich, Nation, Europa. Modelle politischer Ordnung, Frankfurt a.M.

Pei, Minxin/Kasper, Sara (2003): »Lessons from the Past: The American Record on Nation Building «, in: Carnegie Endowment for International Peace, Policy Brief vom 24.03.2003. 


\title{
Europa und die USA im Streit
}

\author{
ERnST-OTto CZEMpiel
}

I.

Der gegenwärtige Streit zwischen Europa und den USA entzündete sich am Irak-Krieg, gilt aber eigentlich der Identität und der Rolle Europas in der Atlantischen Gemeinschaft und in der Welt. Natürlich war der Anlass bedeutend: Mit der Absicht und der Entscheidung, den Krieg gegen den Irak zu führen, obwohl es dafür keinen tragfähigen Grund gegeben hatte, hat sich die Bush-Administration aus der westlichen Wertegemeinschaft entfernt, die seit 1945 geltende Weltordnung demonstrativ gebrochen, das Gewaltverbot nach Artikel 2 Abs. 4 der Charta der Vereinten Nationen umgangen und das Gewaltmonopol des Sicherheitsrates ostentativ missachtet. Sie fand dafür keine Mehrheit im Sicherheitsrat und traf auf den besonderen Widerstand Frankreichs und Deutschlands. Gestützt auf die Öffentlichkeiten in Westeuropa hielten diese beiden Staaten an der alten Weltordnung, dem Kriegsverbot und dem Ordnungsmonopol des Sicherheitsrates fest. Sie forderten, weil es nach der UNO-Reso- 
lution I44I keine akute Bedrohung durch den Irak gab und seine Entwaffnung von Massenvernichtungswaffen durch die Entsendung und erfolgreiche Tätigkeit der Beobachtermission UMSCON gewaltfrei und erfolgreich durchgeführt werden konnte, es beim Aufbau der Drohkulisse zu belassen.

Die von den Vereinigten Staaten am 5. Februar vorgelegten >Beweise für die Existenz von Massenvernichtungswaffen im Irak überzeugten schon zu diesem Zeitpunkt niemanden außerhalb Washingtons. Da der erste von der Bush-Administration genannte Kriegsgrund, die Kooperation zwischen dem Irak und Al Qaida, selbst von den amerikanischen Nachrichtendiensten nicht geteilt wurde, gab es weder Anlass noch Begründung für einen amerikanischen Alleingang. Dass er am 20. März 2003 dennoch begonnen wurde, war in den Augen der Europäer ein massiver Verstoß gegen die Weltordnung. Sie war I945 schließlich nicht von irgendwelchen Idealisten, sondern von so hart gesottenen Realisten wie Präsident F.D. Roosevelt und Premierminister Winston Churchill in die Form der UNO-Ordnung gegossen und von allen amerikanischen Präsidenten anerkannt worden. Sie hatten dagegen verstoßen, aber nie die Norm selbst in Frage gestellt. Das tat die Bush-Administration. Sie re-nationalisierte die Verfügung über den Gewalteinsatz und gestaltete ihn, indem sie sich das Recht zum Präventionskrieg wie zur Präemption zulegte, offensiv und aggressiv.

Ein solcher Dissens in der Sache war zwischen den führenden Staaten Kontinentaleuropas und den USA noch nie aufgetreten, er ging an die Wurzeln der Gemeinsamkeit. Verschärft wurde er durch das apodiktische Verhalten von Bundeskanzler Schröder und Staatspräsident Chirac einerseits, die geradezu an Byzantinismus grenzende Einforderung des Gehorsams der Bundesgenossen durch den amerikanischen Präsidenten andererseits. Damit trat hinter dem Konflikt in der Sache der Konflikt 
um die Machtverteilung im Atlantischen Bündnis zutage. Es wurde sichtbar, dass es sich keinesfalls um ein Bündnis gleicher und souveräner Staaten, sondern um eine hegemoniale bzw. sogar imperiale Figur der Machtverteilung handelte. Die extreme Asymmetrie im Sachbereich der Sicherheit zwischen der Supermacht USA und den fünfzehn Klein- und Mittelstaaten Europas hatte das Verhältnis seit Jahrzehnten belastet. Die Einforderung der Gleichberechtigung durch die Westeuropäer und das demonstrative Versagen seitens der USA traten im Irak-Krieg als das eigentliche Forum der Auseinandersetzung überdeutlich zutage. Dazu hatten mehrere Faktoren beigetragen:

- das Ende des weltpolitischen Konfliktes mit der Sowjetunion und dem Warschauer Pakt, der eine überragende, von selbst wirkende Interessenidentität in der Atlantischen Gemeinschaft hergestellt hatte;

- das wachsende und durch ständige Aufrüstung schon während der Clinton-Administration gestärkte Selbstbewusstsein der Vereinigten Staaten, nunmehr eine überragende, einzigartige und auf Dauer nicht einholbare Machtposition im internationalen System zu besitzen;

- die politische Ausrichtung der Bush-Administration und der sie tragenden Koalition.

Während die Theorie des Realismus sich ausschließlich auf das positionelle Argument verlässt, nach dem die Außenpolitik eines Staates die Funktion seiner relativen Machtposition im internationalen System ist, sehe ich - zusammen mit der Liberalen Schule - im Herrschaftssystem und der politischen Orientierung der herrschenden Elite die entscheidende Variable. Die BushAdministration ist am äußersten Flügel des politischen Spektrums der USA angesiedelt. Sie stützt sich nicht auf den gemä- 
ßigten, sondern auf den radikalen Republikanismus, verstärkt durch Millionen politisierter Evangelikaler und finanziert durch die Raketen- und Energieindustrie.

Außenpolitisch knüpft sie dort an, wo ihr ideologischer Vorgänger, die Administration Ronald Reagan, aufgehört hatte: bei der Forderung nach Herstellung unbedingter Suprematie der USA. Mit dem >Projekt für ein neues amerikanisches Jahrhundert $<$ hatte sich diese Interessenkoalition 1997 erstmals öffentlich zu Wort gemeldet; sie hat den Wahlkampf geführt, sie hat ihn gewonnen. Die Spitzen dieser Gruppe von 1997 bilden heute die Regierung George W. Bush. Zu ihren primären außenpolitischen Zielen gehörte von Anfang an der Aufbau eines Raketenabwehrsystems und der Sturz Saddam Husseins. Dieses Konzept unterscheidet sich fundamental von den Konzepten sämtlicher Vorgänger (Ronald Reagan ausgenommen); es steht nicht in der Tradition der amerikanischen Weltführungspolitik seit I945, sondern strebt, indem es für die Durchsetzung amerikanischer Interessen Gehorsam verlangt und ihn notfalls mit Gewalt zu erzwingen versucht, nach selektiver Weltherrschaft. Von der Radikalität dieses Anspruchs, von der Afghanistan und Irak mit Gewalt betroffen wurden und der Iran möglicherweise alsbald betroffen werden wird, bekamen auch die Westeuropäer ihre Portion ab. In der Absicht, Frankreich und die Bundesrepublik für ihr abweichendes Verhalten >zu bestrafen<, drückt sich aus, dass im Machtverständnis der Bush-Administration die Westeuropäer nicht mehr als Verbündete, sondern nur noch als zur Botmäßigkeit verpflichtete Abhängige gelten. Die Bush-Administration setzte das extreme Machtgefälle zwischen den USA und den europäischen Verbündeten direkt in Politik um. 


\section{II.}

Dieses Machtgefälle, das in der Nachkriegszeit die wirtschaftlichen und die sicherheitspolitischen Beziehungen zwischen den USA und Westeuropa charakterisiert hatte, war auf dem Sachbereich der wirtschaftlichen Wohlfahrt durch die Gründung der Europäischen Wirtschaftsgemeinschaft 1957, durch die Vollendung des Binnenmarktes und dann durch die Bildung der Wirtschafts- und Währungsunion zwischen I2 EU-Mitgliedern einem Gleichgewicht gewichen. EU und USA verfügen ökonomisch über gleiche Potenziale:

\begin{tabular}{|l|c|c|}
\hline & EU & USA \\
\hline Bevölkerung & $\begin{array}{c}374,6 \text { Mio. } \\
\text { (EU der I5) }\end{array}$ & 263 Mio. \\
\hline Bruttoinlandprodukt (BIP) pro Kopf & 20,6 I3 EUR & 26,592 EUR \\
\hline Anteil am Weltexport & I9 $\%$ & I6 \% \\
\hline Anteil am Weltimport & I8 $\%$ & $21 \%$ \\
\hline
\end{tabular}

Nach der Erweiterung der EU 2004 auf 24 Staaten wird sie $45^{\circ}$ Millionen Menschen umfassen, fast doppelt so viel wie die USA.

Gestützt auf die erbrachten Integrationsleistungen spricht die EU im Bereich von Handel und Währung mit einer Stimme, kann also ihr gleichgewichtiges Potenzial direkt in machtpolitischen Anspruch umsetzen. Infolgedessen hat sich im Sachbereich der wirtschaftlichen Wohlfahrt zwischen den USA und der EU ein Gleichgewicht hergestellt, das beide Seiten zur wechselseitigen Rücksichtnahme veranlasst und für die bisher entstandenen Konflikte jeweils eine Kompromisslösung ermöglicht hat. Nimmt man hinzu, dass durch die wechselseitigen Investitionen die beiden Märkte schon fast je zu einem Drittel integriert sind, so ist davon auszugehen, dass die wirtschaftspolitischen Strei- 
tigkeiten die Interessenharmonie und die Kompromissbereitschaft beider Seiten nicht tangieren werden. Allerdings muss angesichts der Tatsache, dass die Bush-Administration sich nicht auf der Mittellinie der bisherigen amerikanischen Weltpolitik bewegt, ein Fragezeichen hinter diese Aussage gemacht werden.

Diese sinnvolle, notwendige und Erfolg versprechende Symmetrisierung der Beziehungen hat sich im Sachbereich der Sicherheit nicht eingestellt. Die Atlantische Gemeinschaft hat hier die höchst asymmetrische Machtfigur behalten, die sie zum Zeitpunkt der Gründung der Nordatlantischen Verteidigungsallianz gehabt und in der Organisation und im Ausbau der Militärallianz institutionalisiert hatte. Alle Führungspositionen der Militärallianz befinden sich unverändert in amerikanischer Hand. Die USA leiten die Allianz als Machtinstrument ihrer Europapolitik.

Europäische Korrekturversuche schlugen durchweg fehl. Das begann mit dem deutsch-französischen Élysée-Vertrag von I962, der auf amerikanischen Druck hin eine, seine politische Bedeutung neutralisierende, Präambel bekam und setzte sich fort mit der amerikanischen Weigerung, eine europäische Identität in der NATO zuzulassen. Nach dem Ende des Ost-WestKonflikts verschärfte sich das europäische Interesse an der Emanzipation: 1992 verlangte der damalige Bundeskanzler Kohl zusammen mit anderen europäischen Regierungschefs eine neue transatlantische Agenda, konnte sich aber nicht durchsetzen. Erst 1999, nach ihrer demonstrativen Demütigung durch die USA im Luftkrieg gegen Serbien, schlossen sich die Westeuropäer zu einer handlungsfähigen Einheit in der EU zusammen. Sie verabredeten die Aufstellung einer schnellen Eingreiftruppe mit den dazugehörigen politischen Entscheidungsorganen und einem Militärausschuss. Diese Truppe trat erstmals mit der Übernahme einer Friedensmission im Kongo (Mai 2003) in 
Erscheinung. Sie steht aber auch bereit, die NATO in Mazedonien und auf dem gesamten Balkan abzulösen.

Ob die USA dazu bereit sind, bleibt abzuwarten. Mit dem Entschluss, sich eine eigene Interventionsstreitmacht zuzulegen, die notfalls auch ohne Rückgriff auf NATO-Einrichtungen eingesetzt werden kann, hat die EU den Rubikon überschritten. Deswegen wurde ihr auf dem NATO-Gipfel im November 2002 in Prag demonstrativ eine schnelle Eingreiftruppe der NATO entgegengestellt. Die Regierung Bush setzt hier nur fort, was alle ihre Vorgänger - mit Ausnahme der Administration Clinton in den ersten beiden Jahren ihrer Tätigkeit - getan hatten: nämlich die Integrations- und Emanzipationsversuche der Westeuropäer im Sachbereich der Sicherheit zu neutralisieren. Mit der genannten Ausnahme waren die USA nie bereit, die Symmetrisierung der Machtbeziehungen im Sachbereich der Sicherheit mit seinen außenpolitischen Implikationen zu akzeptieren.

Die Administration Bush ging weiter. Sie scheute nicht davor zurück, die Beitrittskandidaten der NATO bzw. der EU zu Ergebenheitsbekundungen an die Adresse Washingtons zu stimulieren, um so das >neue< gegen das >alte< Europa aufzubringen. Es muss damit gerechnet werden, dass jeder weitere Integrationsversuch der EU oder einer Kerngruppe solange auf den erbitterten Widerstand Washingtons stoßen wird, bis er sich erfolgreich vollendet hat.

Der Besitz von Macht ist ein äußerst empfindliches Gut, das sich gegen jede Minderung wendet. Umverteilungen von Macht im internationalen System (Gründung des Deutschen Reiches, Auflösung des Osmanischen Reiches, Gründung des Staates Israel) haben stets die Gewaltanwendung angetrieben. Dergleichen wird im Atlantischen Verhältnis natürlich nicht zu erwarten sein, wohl aber massiver Widerstand der USA. Sie kann sich dabei auf die Bilateralisierung ihrer Beziehungen zu jedem ein- 
zelnen europäischen Bündnispartner stützen, die Washington immer gepflegt hat. Andererseits ist damit zu rechnen, dass sich die amerikanischen Regierungen, kommt es zu einer sicherheitspolitisch integrierten EU, mit ihr abfinden, sie akzeptieren und den Vorteil verbesserter, die USA entlastender Arbeitsteilung sehr hoch bewerten werden.

Dieser seit 1962 kontinuierlich andauernde Prozess der langsamen Egalisierung der Machtfigur der Atlantischen Gemeinschaft im Sachbereich der Sicherheit wurde durch die Intransigenz der amerikanischen Position anlässlich des Irakkrieges weiter vorangetrieben. Ungeachtet aller öffentlich zur Schau getragenen Beruhigungsbemühungen hat sich die Kluft zwischen der Bush-Administration auf der einen, Deutschland, Frankreich und den meisten europäischen Gesellschaften auf der anderen Seite nicht schließen lassen. Wie tief sie ist, welche Wirkung sie auf den europäischen Integrationsprozess ausübt, kann man an den Arbeiten des Konvents in Brüssel zur Europäischen Verfassung ablesen. In jedem Fall ist damit zu rechnen, dass aus den seit langem erkennbaren Rissen in der sicherheitspolitischen Kooperation in der Atlantischen Gemeinschaft aufgrund der radikalisierten Weltpolitik der Administration George W. Bush regelrechte Sprünge geworden sind, die zum Einsturz des Gebäudes führen könnten.

\section{III.}

Eine solche Entwicklung muss unter allen Umständen verhindert werden. Die Atlantische Gemeinschaft ist für die Zukunft Nordamerikas und Europas sowie für die der Welt zu wichtig, als dass sie der Reformunfähigkeit der Politiker geopfert werden sollte. Die Atlantische Gemeinschaft wird unter den Bedingungen des 2I. Jahrhunderts nur Kontinuität behalten, wenn ihre 
Machtbeziehungen auch auf dem Gebiet der Sicherheit symmetrisch sein werden. Schon der amerikanische Präsident John F. Kennedy hatte ihr die Figur einer Hantel mit zwei gleichen Gewichten verschrieben. Nach mehr als vierzig Jahren ist es höchste Zeit, dass die Atlantische Gemeinschaft diese Machtfigur jetzt auch erhält.

Die dazu erforderliche Umverteilung der Macht muss sorgfältig gesteuert werden. Es war von vornherein zu erwarten, dass sich dabei auch kathartische Umbrüche einstellen würden - einen solchen bildet die Auseinandersetzung um den Irak. Es ist unvermeidlich, dass dieser Transformationsprozess durch Phasen relativer Dissoziation führen wird. Die Atlantische Gemeinschaft kann nicht symmetrisiert werden, wenn die NATO ihre bisherige Organisationsstruktur sowie ihre Funktion als einzige institutionalisierte Brücke zwischen Europa und Nordamerika beibehält. Diese Funktion muss relativiert und in eine neue Transatlantische Agenda eingefügt werden wie das Bundeskanzler Kohl schon Anfang der 9oer Jahre vorgeschlagen hatte. Die Atlantische Gemeinschaft braucht ein politisches Organ. Der Interdependenzgrad in der Atlantischen Gemeinschaft ist groß genug, um sie beispielsweise als Regionale Organisation nach Kap. VIII der Charta der UNO zu institutionalisieren. Die Verteidigungsallianz würde darin ihren wichtigen Platz behalten, ihn aber in die politische Kooperation einordnen müssen, die sich innerhalb einer solchen Organisation mit den entsprechenden Organen auch einstellt.

Um diese Neuordnung müssen sich in erster Linie die Europäer kümmern, weil sie in deren Interesse liegt. Dazu müssen sich die Westeuropäer aus den nationalen Nischen entfernen, in denen sie sich unter dem langjährigen und so erfolgreichen Schirm amerikanischer Hegemonie eingerichtet hatten. Sie müssen sich entscheiden, ob sie nach der Weiterentwicklung der amerikanischen Hegemonie zur selektiven Weltherrschaft in die 
Rolle von Hilfsdienste leistenden Satelliten absinken oder sich zu brauchbaren Bundesgenossen der USA weiterentwickeln wollen. Dazu müssen sie ihre nationalen Machtpotenziale zusammenfügen, um in deren Integration Gestaltungsmöglichkeiten zurückzugewinnen, die sie als Mittel- und Kleinstaaten schlicht nicht verlangen oder erwarten dürfen. Die USA haben Recht, wenn sie seit langem einen größeren europäischen Beitrag zur Weltführung verlangen; es ist an Europa, im Gegenzug dafür, die amerikanische Akzeptanz eines sicherheitspolitisch integrierten Europas zu fordern.

Diese Symmetrisierung der Machtpotenziale im Sachbereich der Sicherheit wird Europa nicht zum Gegengewicht der USA, sondern zu ihrem gleich starken Partner werden lassen, der mit ihnen kooperiert und der sie entlastet. Im Sachbereich der Sicherheit muss die gleiche stabile und zukunftsträchtige Machtverteilung hergestellt werden wie sie in dem der wirtschaftlichen Wohlfahrt schon herrscht. Dazu gehört:

I. der Wirtschafts- und Währungsunion alsbald die Sicherheits- und Verteidigungsunion Europas an die Seite zu stellen;

2. die weltpolitische Rolle der EU im Kontext der Atlantischen Gemeinschaft zu konzipieren.

Ich werde zunächst den zweiten Aspekt behandeln, weil

- er ebenso wichtig ist wie der institutionelle;

- seine richtige Ausrichtung dazu beitragen kann, amerikanische Widerstände gegen eine solche Integration abzubauen. 
IV.

Die sicherheitspolitische Rolle der EU ist mit ihrem Selbstverständnis als >Zivilmacht< richtig, aber nicht sehr ausführlich beschrieben. Aufgrund ihrer so andersartigen Geschichte und Erfahrungen, die zweihundert Jahre ebenso grausamer wie sinnloser Kriege umfassen, haben die Europäer sich nicht nur dazu entschlossen, mit der EU eine der größten und stabilsten Friedenszonen der Welt auszubilden. Ebenso wie sich die EU in ihrem inneren Aufbau als postnationaler Regionalstaat ausbilden wird, muss sie auch eine Sicherheitspolitik entwickeln, die sich nicht allein auf die Gewalt, sondern in erster Linie auf deren Verminderung und ihren Ersatz durch gewaltfreie Steuerungsmechanismen verlässt.

Damit trüge die EU nicht nur ihrem eigenen Selbstverständnis als neuartiges, nicht auf die Akkumulation, sondern auf die Distribution von Macht ausgerichtetes Staatswesen Rechnung, sie würde auch die Reibungsflächen mit den Vereinigten Staaten erheblich vermindern. Die EU würde in Washington nicht als >Gegengewicht< zu den USA, sondern als Ergänzung erscheinen, als Partner, nicht als Konkurrent. Solange die Vereinigten Staaten den politischen Vorgaben der Bush-Administration folgen, werden sie eine stark militarisierte Außen- und Sicherheitspolitik betreiben, die sich vor allem auf das Instrument militärischer Gewalt verlässt. Die EU würde diese Politik nicht kopieren, sondern ergänzen. Sie braucht ein modernisiertes Militärpotenzial, um selbständig militärisch agieren zu können, sollte sich dies als unvermeidlich erweisen. Die bisher bestehende, aus der vierzigjährigen Arbeitsteilung in der NATO herrührende Abhängigkeit von den Vereinigten Staaten muss möglichst schnell beendet werden. Dazu müssen die Verteidigungsetats nicht erhöht, sondern nur die zur Verfügung stehenden Gelder nicht für Waffensysteme der vergangenen Perioden, 
sondern für die der Zukunft ausgegeben werden. Eine arbeitsteilige Rüstungsproduktion innerhalb der EU würde erhebliche Einspareffekte mit sich bringen.

Ihre sicherheitspolitische Identität aber sollte die EU gewinnen durch die Entwicklung gewaltfreier, innovativer und daher besonders Erfolg versprechender Strategien. Sie sollten Interdependenzen ausnutzen, die Anforderungsprofile der Gesellschaften in den Staaten der Welt berücksichtigen, um die Regierungen zu dem gewünschten, auf Gewaltminderung bedachten Verhalten anzuleiten. Dazu muss die Sicherheitspolitik von der militärischen Intervention auf die politische Prävention umgestellt werden. Den Auftrag dazu hatte der Sicherheitsrat der UNO bereits 1992 erteilt. Die vom damaligen Generalsekretär der UNO Boutros-Boutros Ghali angefertigten Studien sind aber nur in der Wissenschaft beachtet worden. Das Verhalten der westlichen Regierungen wird noch immer von der sschiefen Schlachtordnung beherrscht, die schon im I9. Jahrhundert scharf kritisiert worden ist. Die Regierungen sind nach wie vor bereit, sehr viel Geld für militärische Einsätze aufzuwenden, die am Ende einer Konflikteskalation möglicherweise Schlimmeres verhüten, aber keine brauchbaren Dauerlösungen erzeugen können. Die politische Prävention dagegen setzt am Beginn des Konfliktzyklus an, interveniert frühzeitig, politisch und wirtschaftlich, gewaltfrei und mit bedeutenden Erfolgsaussichten. Dazu sind die westlichen Regierungen noch immer nicht imstande. Für eine solche Vorbeugungspolitik wird sehr viel weniger Geld aufgewendet als für die verspätete militärische Intervention. Die finanzielle Ausstattung des EU-Stabilitätspakts für den südlichen Balkan zeigt das zur Genüge.

Dieses Versäumnis endlich zu korrigieren, die Außenpolitik der Zivilmacht EU auf die rechtzeitige gewaltfreie, politischökonomische Intervention auszurichten und damit das längst überfällige neue Paradigma einer auf die Bedingungen des 2I. 
Jahrhunderts ausgerichteten neuen Außenpolitik zu entwerfen und zu befolgen, müsste die wichtigste Aufgabe der Sicherheitspolitik der EU werden.

Ihr Ausbleiben hat bewirkt, dass die drei großen Felder der Unordnung, die die gegenwärtige Weltpolitik kennzeichnen, noch immer nicht zureichend bearbeitet werden:

- der Nahostkonflikt,

- die Korrektur der westlichen Dominanz,

- die Beseitigung der Armut auf der Welt.

\section{IV.1}

Die militärisch wie ökonomisch praktizierte, mit dem Begriff der Globalisierung verdeckte westliche Dominanz wird in allen davon betroffenen Ländern als Bevormundung, wenn nicht sogar als Ausbeutung empfunden. Führung ist erwünscht, wenn und weil sie die Interessen der davon Betroffenen mit berücksichtigt. Dominanz hingegen, die diese Rücksicht nicht nimmt, wird zunehmend abgelehnt. Alle Umfragen unter den politischen Eliten der Welt, die das überparteiliche amerikanische PEW-Forschungszentrum seit der Jahrtausendwende vorgelegt hat, beweisen das. Die Ablehnung dieser Dominanz war in der muslimischen Welt besonders ausgeprägt, der amerikanische Irakkrieg hat sie nochmals exponentiell erhöht.

Neben dem Verzicht auf Angriffskriege, wie dem gegen den Irak, könnte die westliche Dominanz - an der schließlich auch die EU beteiligt ist - gemindert werden durch eine Stärkung des Multilateralismus. Er würde die Betroffenen beteiligen. Die beste Strategie dazu besteht in der Stärkung internationaler Organisationen, der Vereinten Nationen sowohl wie regionaler Institutionen, - die freilich erst geschaffen werden müssten. Hauptaufgabe dieser Organisationen wäre, den Dialog zwischen der 
Atlantischen Gemeinschaft und ihrer internationalen Umwelt überhaupt in geordneter regelmäßiger Form aufzunehmen und ihn dann $\mathrm{zu}$ verstetigen. Insbesondere die islamisch-arabische Welt hätte dann ein Forum, auf dem sie sich artikulieren und ihre Sicht der politischen Probleme dem Westen präsentieren könnte. In diesen Dialog sollten auch die gesellschaftlichen Akteure eingebunden werden, die NGOs vor allem, aber auch gesellschaftliche Akteursgruppen religiöser oder politischer Art.

Dieser Dialog der Kulturen gehört nicht in die UNESCO, sondern in politische Organisationen, weil er kein kulturelles, sondern ein eminent politisches Phänomen ist. Er würde schon ausreichen, um in den Augen der Betroffenen die westliche Dominanz in einen akzeptablen Führungsanspruch zu verringern. Dem Westen würde er die Gelegenheit geben, Einblick in die Quellen des politischen Terrorismus zu nehmen, dessen Bedeutung der II. September 200I markiert. Der Westen würde dabei lernen, dass dieser politische Terrorismus die wirkliche neue Gefahr des 2I. Jahrhunderts darstellt. Weder die palästinensischen noch die tschetschenischen Widerstandskämpfer gehören in diese Kategorie, noch die blinden Terroristen vom Typ der AUM-Sekte. Der politische Terrorismus, der sich in dem Angriff auf New York und Washington erstmals gezeigt hat, muss politisch als extreme Reaktion auf den westlichen Dominanzanspruch interpretiert werden. Natürlich muss dieser Terrorismus polizeilich und notfalls militärisch bekämpft werden; aussterben wird er in dem Moment, in dem seine Quellen, zu denen auch die westliche Dominanz gehört, ausgetrocknet worden sind.

Aufgabe der Weltpolitik der EU müsste es auch sein, bewährten Strategien der Vergangenheit, die von der Bush-Administration demonstrativ vernachlässigt werden, wieder zu ihrem Wirkungsfeld zu verhelfen. Das gilt insbesondere für die Rüstungskontrolle sowohl der Massenvernichtungswaffen wie der 
konventionellen Waffen. Die Bush-Administration hat diese multilaterale Strategie, die sich über vierzig Jahre hindurch bewährt hat, aufgegeben zugunsten der einseitigen, von ihr notfalls mit militärischer Gewalt durchgesetzten Politik der counterproliferation. Sie wird, gerade im Bereich der biologischen und chemischen Waffen, ihr Ziel nicht erreichen, weil deren Beseitigung nur durch die Kooperation bewirkt werden kann. Die auf riesige Rüstungsanstrengungen der USA, auf die Errichtung eines Raketenabwehrsystems gestützte Gewaltpolitik der counterproliferation wird primär die Rüstungsdynamik wieder anheizen und Rüstungswettläufe in Gang setzen, sodass das Sicherheitsdilemma, eine der größten Kriegsursachen, in die Welt zurückkehrt. Der Prozess ist bereits in Gang, wie man z.B. in Japan, in Indien, in Pakistan und in Nordkorea sehen kann. Umso mehr müsste sich die EU dafür einsetzen, dass dieser Irrweg beendet und die kooperative Rüstungskontrolle wieder in Gang gesetzt wird.

Was sie bewirken kann, lässt sich an der OSZE ablesen. Mit der Vereinbarung über die konventionelle Abrüstung in Europa und in den zahlreichen Wiener Dokumenten hat die OSZE ein System der wirklich kontrollierten und verifizierten Rüstungskontrolle und Abrüstung eingerichtet. Es hat im Einzugsbereich des früheren Ost-West-Konflikts einen Grad von Transparenz und wechselseitigem Vertrauen geschaffen, der in der Geschichte außerhalb der EU einmalig ist. In Euro-Atlantik gibt es kein Sicherheitsdilemma mehr, kein Misstrauen, keine Unklarheiten. Diese Verfahren weiter auszuarbeiten und sie so anzupassen, dass sie auch in Weltregionen mit unterschiedlicher Interdependenzdichte benutzt werden können, wäre eine wichtige innovative Aufgabe der EU. Sie sollte deswegen auch dafür sorgen, dass die OSZE den wichtigen Platz in der Sicherheitsarchitektur Euro-Atlantik wieder zurückerhält, der ihr von der NATO streitig gemacht worden ist. 
$\mathrm{Zu}$ der innovativen Strategie der Vorbeugung gehört, die Demokratisierung aller Herrschaftssysteme mit Vorrang zu betreiben. Das demokratische Herrschaftssystem ist der wichtigste Garant für das gewaltfreie Verhalten eines Staates gegenüber seiner internationalen Umwelt. Das weiß die Politik seit Woodrow Wilson. Die Charta von Paris (I990) hat die Demokratisierung der europäischen Herrschaftssysteme zur wichtigsten sicherheitspolitischen Strategie erhoben. Der amerikanische Präsident Bill Clinton hat, jedenfalls zwei Jahre lang, diese Demokratisierungsstrategie weltweit betrieben. Seit 1994 ist dieser Impetus abgeflacht, und nur noch die Europäische Kommission hält ihn bei der Heranführungsstrategie gegenüber den osteuropäischen Staaten hoch. Die EU sollte diese Strategie weltweit verfolgen. Die Demokratisierung der Herrschaftssysteme ist die wichtigste Voraussetzung für die endgültige Beseitigung des Krieges.

Diese Strategie lässt sich nicht mit militärischer Gewalt implementieren. Die Bush-Administration wird das im Irak erneut lernen müssen - obwohl die Vereinigten Staaten in Vietnam, in Somalia und in Afghanistan bereits einschlägige Erfahrungen sammeln konnten. Die Demokratisierung muss von der jeweiligen Gesellschaft selbst gegenüber ihrem Herrschaftssystem durchgesetzt werden. Dazu kann die Umwelt erhebliche Beihilfen leisten. Gerade amerikanische Politologen haben die dazugehörigen Verfahren seit langem ausgearbeitet; ganze Zeitschriften beschäftigen sich mit den Strategien der Demokratisierung. Sie von der Wissenschaft in die politische Praxis zu übernehmen und zu übersetzen, wäre eine Hauptaufgabe einer modernen Sicherheitspolitik der EU. Ihr allgemeines Kennwort lautet: kooperieren und (gewaltfrei) intervenieren, um die internen Verhältnisse der Staaten so zu gestalten, dass die Gewalt vermindert und die Kooperation verstärkt wird. 


\section{IV.2}

Der zweite große ordnungspolitische Bedarf steckt in der Ungleichverteilung des in der Globalisierung erzeugten Reichtums. Noch immer ist mehr als die Hälfte der Menschheit arm, ist der unheilvolle Zyklus von Armut, Krankheit, Gewalt und Destabilisierung nicht gebrochen. Er enthält anerkanntermaßen die zweite große Quelle des politischen Terrorismus. Die Armut zu beseitigen bildet daher die zweite große Sicherheitsstrategie. Sie endlich als solche zu begreifen, darzustellen und finanziell auszustatten ist die programmatisch besondere Herausforderung der EU.

Noch immer werden 830 Mrd. Dollar pro Jahr für militärische Rüstungsgüter ausgegeben, für eine Strategie also, die zwar Verteidigung ermöglicht, aber keine Sicherheit erzeugt. Weniger als ein Zehntel, 70 Mrd. Dollar, würden ausreichen - hat das World Watch Institute in Washington errechnet -, um die Armut $\mathrm{zu}$ beseitigen. Die Welt braucht also keineswegs bis $2015 \mathrm{zu}$ warten, und die EU, die wirtschaftlich genauso stark ist wie die Vereinigten Staaten, könnte notfalls ohne die USA die Hälfte des Armutsproblems aus der Welt schaffen.

Das gilt insbesondere für Afrika, wo der Zyklus von Armut und Gewalt seit Jahren Tausende von Menschenleben fordert. Afrika ist seit mehr als dreißig Jahren mit der EU in den AKPVerträgen verbunden. Die EU hat hier nicht nur besondere Interventionsmöglichkeiten, sie hat auch besondere Interventionsverpflichtungen. Der europäische Agrarmarkt ist mit seinen protektionistischen Hürden eines der wichtigsten Hindernisse für die Entwicklung der außereuropäischen Welt; ihn endlich zu öffnen wäre die wichtigste Entwicklungsstrategie. Wenn sie als das gesehen würde, was sie ist - nämlich die beste Sicherheitsstrategie in der Welt des politischen Terrorismus -, müsste sich 
der hindernde Einfluss der relevanten starken Interessengruppen brechen lassen.

\section{IV.3}

Bei der Beendigung des Nahost-Konflikts sind aus vielerlei Gründen die Vereinigten Staaten mehr gefordert als die Europäer. Aber auch die EU könnte mehr tun als bisher. Sie verfügt über genügend Definitionsmacht, um dem Nahost-Konflikt vorrangige strategische Aufmerksamkeit zu sichern. Wäre dieser Konflikt gelöst, und zwar zur Zufriedenheit beider Seiten, wären 90 Prozent der Quellen des politischen Terrorismus versiegt. Das wusste die Politik im Spätherbst 200I sehr genau. Sie hat aber zwei Jahre ungenutzt verstreichen lassen, weil sie sich anderen Zielen, dem Krieg gegen Afghanistan und gegen den Irak, gewidmet hatte.

Glücklicherweise hat die Administration George W. Bush ihre zweijährige Abstinenz beendet und sich wieder aktiv in die Lösungsbemühungen in diesem Konflikt eingeschaltet. Die EU sollte Washington hierin massiv unterstützen. Als einer der vier Autoren der >Straßenkarte< sollte die EU darauf achten, dass die Strategie nicht wieder beiseite gelegt und vor allem in ihrer Zielrichtung nicht geändert wird.

\section{V.}

Den Aussichten der EU, sich zu einer außen- und sicherheitspolitischen Organisation weiterzuentwickeln, kann ich hier nur ein paar Andeutungen widmen. Der Prozess ist voll im Fluss, der Konvent hat seine Arbeiten für eine Europäische Verfassung Mitte des Jahres 2003 abgeschlossen. Es wird sich nun zeigen, ob die Union einen intergouvernementalen oder einen föderalen 
Charakter haben wird, ob sie eine Union der Staaten oder eine Union der Bürger werden wird.

$\mathrm{Zu}$ vermuten ist, dass die Entscheidung darüber nicht für die erweiterte Union insgesamt getroffen werden kann, sodass die Prozesse der Vertiefung und der Erweiterung nicht, wie bisher rhetorisch immer eingefordert, gleichzeitig verlaufen werden. Unter der Führung Großbritanniens wollen viele Mitglieder der EU, neue wie alte, sie als gemeinsamen Markt und Zollunion weiterführen, während andere, darunter vor allem die ursprünglichen sechs, den engeren Zusammenschluss zu einer sicherheits- und verteidigungspolitischen Union bevorzugen.

Wie das Problem gelöst werden wird - ob es sich überhaupt lösen lässt -, ob die Union diese Krisensituation übersteht und wenn, in welcher Verfassung, wird die Zukunft zeigen. Mir geht es darum, dass, in welcher Form auch immer, die EU sich zu einer außen- und sicherheitspolitischen Einheit weiterentwickelt, sie dies im Hinblick darauf tut, die Beziehungen zu den Vereinigten Staaten dauerhaft zu erhalten. Dazu muss entweder die EU als Ganze oder ein Kern der verstärkten Zusammenarbeit die Asymmetrie beenden, die die Atlantische Gemeinschaft stört und sogar zu Fall bringen könnte. Werden die Beziehungen im Sachbereich der Sicherheit aber symmetrisiert, hat die Atlantische Gemeinschaft begründete Aussicht auf Dauer und auf Erfolg. Bei ihrem Bemühen um ein euro-amerikanisches Gleichgewicht im Sachbereich der Sicherheit, sollte sich die EU darum bemühen, die amerikanische Politik nicht zu korrigieren, sondern zu ergänzen. Davon wird die Partnerschaft der Atlantischen Gemeinschaft profitieren. Diese Orientierung wird es aber auch den USA erleichtern, den Aufwuchs der Europäischen Alliierten zu einem gleich starken Partner als Vorteil zu begreifen. 


\section{Literatur}

Bender, Peter (2003): Weltmacht Amerika - das Neue Rom, Stuttgart.

Brzezinski, Zbigniew (2000): Die einzige Weltmacht. Amerikas Strategie der Vorherrschaft, Frankfurt a.M.

Czempiel, Ernst-Otto (2003): Weltpolitik im Umbruch. Die Pax Americana und die Zukunft der internationalen Beziehungen, München.

Heinrichs, Hans-Jürgen (2003): Die gekränkte Supermacht. Amerika auf der Couch, Düsseldorf.

Hoyer, Werner/Kaldrack, Gerd F. (Hg.) (2002): Europäische Sicherheits- und Verteidigungspolitik (ESVP): Der Weg zu integrierten europäischen Streitkräften?, Baden-Baden.

Kagan, Robert (2003): Macht und Ohnmacht. Amerika gegen Europa in der neuen Weltordnung, Berlin.

Kubbig, Bernd W. (Hg.) (200I): »Toward a New American Century? The U.S. Hegemon in Motion«, in: Amerikastudien 46, 4 .

Müller, Harald (2003): Amerika schlägt zurück. Die Weltordnung nach dem 11. September, Frankfurt a.M.

Münkler, Herfried (2003): Der neue Golfkrieg, Reinbek.

Nye, Joseph S. (2002): The Paradox of American Power. Why the World's Only Superpower Can't Go it Alone, New York.

Pitt, William Rivers/Ritter, Scott (2002): Krieg gegen den Irak Was die Bush-Regierung verschweigt, Köln.

Roloff, Ralf/Rösch, Walter (Hg.) (2003): Politik und Terrorismus. 11. September 2001, Schwerpunktheft der Zeitschrift für Politikwissenschaft, I3. Jg., Heft I.

Rudolf, Peter/Wilzewski, Jürgen (Hg.) (2000): Weltmacht ohne Gegner. Amerikanische Außenpolitik zu Beginn des 21. Jahrhunderts, Baden-Baden. 
Schubert, Klaus/Müller-Brandeck-Bocquet, Gisela (Hg.) (2000): Die Europäische Union als Akteur der Weltpolitik, Opladen.

Todd, Emmanuel (2003): Weltmacht USA - ein Nachruf, München.

Ziegler, Jean (2003): Die neuen Herrscher der Welt, München. 



\title{
Das Völkerrecht und die Rolle
}

\section{der Vereinten Nationen}

\author{
Christian Tomuschat
}

\section{Einleitung}

Der Irak-Krieg und seine Folgen sind schon wieder von den Frontseiten der Zeitungen verschwunden, und im Fernsehen sind die jüngsten Nachrichten aus dem Land an Euphrat und Tigris an das Ende der Sendungen gerückt. Andere Krisenherde schieben sich in den Vordergrund. Der Krieg scheint fast schon >abgehakt< zu sein. Die Tagesaktualität hat neue Schwerpunkte gewonnen, wie dies in einem System freier Berichterstattung ganz unvermeidlich ist. Allerdings stellt sich jetzt heraus, dass dem Blitzkrieg keine blitzartige Erneuerung des Landes gefolgt ist, das in Anarchie zu versinken droht, und auch was seine langfristigen Auswirkungen auf die Weltordnung angeht, kann der Konflikt nicht so schnell verdrängt werden. Zahlreiche Fragen hat der amerikanisch-britische Angriff auf den Irak hinterlassen. 
Nur die wichtigsten unter ihnen sollen genannt werden: Wie steht es mit dem Recht der Selbstverteidigung? Gibt es heute, bestätigt durch das Vorgehen der Invasionstruppen, ein Recht der Selbstverteidigung, das sich auf bloße Verdachtsgründe stützen darf? Muss sich ein Land, das beschuldigt wird, Massenvernichtungswaffen $\mathrm{zu}$ besitzen, gegebenenfalls damit abfinden, militärisch angegriffen zu werden? Und die zweite Frage: Was bedeutet der amerikanisch-britische Alleingang ohne ausdrückliche Zustimmung des Sicherheitsrates für die UN? Ist der Sicherheitsrat damit in eine unbedeutende Statistenrolle abgedrängt worden? Und schließlich: Was bedeutet die Nichtbeachtung und Umgehung der Vereinten Nationen für die Völkerrechtsordnung insgesamt? Zieht ein neues Zeitalter herauf, das nur noch von einer Macht bestimmt wird, nämlich den Vereinigten Staaten von Amerika, die sich anschicken, eine weltweit geltende Hegemonialordnung aufzubauen?

\section{Präventive Selbstverteidigung?}

Als Präsident Bush am 2. Mai 2003 vom Deck des Flugzeugträgers Abraham Lincoln aus das Ende der Kampfhandlungen im Irak verkündete, erklärte er gleichzeitig, dass der Krieg gegen den Terrorismus fortgesetzt werde; jedes außerhalb des Rechts stehende Regime, welches Verbindungen $\mathrm{zu}$ terroristischen Gruppen habe und im Besitz von Massenvernichtungswaffen sei oder solchen Besitz anstrebe, stelle eine schwerwiegende Gefahr für die zivilisierte Welt dar und müsse sich auf eine Auseinandersetzung einstellen. ${ }^{\mathrm{I}}$ Mit anderen Worten, Präsident Bush machte deutlich, dass die USA entschlossen seien, präventiv Selbstverteidigung zu üben, falls sie sich in ihrer Sicherheit bedroht fühlten. 
Dies ist keine plötzliche Wende in der amerikanischen Außen- und Verteidigungspolitik. Im September 2002 wurde die Doktrin der präventiven Selbstverteidigung offiziell in der neu formulierten Nationalen Sicherheitsstrategie festgeschrieben. Diese offizielle Erläuterung der amerikanischen Politikziele, die auch zahlreiche lobenswerte Passagen enthält, gipfelt allerdings für den aufmerksamen Leser in dem Abschnitt $\mathrm{V}$, wo es heißt:

»Die Vereinigten Staaten haben sich seit langem die Option vorbeugenden Handelns (preemptive actions) offengehalten, um einer ernstlichen Bedrohung unserer nationalen Sicherheit entgegenzutreten. Je größer die Bedrohung ist, um so größer ist das Risiko der Untätigkeit - und um so zwingender der Grund für vorweggreifendes Handeln (anticipatory action) zu unserer Verteidigung, selbst wenn Unsicherheit über die Zeit und den Ort des feindlichen Angriffs besteht. Um solchen feindlichen Handlungen durch unsere Gegner zuvorzukommen oder sie zu verhindern, werden die Vereinigten Staaten, falls erforderlich, vorbeugend handeln. $\varkappa^{2}$

Auch die Nationale Sicherheitsstrategie stellt in der Tat keine absolute Neuerung dar, sondern formuliert lediglich in Worten, was schon seit einer ganzen Reihe von Jahren Praxis amerikanischer Politik war. Man denke etwa zurück an die Unterstützung der sog. >Contras<, die in Honduras stationiert waren und von dort aus in den Jahren von I98I bis I984 Überfälle auf das Nachbarland Nicaragua ausführten, das seinerzeit von dem kommunistischen Sandinisten-Regime beherrscht wurde. In diesem Fall kam es zu einem Verfahren vor dem Internationalen Gerichtshof. In seinem Urteil zur Hauptsache vom Juni 1986 (vgl. ICJ Reports I986: I4) verurteilte der Gerichtshof das amerikanische Vorgehen und stellte fest, dass die USA sich gegenüber Nicaragua schadensersatzpflichtig gemacht hätten. (Ebd.: I49) 
Auf ähnlicher Linie liegt die Verhaftung des panamesischen De-facto-Staatschefs General Noriega, die auf panamesischem Boden stattfand, nachdem amerikanische Streitkräfte im Dezember 1989 gewaltsam in das Land eingedrungen waren - eine Intervention, die wohl Hunderte von Zivilisten das Leben gekostet hat. Im Falle Nicaragua war es die kommunistische Gefahr, welche die USA zu ihrer Intervention veranlasste, im Falle Panama war es der Drogenschmuggel, der offenbar von dem Manne organisiert und zentralisiert wurde, der gleichzeitig als panamesischer Präsident fungierte. Auch die Intervention auf der Karibik-Insel Grenada im Oktober I983 darf in diesem Zusammenhang nicht unerwähnt bleiben.

Insgesamt hat Lateinamerika ungute Erinnerungen an eine Vergangenheit, wo insbesondere die zentralamerikanischen Staaten als eine Art >Hinterhof^ der USA behandelt wurden und beständig damit rechnen mussten, zur Zielscheibe amerikanischer Militär-Interventionen zu werden. Von dort aus werden deswegen auch die jüngsten programmatischen Äußerungen der Regierung Bush mit besonderem Misstrauen beobachtet.

In der Tat ist das Thema >Gewalt< auf der völkerrechtlichen Ebene außerordentlich problemträchtig. Im klassischen Völkerrecht der zweiten Hälfte des I9. Jahrhunderts bis zum Ausbruch des Ersten Weltkrieges wurde der Krieg mehr oder weniger als ein Naturereignis angesehen, dem man mit rechtlichen Mitteln jedenfalls nicht beikommen könne. Kriege galten als Bestandteil des Lebens der Völker mit ihren unvermeidbaren Interessenkonflikten. So heißt es noch in dem deutschen Standardlehrbuch von Franz von Liszt aus dem Jahre I925:

»Das äußerste Mittel zur Durchsetzung eines wirklichen oder vermeintlichen Anspruches, die ultima ratio zur Erledigung einer völkerrechtlichen Streitigkeit, bleibt auch im heutigen Völkerrecht der Krieg.« (Liszt I925: 445) 
Weitsichtige Staatsmänner versuchten auf den großen Haager Friedenskonferenzen der Jahre I899 und I907 die Folgen bewaffneter Auseinandersetzungen durch die Statuierung von Regeln über den Schutz der Kriegsopfer abzumildern. Aber es blieb auch über die Gründung des Völkerbundes bis zum Jahre I928 dabei (vgl. Tomuschat 200I: 39I) ${ }^{3}$, dass es keinen Verstoß gegen das Völkerrecht bildete, einen Krieg zu entfesseln. Und erst die Charta der Vereinten Nationen legte I945 in ihrem Artikel 2 Abs. 4 ein umfassendes Gewaltverbot fest. Die Schöpfer der Charta ließen sich dabei von der Hoffnung leiten, dass nach den Schrecken des Zweiten Weltkrieges die Staaten und ihre Regierungen in Zukunft darauf verzichten würden, ihre Kontroversen mit gewaltsamen Mitteln auszutragen. Neben das Verbot der Gewaltanwendung wurde daher in Artikel 2 Abs. 3 die Verpflichtung gestellt, alle Streitigkeiten auf friedlichem Wege zu lösen. Um die Einhaltung dieser Grundsatzbestimmungen zu sichern, wurde der Sicherheitsrat eingesetzt. Die Verfasser der Charta waren also keine blauäugigen Idealisten. Als erfahrene Politiker und Diplomaten wussten sie vielmehr sehr genau, dass Vorsorge für den Fall von Verletzungen dieser neuen Friedensordnung getroffen werden musste.

Natürlich kann das Gewaltverbot nicht uneingeschränkt gelten. Insbesondere muss ein Aggressionsopfer die Möglichkeit haben, sich selbst zu verteidigen, ehe der Sicherheitsrat die notwendigen Schutzmaßnahmen zu seinen Gunsten getroffen hat. Aus diesem Grunde sieht Artikel 5I der Charta ein Recht der Selbstverteidigung vor. Es kommt »im Falle eines bewaffneten Angriffs« zur Anwendung, wie dies der deutsche Text sagt. Die zitierte Wendung ist eine durchaus treffende Übersetzung der verbindlichen Fassungen in englischer, französischer und spanischer Sprache. Der englische Text, der überwiegend den Verhandlungen zur Grundlage gedient hat, formuliert wie folgt: »if an armed attack occurs«. Dieser Wortlaut lässt eigentlich keine 
Zweifel offen. Er kann nur dahin gedeutet werden, dass ein militärischer Angriff tatsächlich stattgefunden haben muss, ehe zur Abwehr ebenfalls militärische Mittel eingesetzt werden dürfen.

Sklavisch darf man freilich nicht am Text der Vorschrift haften bleiben. Dies wurde schon in der Anfangsphase nach 1945 von Beobachtern betont, die darauf hinwiesen, dass angesichts moderner Waffentechniken, insbesondere der Atomwaffe, ein Staat, der abwarten müsste, bis der Gegner die Kampfhandlungen eröffnet, möglicherweise dann schon unrettbar verloren wäre. Es kann Situationen geben, wo die Kriegsvorbereitungen eines auf Aggression bedachten Landes schon so weit gediehen sind, dass der Ausbruch des bewaffneten Konfliktes als unausweichlich und unabwendbar erscheinen muss. Der angesehene israelische Jurist Yoram Dinstein spricht angesichts eines solchen Geschehensablaufs von »interceptive strike«, also einem »Abfangschlag«, der einen schon fertig durchorganisierten Angriffsplan im letzten Augenblick gerade noch durch Gegenwehr verhindert. Auch in einer von der UNO-Generalversammlung angenommenen Definition der Aggression (vgl. Res/GV 3314 [XXIX], I974) heißt es, dass der erste Schuss lediglich ein Beweisanzeichen bilde, von dem sich der Sicherheitsrat distanzieren dürfe, um eine andere Wertung vorzunehmen.

Was indes die USA jetzt in ihrer Nationalen Sicherheitsstrategie formuliert haben, geht weit über diese Ansätze hinaus, die jeweils fordern, dass eine unmittelbar drohende Gefahr gegeben sein müsse. Eine solche unmittelbare Gefahr stellte der Irak weder für seine Nachbarn noch gar für die USA dar. Bis wenige Tage vor dem Beginn des Angriffs am 20. März 2003 waren im Auftrag des Sicherheitsrates umfangreiche Inspektionsteams im Lande, die herausfinden sollten, ob der Irak tatsächlich Massenvernichtungswaffen besitze. Angesichts dieser Präsenz ausländischer Beobachter war es dem Irak gar nicht möglich, irgendwelche Vorbereitungen für einen Angriff auf ein anderes Land zu 
treffen. Bis heute sind im Übrigen die behaupteten Massenvernichtungswaffen nicht gefunden worden, was zumindest belegt, dass sie im Irak jedenfalls nicht in einsatzfähiger Form vorhanden waren. Die einzige deutlich erkennbare Gefahr bildete die Person des Diktators Saddam Hussein, von dem bekannt ist, dass er im Jahre I980 einen Aggressionskrieg gegen den Iran vom Zaune brach, dass er im Jahre I988 Tausende von Kurden durch einen Giftgasangriff umbringen ließ und dass er im Jahre I990 einen Überfall auf Kuwait ausführte. Hinzu kommt, dass Saddam Hussein im Innern des Irak mit den schlimmsten menschenverachtenden Methoden gegen alle seine Widersacher gewütet hatte. Willkürliche Verhaftung, Folter und Mord waren die selbstverständlichen Werkzeuge seiner Politik. Selbst im Irak wird sich deshalb wohl binnen kurzem außer den Günstlingen des Regimes niemand mehr wehmutsvoll an die Diktatur zurückerinnern. Aber das Recht der Selbstverteidigung ist nicht als Waffe zum Sturz despotischer Regierungen konzipiert worden. Es setzt immer eine konkrete Bedrohungslage voraus. Der Angegriffene soll sich wehren können, ehe er Unterstützung durch die internationale Gemeinschaft erhält.

Würde man das Recht der Selbstverteidigung so weit ausdehnen, wie es ganz offensichtlich den USA vorschwebt, so würde dies keinen Gewinn an internationaler Sicherheit mit sich bringen. (Vgl. Kohen 2003) Die USA wollen ein Recht der Selbstverteidigung für sich auch dann in Anspruch nehmen dürfen, wenn nicht mehr als Verdachtsgründe vorliegen und keineswegs sicher und bewiesen ist, dass der anvisierte Staat tatsächlich eine Gefahr für die Allgemeinheit darstellt. Und es liegt im Übrigen auf der Hand, dass auch andere Staaten sich in Zukunft auf den Präzedenzfall Irak berufen werden. Was den USA recht war, wird ihnen billig sein. Allerdings ist ohne weiteres zu erkennen, dass ein erweitertes Selbstverteidigungsrecht nur den großen und mächtigen Staaten zugute kommen könnte. Liechtenstein 
und Andorra würden wohl kaum jemals ihre Nachbarn mit der Behauptung angreifen, sie würden den Weltfrieden und die internationale Sicherheit bedrohen. Gefährlich nahe kommt man damit an ein Zweiklassenrecht im Völkerrecht, das die tatsächlich bestehenden Machtunterschiede auch in rechtliche Qualitätsunterschiede ummünzt. ${ }^{4}$

Selbstverständlich gelten die soeben vorgetragenen Erwägungen auch für den sog. >Kampf gegen den Terrorismus <. Es ist eine Sache, wenn ein Land auf seinem Gebiet offen das Treiben terroristischer Banden, die von dort aus als ihrer Operationsbasis Anschläge in anderen Ländern vorbereiten und durchführen, duldet und sogar fördert. So verhielt es sich mit den Attentätern vom II. September 200I. Schon lange zuvor war das TalibanRegime in Afghanistan von Generalversammlung und Sicherheitsrat aufgefordert worden, den Aktivitäten von Al Qaida auf afghanischem Boden ein Ende zu machen. Noch nach dem II. September 200I brüstete sich das Taliban-Regime mit seiner Unterstützung von Al Qaida. In solchen Fällen, wo tatsächlich bewaffnete Angriffe durchgeführt werden, kann sich der Unterstützerstaat nicht auf die Schutzbehauptung zurückziehen, dass ja nicht er selbst der Urheber der Angriffe sei. Demgemäß hat der Sicherheitsrat seinerzeit auch den USA bescheinigt, dass die Angriffe des II. September 200I zur Selbstverteidigung nach Artikel 5I berechtigten, auch wenn die Formulierungen der beiden einschlägigen Resolutionen in etwas gewundener Form gefasst waren. (Vgl. Tomuschat 200I)

Eine völlig andere Sache ist es indes, wenn lediglich angenommen wird, dass ein Land eines Tages mit terroristischen Gruppierungen zusammenarbeiten und diesen dann Massenvernichtungswaffen zugänglich machen könnte. Für zahlreiche Länder gilt, dass sie sich mit absoluter Überzeugungskraft einem solchen Verdacht kaum entziehen könnten. Soll tatsächlich jeder Staat, der von einem mächtigeren Nachbarn beschuldigt wird, A-, 
B- oder C-Waffen zu besitzen, vorbeugend angegriffen werden können? Es ist leicht zu erkennen, dass eine solche Rechtsregel verheerende Auswirkungen im wahren Sinne des Wortes haben könnte.

Bewusst haben die Schöpfer der Charta der Vereinten Nationen solche Aktionen zur vorbeugenden Friedenssicherung in die Zuständigkeit der Vereinten Nationen gelegt. Dem Sicherheitsrat obliegt nach Art. 24 die Hauptverantwortung für die Wahrung des Weltfriedens und der internationalen Sicherheit. Ihm ist es demzufolge nach Art. 39 aufgetragen, nicht nur den Opfern einer Aggression oder eines Friedensbruchs Hilfe zu leisten, sondern darüber hinaus auch schon dann einzuschreiten, wenn lediglich eine Bedrohung des Friedens vorliegt. Damit stellt sich die Frage, wie die Vereinten Nationen in der Irak-Krise agiert haben und welche Auswirkungen der tatsächliche Geschehensablauf auf ihre Zentralstellung im Aufgabenfeld der Friedenssicherung haben wird oder zumindest haben kann.

\section{Auswirkungen auf die Vereinten Nationen}

Die Vereinten Nationen sind ein freiwilliger Zusammenschluss von Staaten, die es sich zum Ziel gesetzt haben, die laufenden Probleme der Weltpolitik in ihren grenzüberschreitenden Dimensionen durch gemeinschaftliches Zusammenwirken im Geiste friedlichen Ausgleichs zu lösen. Sie sind keine eigenständige Macht, sondern leben von den Beiträgen und Leistungen ihrer Mitglieder. Sie sind das, was ihre Mitglieder aus ihnen machen. In aller Regel ist es daher kurzsichtig, ja rundweg falsch, für einen bestimmten Missstand >die Vereinten Nationen< verantwortlich $\mathrm{zu}$ machen. Durchweg lässt sich hinter einer diagnostizierten Fehlentwicklung das Versagen oder der Rechtsbruch eines Staates oder einer Staatengruppe entdecken. Ganz 
allgemein benötigen die Vereinten Nationen für den Erfolg ihrer Bemühungen die Kooperationsbereitschaft ihrer Mitglieder. Einseitiges Handeln an ihnen vorbei oder gegen ihre Entscheidungen läuft deswegen den Zielsetzungen der Weltorganisation grundsätzlich zuwider.

Selten ist es im Übrigen richtig, pauschal von >den< Vereinten Nationen zu sprechen. Fast durchweg muss nach den einzelnen Organen unterschieden werden. Das Repräsentativorgan, in dem alle Mitgliedstaaten vertreten sind und über eine Stimme verfügen, ist die Generalversammlung. Sie stellt einen Marktplatz der Meinungen dar, wo jede Nation das Recht hat, ihre Meinung zu den Weltgeschehnissen kundzutun. Insofern bildet die Generalversammlung gleichsam ein Stimmungsbarometer, das zwar nicht in einem unmittelbar fassbaren Sinne Entscheidungen zu Fragen der Weltpolitik treffen darf, aber doch den Grundströmungen Ausdruck gibt, die sich durch alle Erdteile hindurchziehen. Die Generalversammlung ist zum Irak-Krieg merkwürdig still geblieben. Aber es wird ohne jeden Zweifel einen Nachhall geben, den auch die USA und das Vereinigte Königreich nicht als irrelevant werden abtun können. Insofern lässt sich im jetzigen Zeitpunkt noch kein genaues Urteil über die Auswirkungen des Irak-Konflikts auf das Zentralorgan der Vereinten Nationen abgeben.

Etwas anders steht es hinsichtlich des Sicherheitsrates. Nach dem Kapitel VII der Charta ist er ermächtigt, verbindliche Entscheidungen $\mathrm{zu}$ treffen und diese gegebenenfalls auch mit Zwangsmitteln durchzusetzen. Freilich haben ihm die Mitgliedstaaten die Verfügungsmacht über eigene Truppenkontingente versagt, wie dies in der Charta an sich vorgesehen ist (Art. 42). Folglich ist der Sicherheitsrat darauf angewiesen, jeweils eine Koalition handlungsbereiter Staaten zu finden, wenn nach seinem Urteil eine militärische Operation im Interesse des Weltfriedens notwendig ist. Im zweiten Golf-Krieg, der Auseinander- 
setzung zwischen Irak und Kuwait im Jahre I990/9I, war eine Ermächtigung zum militärischen Vorgehen gegen die irakischen Invasionstruppen in der berühmten Resolution 678 vom 29. November 1990 an das um Kuwait gescharte Bündnis erteilt worden. (Vgl. Res/SR I990)

Jedermann weiß, dass der Sicherheitsrat von den USA und dem Vereinigten Königreich links liegen gelassen wurde, nachdem ihre Bemühungen, zu dem gewünschten Zeitpunkt im März letzten Jahres eine Ermächtigung für ein militärisches Vorgehen gegen den Irak zu erhalten, gescheitert waren. Während der gesamten Dauer der Verhandlungen hatten Präsident Bush und seine Minister immer wieder erklärt, dass sie eine solche Ermächtigung gar nicht benötigten - was nicht der wahren Rechtslage entsprach, weil, wie schon gezeigt, ein Recht der Selbstverteidigung nicht bestand und auch keiner der früheren Irak-Beschlüsse des Sicherheitsrates eine Autorisierung zur Anwendung militärischer Gewalt enthielt. Zwar haben sich die USA und das Vereinigte Königreich zur Rechtfertigung ihres Vorgehens auch auf die bereits genannte Resolution 678 aus dem Jahre 1990 berufen. Aber diese Resolution hatte nach dem Ende des Krieges gegen Kuwait im Jahre I99I ihre Erledigung gefunden, und die im November 2002 vom Sicherheitsrat angenommene Resolution I44I enthielt zwar eine ernste Warnung an den Irak, sprach sich aber gerade nicht über die konkreten Konsequenzen im Falle der Missachtung dieser Warnung aus. Ist der Sicherheitsrat als Hüter des Weltfriedens damit definitiv aufs Abstellgleis geschoben worden? Ich bin nicht überzeugt, dass man den Sicherheitsrat so schnell aufgeben muss. Er wird auch von den USA wieder benötigt werden. ${ }^{5}$

Die unmittelbaren Folgen der Übergehung des Sicherheitsrates haben manchen Beobachter geradezu euphorisch gestimmt. Der Irak ist von seinem Diktator befreit worden. Die Folterkeller sind verschwunden. Das Volk wird demnächst in 
freier Selbstbestimmung nach demokratischen Methoden und Verfahren über seine Angelegenheiten entscheiden können. Aber diese positiven Ergebnisse der amerikanisch-britischen Intervention, denen im Übrigen auf der Negativseite der Bilanz die Verluste an Menschenleben, vor allem unter der Zivilbevölkerung, wie auch die Verluste an Sachgütern und die, noch viele Wochen nach dem Ende der Kämpfe herrschende, chaotische Unsicherheit gegenübergestellt werden müssen, dürfen nicht die Grundsatzfrage verdrängen. Bedeutet es einen Gewinn für die Grundwerte der internationalen Gemeinschaft, nämlich Frieden, Sicherheit und Menschenrechte, wenn eine Hegemonialordnung aufgerichtet wird, in der ein einziges Land das Sagen hat, während alle Übrigen unter seiner Aufsicht stehen?

Zunächst darf man mit hoher Gewissheit annehmen, dass eine solche Hegemonialordnung auf Dauer von den Völkern der Welt nicht akzeptiert werden würde. Unter den Vorzeichen von Demokratie und Selbstbestimmungsrecht, die den öffentlichen Diskurs über die Legitimität von Regierungssystemen bestimmen, lässt es sich nicht rechtfertigen, dass ein einziges Land, genauer gesagt: die Regierung eines einzigen Landes, Vorrechte genießen soll, die sich dann in Diskriminierungen aller übrigen Länder niederschlagen. Weltpolitische Entscheidungen, die ihre Geltungskraft allein aus der faktischen Überlegenheit ihres Urhebers beziehen, werden zwangsläufig als bloßes Machtdiktat empfunden. Ein solches Diktat vermag sich zwar durchzusetzen, solange die bestehenden Herrschaftsverhältnisse andauern, zerfällt aber sogleich, wenn die Machtlage sich verschiebt. Nur Entscheidungen, die von den Repräsentativorganen der internationalen Gemeinschaft getragen werden, eignet die Legitimität, die erforderlich ist, damit sie auch ohne die Anwendung von Zwang und Gewalt befolgt werden. In diesem Sinne ist es durchaus vorstellbar, dass der irakische Diktator Saddam Hussein ohne Kampf nachgegeben hätte, wenn ein Beschluss über den Einsatz 
militärischer Mittel vom Sicherheitsrat in seiner Gesamtheit einstimmig gefasst worden wäre. Unter diesen Umständen nämlich hätte sich der Diktator sagen müssen, dass er keine Chance habe, sich der geballten Kraft der gesamten internationalen Gemeinschaft zu widersetzen.

Auch das überragende wirtschaftliche und militärische Potenzial der USA ist nicht in der Lage, eine Vielzahl von Ländern in der Dritten Welt zu kontrollieren. Bereits jetzt ist der amerikanische Staatshaushalt in riesige Defizite abgerutscht. Außerdem befinden sich die USA - wie im Übrigen auch Europa - in einer strukturellen Abhängigkeit von Energiezufuhren aus dem Ausland, insbesondere von Ölimporten. Eine Unterbrechung dieses Handelsflusses würde das gesamte Wirtschaftsleben lähmen und mit einem Schlage die Schwächen des Riesen bloßlegen. Niemand in der westlichen Welt kann ein Interesse daran haben, dass es zu solchen existenziell bedrohlichen Verwicklungen kommt. Die USA müssen sich allerdings Rechenschaft darüber ablegen, dass ihre Machtstellung keineswegs so unerschütterlich ist, wie dies von einigen ideologischen Unterstützern der gegenwärtigen Außenpolitik irrig angenommen wird.

So bietet es sich für die USA mit hoher Dringlichkeit an, künftig wieder den Weg über die Vereinten Nationen zu gehen, wenn es um, für die internationale Gemeinschaft essenzielle, Fragen von Krieg und Frieden geht. Aufgrund ihrer Stellung als ständiges Mitglied im Sicherheitsrat haben sie dort eine dominierende Stellung. Zunächst können sie mit ihrem Vetorecht das Zustandekommen jeder Entscheidung verhindern, die gegen ihre Interessen gerichtet ist. Aber auch wenn es für sie um die aktive Herbeiführung von Entscheidungen geht, sind sie aufgrund ihrer faktisch überragenden Macht in einer bevorzugten Position. Natürlich funktioniert der diplomatische Prozess im Sicherheitsrat nicht auf Knopfdruck. Kein Staat, auch nicht die USA, kann erwarten, dass seinen Wünschen sofort und ohne 
Vorbehalt stattgegeben wird. Jedes Mitglied im Sicherheitsrat muss ernst genommen werden mit seinen Bedenken und Vorschlägen. Jeder muss bereit sein, aufmerksam zuzuhören und gegebenenfalls auch die eigene Position $z u$ modifizieren. Vorfestlegungen darf es nicht geben, zumal dann nicht, wenn der Sicherheitsrat eine Untersuchung in Auftrag gegeben hat, deren Ergebnisse die Grundlage für die zu treffende Entscheidung bilden sollen. Denn die Mitgliedschaft im Rat ist eine treuhänderische Position, welche im Interesse der gesamten internationalen Gemeinschaft wahrzunehmen ist. Auch die ständige Mitgliedschaft ist den fünf Mächten nicht zu dem Zweck verliehen worden, dass sie schonungslos nur ihre eigenen Interessen fördern. So war Präsident Bush in einem grundlegenden Irrtum befangen, als er erklärte, der Sicherheitsrat mache sich »irrelevant«, wenn er nicht den amerikanischen Wünschen nach einer neuen Resolution über den Irak innerhalb bestimmter Fristen entspreche. Der Sicherheitsrat hätte nur dann seine institutionelle Verantwortung verfehlt, wenn seine Mitglieder kategorisch erklärt hätten, dass sie auf keinen Fall, unabhängig von den Ergebnissen der laufenden Untersuchungen, bereit sein würden, der Anwendung von Gewalt gegen den Irak zuzustimmen. Aber eine solche Verweigerungshaltung war jedenfalls in der letzten Phase der Beratungen im Sicherheitsrat bei keinem Mitglied mehr anzutreffen. Es ging nur noch um die Frage, wie lange die Ermittlungen über mögliche Bestände an Massenvernichtungswaffen eventuell fortgesetzt werden sollten. In dieser Frage war es gewiss nicht unvernünftig, die Auffassung zu vertreten, dass dem Team von Hans Blix und dem zweiten Team unter den Auspizien der Internationalen Atomenergiebehörde noch wenige Wochen mehr Zeit eingeräumt werden sollten. Von Obstruktion durch die oder einige der anderen I4 Staaten im Sicherheitsrat konnte also ernstlich nicht die Rede sein, auch wenn eine Motiv- 
forschung die unterschiedlichsten nationalen Interessenerwägungen zutage gefördert hat.

Auch generell lässt sich gegenüber dem Sicherheitsrat heute jedenfalls nicht mehr der Vorwurf erheben, dass er unfähig sei, die ihm zugedachten Aufgaben zu erfüllen. Seit der großen Wende des Jahres I990, dem Zusammenbruch der sozialistischen Zwangsherrschaft in Mittel- und Osteuropa, kann von einer strukturellen Blockade, wie sie während der Zeit des Kalten Krieges über Jahrzehnte hinweg zu beobachten war, nicht mehr gesprochen werden. Der erste sichtbare Ausdruck einer wiedergefundenen Harmonie zwischen den ständigen Ratsmächten USA und Sowjetunion war im Jahre 1990 die Verabschiedung der Resolution 660 mit der Aufforderung an den Irak, sich aus Kuwait zurückzuziehen, und zwar noch am Tage des irakischen Überfalls, also ohne lange Verhandlungen; ihre konsequente Fortsetzung fand diese erste Resolution mit der Resolution 678, welche den Einsatz militärischer Gewalt gegen die irakischen Invasionstruppen billigte, und der wenige Monate späteren Resolution 687, mit der dem Irak harsche, aber fast durchweg gerechte Friedensbedingungen auferlegt wurden. Wenig zu überzeugen vermochte freilich seine Handhabung der Jugoslawien-Krise wie auch der apokalyptischen Situation in Ruanda, wo unterschiedliche Wertungen aufeinander prallten. Als Zeichen echter Kooperationsbereitschaft zwischen den Mitgliedern des Sicherheitsrates lässt sich aber wiederum die Resolution I244 vom Io. Juni I999 beurteilen, wo schon am Tage der Beendigung der NATOLuftangriffe auf Jugoslawien eine (vorläufige) Status-Entscheidung über den Kosovo getroffen wurde. Überdies darf nicht vergessen werden, dass der Sicherheitsrat den USA nach den Terroranschlägen vom II. September 200I mit seinen Resolutionen i368 (schon am folgenden Tage verabschiedet!) und I373 (vom 28. September 200I) großzügige rechtliche Unterstützung 
für den Kampf gegen die Urheber jener Anschläge leistete. Die Diagnose, der Sicherheitsrat sei ungeeignet als Instrument der Friedenssicherung, erweist sich mithin als unüberlegt und allzu grobschlächtig. Freilich muss die politische Großwetterlage stimmen. Es lässt sich nicht leugnen, dass das Damoklesschwert des Vetos über allen Entscheidungsprozessen im Sicherheitsrat hängt.

So besteht unbezweifelbar ein Bedürfnis nach einfacheren, zügigeren Verfahren. Eine Reform des Sicherheitsrates bleibt in diesem Sinne auf der Tagesordnung. Aber diese Tagesordnung sieht nach dem Irak-Konflikt offensichtlich ganz anders aus als zuvor. Während über Jahre hinweg eine Vergrößerung des Rates ins Auge gefasst worden war, weil zu Recht Zweifel an seiner richtigen Zusammensetzung geäußert worden waren - seine gegenwärtige Mitgliederstruktur spiegelt die Machtkonstellationen des Jahres I945 wider -, dürften jetzt, nach den schwierigen Verhandlungen über eine zweite Irak-Resolution, die Chancen für eine Erweiterung auf Null gesunken sein - und damit auch die Aussichten auf einen ständigen deutschen Sitz. Praktische Vorschläge zu machen für neue, bessere Entscheidungsverfahren grenzt in seiner Schwierigkeit an die Aufgabe, den gordischen Knoten zu lösen - mit dem Unterschied nur, dass das von Alexander dem Großen angewendete Verfahren hier kaum Erfolg verspricht. Keinem einzigen ständigen Mitglied kann man ohne weiteres seine Rechtsstellung und das damit verbundene Vetorecht nehmen. Frankreich und das Vereinigte Königreich werden wohl niemals einer solchen Relegierung aus dem vornehmen Club der Fünf zustimmen. Ein europäischer Sitz andererseits bleibt gerade angesichts der im Irak-Konflikt aufgetretenen Spannungen reine Phantasterei. Auch wäre eine Ausstoßung aus dem Paradies der rechtlichen Macht bei China und Russland in rechtspolitischer Hinsicht ein Ding der Unmöglichkeit. Obwohl beide Länder nicht die Statur der USA besitzen, kann Weltpolitik 
an ihnen vorbei schlechthin nicht gemacht werden. Irgendwie müsste der Gedanke einer institutionellen Verantwortlichkeit aller Sicherheitsratsmitglieder stärker als bisher zur Geltung gebracht werden. Wie das aber geschehen kann, braucht lange Überlegung im Kreise erfahrener Politiker und Juristen und kann hier leider nicht als Ideallösung aus dem Ärmel gezaubert werden.

\section{Auswirkungen auf die Völkerrechtsordnung insgesamt}

Die dritte Grundsatzfrage lautet, welche Folgen der Ausgang des Irak-Konflikts auf die Völkerrechtsordnung insgesamt haben wird. Anzusetzen ist hierbei zunächst wieder bei der Relativierung des Gewaltverbots durch die USA. Das Gewaltverbot ist nicht etwa irgendeine beliebige der Regeln des geltenden Völkerrechts. Vielmehr hat es eine doppelte Funktion. Neben der Gewährleistung der Friedlichkeit in den internationalen Beziehungen soll es die souveräne Gleichheit der Staaten - oder ihre gleiche Souveränität - sichern. Nur wenn es das Gewaltverbot gibt, kann, jedenfalls im Rechtssinne, davon die Rede sein, dass sowohl San Marino wie Italien, Liechtenstein wie Indien, Slowenien wie China in gleicher Weise vom Völkerrecht mit Rechten ausgestattet und respektiert werden. Solange der Krieg als Naturereignis galt, stand die Souveränität der kleinen Staaten stets unter einem großen Vorbehalt, der sich jederzeit aktualisieren konnte. Erst die durch die Charta der Vereinten Nationen im Jahre I945 begründete neue Völkerrechtsordnung hat also das Prinzip der souveränen Gleichheit durch die Statuierung des Gewaltverbots konsequent verwirklicht. Nun scheint sich erneut eine Hierarchisierung anzubahnen, welche jedenfalls die kleineren Staaten einer Oberaufsicht unterwirft, die nicht von der internationa- 
len Gemeinschaft in ihrer Gesamtheit getragen wird. Nicht auf den ersten Blick lässt sich erkennen, welche Position in dieser Frage der Beschluss des CDU-Bundesvorstands vom 28. April 2003 bezieht, wenn es dort heißt, dass »sich die Prinzipien der staatlichen Souveränität, territorialen Integrität und das völkerrechtliche Interventionsverbot als alleinige Ordnungsparameter zunehmend problematisch« erwiesen.

Mit dem von den USA favorisierten neuen Ordnungsmodell würde ihre Staatsverfassung gleichsam zu einem Stück Verfassungsordnung für die Staaten der Welt aufsteigen. Deren Schicksal geriete in Abhängigkeit von den internen Entscheidungsverfahren, die sich im Machtdreieck zwischen Präsident, Kongress und Oberstem Gerichtshof abspielen. Leider muss festgestellt werden, dass dort gerade in der jüngeren Vergangenheit häufig wenig Verständnis für die Belange der internationalen Gemeinschaft gezeigt worden ist. Immer wieder haben die USA versucht, sich den Bindungen des Völkerrechts zu entziehen und eine Sonderstellung für sich zu beanspruchen. Die Liste dieser Vorgänge ist umfangreich. Deshalb kann sie auch nicht als eine unglückliche Verkettung von Zufälligkeiten abgetan werden.

Seit Jahren haben es die USA versäumt, ihre Beitragsschulden für die Vereinten Nationen korrekt zu begleichen. Vielmehr wurden diese Verpflichtungen mehr oder weniger als Chip in einem nach politischen Regeln ablaufenden Spiel betrachtet. Der Internationale Pakt über bürgerliche und politische Rechte wurde zwar im Jahre I992 ratifiziert (vgl. Hannum/Fischer I993), doch mit der Maßgabe, dass seine Bestimmungen innerstaatlich keine Anwendung finden würden. Damit ist er bisher für die Bürger der USA toter Buchstabe geblieben. Den Gefangenen in Guantanamo sind demzufolge die elementarsten Freiheitsrechte vorenthalten worden, die gerade der Pakt wie auch die Genfer Abkommen über das humanitäre Recht jedem Kriegsgefangenen gewährleisten. Keiner von ihnen hat Rechtsbeistand erhalten, kei- 
nem ist der Weg zu einer Gerichtsinstanz gestattet worden, die in der Lage wäre, die Rechtmäßigkeit der Freiheitsentziehung zu überprüfen. (Vgl. Schäfer 2003) Als am 3. März I999 der Internationale Gerichtshof eine einstweilige Anordnung erließ, derzufolge die Hinrichtung des deutschen Staatsangehörigen Walter LaGrand bis zur Entscheidung in der Hauptsache aufzuschieben sei (vgl. I.C.J. Reports I993: 9, I6), setzte sich der Gouverneur des Bundesstaates Arizona in einer Mischung von Arroganz und Ignoranz über diese richterliche Anordnung hinweg, und auch der Oberste Gerichtshof machte in dieser Auseinandersetzung eine höchst unglückliche Figur. Geradezu in einen Rausch des Kampfes gegen die Völkerrechtsordnung haben sich die USA in ihrer Abneigung gegen das Römische Statut des Internationalen Strafgerichtshofs hineingesteigert. Nicht nur haben sie es abgelehnt, das Statut zu ratifizieren, was an sich ihr souveränes Recht ist, aber in einem merkwürdigen Widerspruch zu ihrer Mitwirkung bei der Schaffung des Nürnberger Gerichtshofs, des Internationalen Strafgerichtshofs für das ehemalige Jugoslawien und des Internationalen Strafgerichtshofs für Ruanda steht. Sie haben überdies ein Gesetz erlassen, den American Servicemembers' Protection Act vom 23.I.2002, der den amerikanischen Behörden nicht nur jede Zusammenarbeit mit dem Internationalen Strafgerichtshof untersagt, sondern auch die amerikanischen Streitkräfte ermächtigt, Gewalt anzuwenden, um gegebenenfalls jeden angeklagten amerikanischen Staatsangehörigen $\mathrm{zu}$ befreien. Sarkastisch hat man diesem Gesetz den Beinamen >Hague Invasion Act< gegeben. Eine der jüngsten Merkwürdigkeiten amerikanischer Diplomatie ist der bis zur letzten Sekunde geführte Kampf gegen ein Fakultativ-Protokoll zur Anti-Folter-Konvention der Vereinten Nationen. Dieses Protokoll sieht vor, dass die Mitglieder eines Expertenausschusses jeden Ort, an dem Menschen gegen ihren Willen festgehalten werden, zur Überprüfung der konkreten Bedingungen der Freiheitsentziehung besichtigen 
dürfen. Als das Protokoll nach vielen Jahren der Auseinandersetzungen schließlich am I8. Dezember 2002 von der Generalversammlung angenommen wurde (Res/GV 57/I99), fanden sich die USA mit ihrem Nein nur noch in Gesellschaft der MarshallInseln, Palaus und Nigerias. Auch hier manifestierte sich also ein entschiedener Wille, jede Art internationaler Aufsicht jedenfalls für sich abzulehnen. Ganz ähnliche Motive hatten offensichtlich wenige Wochen zuvor im November 2002 zu der Weigerung geführt, ein Fakultativ-Protokoll zum Abkommen gegen biologische Waffen mit Regelungen über ein Inspektionsregime $\mathrm{zu}$ akzeptieren - zu einer Zeit, da dem Irak vorgeworfen wurde, er führe Experimente mit solchen Waffen durch und entziehe sich jeder Art von Kontrolle durch die Vereinten Nationen. Derzeit besteht also für die internationale Gemeinschaft wenig Grund, die USA als einen verlässlichen Sachwalter ihrer Interessen anzuerkennen.

Die soeben geschilderten Beobachtungen führen auf eine Grundsatzfrage. Das Völkerrecht ist keine hierarchisch gegliederte Kommandoordnung. Sowohl im Vertragsrecht und im Gewohnheitsrecht wie schließlich auch in den allgemeinen Rechtsgrundsätzen spiegelt sich ein Konsens der Staatengemeinschaft wider. Aus dieser Übereinstimmung der Ansichten über das, was als allgemeiner Verhaltensmaßstab taugt, erwächst die normative Kraft des Völkerrechts. Niemand kann auf der Ebene des zwischenstaatlichen Verkehrs einseitige Anordnungen treffen. Zwar haben die mächtigen Staaten der Welt stets eine führende Rolle auch bei der Schaffung neuer völkerrechtlicher Regeln gespielt. Eines der herausragenden Beispiele ist die Begründung der Rechte am Festlandsockel zunächst durch eine einseitige Proklamation der USA zur Zeit von Präsident Truman im September 1945. (Vgl. Whiteman I965: 756) Aber diese Proklamation fand sehr schnell den Beifall der übrigen Küstenstaaten, die mit nur kurzer zeitlicher Verzögerung begannen, ähnliche Rechte für 
sich in Anspruch zu nehmen. Man mag auch an das Weltraumrecht denken, das sich unter dem Einfluss der technologisch zur Raumfahrt befähigten Staaten Sowjetunion und USA seit dem Flug des ersten Sputniks im Jahre I957 sehr schnell im Sinne der Freiheit des Weltraums entwickelte. In beiden Fällen war der entscheidende Test die Reaktion der internationalen Gemeinschaft in ihrer Gesamtheit. So hat auch der Internationale Gerichtshof in der Frage, ob ein ständiges Mitglied des Sicherheitsrats der Vereinten Nationen diesen durch Abwesenheit, also gleichsam ein strukturelles Veto, lahm legen kann, nicht nur auf die Praxis hingewiesen, dass auch in einer solchen Lage tatsächlich Beschlüsse gefasst werden, sondern auch auf die Tatsache, dass diese Praxis innerhalb der Weltorganisation breite Zustimmung gefunden habe. (Vgl. I.C.J. Reports I97I: I6, 22) Allein diese Betrachtungsweise entspricht dem Grundaxiom, dass die Völkerrechtsordnung ein System unter ranggleichen Akteuren bildet, das seinen rechtlichen Niederschlag in dem Prinzip der souveränen Gleichheit der Staaten gefunden hat.

\section{Schlussbetrachtung}

Aus rechtlicher, aber auch aus machtpolitischer Perspektive ist daher von vornherein kaum damit zu rechnen, dass nun ein amerikanisches Zeitalter heraufzieht, in dem die Völkerrechtsordnung für alle Staaten bindend ist, nur nicht für die USA. Modell für ein solches Zeitalter würde nach den jetzt sichtbaren Vorgaben nicht die Heilige Allianz sein, das aus dem Wiener Friedenskongress von I8I5 geborene Bündnis der führenden europäischen Mächte England, Frankreich, Österreich, Preußen und Russland, sondern die pax romana, die jahrhundertelang rings um das Mittelmeer herrschte, getragen von einer einzigen Macht, nämlich dem Römischen Reich. Trotz aller äußeren An- 
zeichen, dass die Regierung Bush einen solchen Zustand gewiss nicht mit Abneigung betrachten würde, darf man doch annehmen, dass die USA sehr bald wieder die Vorzüge einer durch feste Regeln gebändigten Außenpolitik erkennen werden. Nur wer selbst die Völkerrechtsordnung achtet, vermag sich Vertrauen zu erwerben. Nur Entscheidungen, die in allgemein anerkannten Verfahren ergangen sind, besitzen die Legitimität, die ihnen eine länger dauernde Wirkung und Lebenskraft sichert. Der Multilateralismus ist entgegen den Thesen von Robert Kagan (2003) oder den hasserfüllten Tiraden eines Ralph Peters (2003) keine Marotte der an Auszehrung leidenden Europäer, sondern bezeichnet ein Prinzip effektiver langfristiger Politik. Sprunghafter Unilateralismus zerstört hingegen den Boden, aus dem fruchtbare Zusammenarbeit erwachsen kann. Es liegt an den Europäern, die USA von den Vorteilen einer Rechtsordnung zu überzeugen, die für alle gleich ist. Ein Zweiklassenrecht kann und wird es nicht geben. Niemals wird die internationale Gemeinschaft bereit sein, sich dem Hegemonialanspruch einer einzigen Supermacht zu unterwerfen.

\section{Anmerkungen}

I »Any outlaw regime that has ties to terrorist groups, and seeks or possesses weapons of mass destruction, is a grave danger to the civilized world, and will be confronted.« (Whitehouse 2003)

2 »The United States has long maintained the option of preemptive actions to counter a sufficient threat to our national security. The greater the threat, the greater is the risk of inaction - and the more compelling the case for taking anticipatory action to defend ourselves, even if uncertainty remains as to the time and place of the enemy's attack. To forestall or 
prevent such hostile acts by our adversaries, the United States will, if necessary, act preemptively.« (Whitehouse 2002: 15)

3 Abschluss des sog. Briand-Kellogg-Paktes vom 27.8.1928.

4 Die vom Europäischen Rat auf seinem Gipfeltreffen in Thessaloniki am I9. und 20. Juni 2003 angenommene »Erklärung zur Nichtverbreitung von Massenvernichtungswaffen « (Anlage II) stellt ausdrücklich fest (Nr. 4), dass gegen die Verbreitung solcher Waffen vorzugehen sei und dass dabei als letztes Mittel auch Zwangsmaßnahmen in Betracht kämen, freilich nur »im Einklang mit der Charta der Vereinten Nationen«. (Vgl. Europäischer Rat 2003)

5 Durch die Resolution I483 vom 22. Mai 2003 haben sich die Mitglieder der Koalition ihre Befugnisse und Verantwortlichkeiten als Besatzungsmächte bestätigen lassen, um dadurch die Legitimität ihrer vorübergehenden Herrschaft im Irak zu sichern.

\section{Literatur}

Europäischer Rat (2003): Tagung vom 19. und 20. Juni 2003. Schlussfolgerungen des Vorsitzes, online unter: http://ue.eu.int/ pressData/de/ec/76285.pdf, besucht am I5.I2.2003.

Hannum, Hurst/ Fischer, Dana (Hg.) (I993):U.S. Ratification of the International Covenants on Human Rights, Irvington-onHudson, New York.

I.C.J. Reports (197I): Gutachten zum Status von Namibia vom 2I.6.I97I.

I.C.J. Reports (I993).

Kagan, Robert (2003): Of Paradise and Power, New York.

Kohen, Marcelo G. (2003): »The use of force by the United States after the end of the Cold War, and its impact on international 
law « in: Michael Byers (Hg.): United States Hegemony and the Foundations of International Law, Cambridge, S. I97-23I.

Liszt, Franz von (1925): Das Völkerrecht, I2. Aufl. bearbeitet von M. Fleischmann, Berlin.

Peters, Ralph (2003): »Hitler war wenigstens ehrlich. Ihr widert uns an: Die Amerikaner sind mit den Deutschen fertig «, in: Frankfurter Allgemeine Zeitung vom I5.05.03.

Resolution 33I4 (XXIX) der Generalversammlung der Vereinten Nationen vom I4.I2.I974: Definition der Aggression, online unter: http://www.un.org/Depts / german/gv-early/ar33I4_neu. pdf, besucht am I5.I2.2003.

Resolution 57/199 der Generalversammlung der Vereinten Nationen vom 9.01.2002: Optional Protocol to the Convention against Torture and Other Cruel, Inhuman or Degrading Treatment or Punishment, online unter: http://www.un.org/Depts/ dhl/resguide/r57.htm, besucht am I5.I2.2003.

Resolution 678 des Sicherheitsrates der Vereinten Nationen vom 29.II.I990: Iraq - Kuwait, online unter: http://www.un.org/ Docs/scres/1990/scres9o.htm, besucht am I5.I2.2003.

Schäfer, Bernhard (2003): »Guantánamo Bay«: Status der Gefangenen und habeas corpus, Potsdam.

Tomuschat, Christian (200I): »Der II. September 200I und seine rechtlichen Konsequenzen«, in: Europäische Grundrechte-Zeitschrift 28, S. 535-545.

Whitehouse (2002): The National Security Strategy of the United States, online unter: http://www.whitehouse.gov/nsc/nss.pdf, besucht am I5.12.2003.

Whitehouse (2003): President Bush announces Major Combat Operations in Iraq Have Ended, online unter: http://www. whitehouse.gov/ news / releases / 2003/05/iraq/2003050I-I5. html, besucht am I5.I2.2003.

Whiteman, Marjorie M. (Hg.) (1965): Digest of International Law, 4. Auflage, Washington. 


\section{Die NATO im Geflecht internationaler}

\section{Organisationen}

August Pradetto

Dass sich die westliche Allianz in einer Krise befindet, ist evident. Die nachfolgenden Ausführungen gehen drei Fragen nach: Die erste lautet, worauf die gegenwärtige Unsicherheit über die Fundamente des Bündnisses, über dessen Zielsetzungen und Aufgaben sowie über die Strategien und Instrumente beruht. Zweitens wird die Frage zu beantworten gesucht, wie die Positionierung der Allianz von unterschiedlichen politischen Kräften im Kontext anderer internationaler Organisationen gesehen wird. Und schließlich bedingt die Frage, welchen Platz die NATO in der internationalen Politik einnimmt, eine Bestimmung des Verhältnisses zwischen den Vereinigten Staaten und Europa in der und in Bezug auf die Organisation.

Prognosen, wohin die >NATO des 2I. Jahrhunderts $<$ geht, verbieten sich: Wenn etwas in den letzten fünfzehn Jahren besonders signifikant war, dann war es die Unvorhersagbarkeit der Entwicklung der Allianz. An der Wende zu den goer Jahren 
hätte noch kaum jemand vermutet, dass der Kollaps von Warschauer Pakt und Sowjetunion die Organisation in derartige Identitätsprobleme bringen könnte, dass einige Politiker apodiktisch die Alternative »out of area or out of business« aufwerfen würden. Im Jahre I990 bei den Zwei-Plus-Vier-Verhandlungen über die Herstellung der deutschen Einheit, als es unter anderem um die Einbeziehung der früheren DDR in den NATORaum ging, hätte kein Experte ernsthaft an eine darüber hinausgehende Erweiterung des Bündnisses in Richtung Osten gedacht. Drei Jahre später wurde eben dies zu einem prioritären Punkt auf der Agenda der Organisation. Zu Beginn der goer Jahre war es jenseits des Horizonts politischen Vorstellungsvermögens, die NATO könnte außerhalb des Bündnisgebietes und außerhalb ihres Verteidigungsauftrags unter der Führung oder im Mandat der Vereinten Nationen tätig werden. I994/95 setzte die Organisation sowohl die Luftwaffe als auch Bodentruppen in Bosnien-Herzegowina ein. Ebenso undenkbar war bis in die zweite Hälfte der goer Jahre, dass das Verteidigungsbündnis ohne eine Mandatierung durch den Sicherheitsrat der Vereinten Nationen militärisch die Souveränität eines anderen Staates verletzen würde, ohne selbst angegriffen zu werden. 1999 führte die NATO ihren ersten Krieg überhaupt in der Geschichte des Bündnisses - außerhalb des Bündnisgebietes, außerhalb der Vereinten Nationen und außerhalb des Rechts auf Selbstverteidigung.

Ebenso wenig vorstellbar war bis kurz vor dem Krieg gegen Jugoslawien, dass diese Entgrenzung der Aufgabenstellung des Bündnisses und seiner Einsatzmöglichkeiten als Doktrin festgeschrieben werden könnte, wie dies mit dem neuen strategischen Konzept auf dem Washingtoner Gipfel im April 1999 erfolgte. Noch Anfang des Jahres 200I war es für die meisten NATO-Staaten und den Großteil der sicherheitspolitischen Experten höchst unwahrscheinlich, dass dem Wunsch der baltischen Staaten nach 
Aufnahme in die Organisation in den folgenden Jahren entsprochen würde. Auf dem Prager Gipfel im November 2002 wurden nicht nur die drei baltischen Staaten, sondern auch Bulgarien, Rumänien, Slowenien und die Slowakei zu Beitrittsverhandlungen eingeladen. Und ebenso wenig denkbar war bis vor kurzem, dass die NATO in quasi Peace keeping-Einsätzen nach einem von den USA militärisch erzwungenen Regimewechsel in Afghanistan oder Irak tätig werden würde. Stattdessen wurde an der Wende zum neuen Jahrzehnt über eine mögliche Aufnahme neutraler Länder in die Organisation spekuliert. Davon war nach dem Irak-Krieg keine Rede mehr. Stattdessen wurden wieder verstärkt Überlegungen angestellt, Russland noch weiter in die NATO zu integrieren und eventuell sogar aufzunehmen. (Vgl. Gordon/Steinberg 200I; Gordon 200I)

All diese Wendungen und überraschenden Veränderungen seit Ende der 8oer Jahre zeigen nicht nur, wie vorsichtig mit Vorhersagen über die künftige Entwicklung der Organisation umgegangen werden sollte. Sie zeigen auch keineswegs nur worauf in der NATO immer wieder mit Stolz verwiesen wird die Anpassungsfähigkeit und Flexibilität der Allianz. Sie demonstrieren vielmehr auch den kontingenten Transformationsprozess, dem die NATO unterliegt und der von vielen zufälligen, schwer bestimmbaren Variablen beeinflusst wird.

Oft wird angeführt, die NATO habe schon viele Kontroversen und Auseinandersetzungen in ihrer Geschichte überstanden. Auch Instrumentalisierungsversuche wie in der Irak-Frage seien keineswegs neu. Die USA beispielsweise bei ihrem Engagement in Vietnam und Frankreich beim Versuch, militärisch in ehemaligen Kolonien in Afrika zu intervenieren, hätten dies ebenfalls vergeblich probiert. Die Problematik geht jedoch seit dem Ende des Kalten Krieges tiefer. Bis zur Auflösung von Warschauer Pakt und Sowjetunion war die Identität der NATO konsensual. Die kollektive Verteidigung und das Bemühen um eine politische 
Entspannung waren das von allen Mitgliedern geteilte Fundament der Organisation. Alle Kontroversen hatten mit unterschiedlichen Ansichten darüber zu tun, wie diese Aufgabe am besten zu lösen sei. Dieses Fundament ist mit dem Abhandenkommen des ehemaligen Gegners zerbröckelt. Seitdem kreisen die Diskussionen und Kontroversen um die Frage der Identität der NATO selbst, und diese Debatte hat seit der Polarisierung in der Weltpolitik nach den Terroranschlägen vom II. September 200I auf New York und Washington ihren Höhepunkt erreicht. Der einstige gemeinsame Nenner kollektiver Verteidigung, der die Existenz der Organisation außer Frage gestellt hat, existiert nicht mehr. Er ist reduziert auf das Bewusstsein seiner Mitglieder, die Allianz werde aus Stabilitätsgründen weiterhin gebraucht. Wie dieses viel diffusere Ziel der >Stabilität $<$ zu erreichen sei - darüber gehen die Meinungen mehr denn je auseinander. Tatsächlich sind der NATO, als vorrangig militärischer Organisation, die dem klassischen Bemühen um Verteidigung der Souveränität ihrer Mitglieder entspricht, die so genannten neuen Bedrohungen fremd. Doch klassische Verteidigungspolitik und das Bemühen um Entspannung zwischen staatlichen Akteuren werden als nur mehr untergeordnete Aufgaben beim Versuch gewertet, neuen Herausforderungen für die Sicherheit von Staat und Gesellschaft zu begegnen.

\section{Bekämpfung des internationalen Terrorismus als künftige Hauptaufgabe der NATO?}

Die Londoner Erklärung der NATO im Juli I990 kündigte eine fundamentale Änderung der Strategie der Allianz an, die den weltpolitischen Umbrüchen gerecht werden sollte. (Vgl. The London Declaration I990) Seither wurden viele Strategiepapiere 
geschrieben, Änderungen eingeleitet und Umwertungen vorgenommen. Seit 1990 befindet sich die NATO in einem permanenten Reformprozess. Eine konsistente Vorstellung über die $\mathrm{Zu}$ kunft der Organisation ist bis heute nicht entwickelt worden. Das Engagement der NATO in den Balkankriegen und die Erklärung des Bündnisfalles nach den Terroranschlägen in den USA im September 200I haben die Identitätskrise nur zeitweise überdeckt. Zwar sind neue Aufgabenstellungen in der Sicherheitsproduktion deutlich geworden. Doch gleichzeitig haben diese Aktivitäten die Debatte über die Grundlagen und die Zukunft der NATO weiter verschärft. Das neue strategische Konzept von I999 (The Washington Declaration I999) spiegelt sicher einerseits die Veränderung der NATO, die Erweiterung des Aufgabenspektrums, das neue Verständnis in der Organisation wider. Auf der anderen Seite ist dieses Dokument Ausdruck auch der Hilflosigkeit: ein Sammelsurium von Bedrohungsszenarien und Aufgabenstellungen, die vom ungebremsten demographischen Wachstum in Teilen der Dritten Welt über soziale Probleme, die durch die Globalisierung entstehen, bis zum internationalen Terrorismus reichen. Außer dem Plädoyer, man müsse sich hierauf einstellen, sind seither wenig konkrete Festlegungen getroffen worden.

Mitte der goer Jahre wurde - vor allem nach dem Abschluss des Dayton-Vertrages über Bosnien-Herzegowina, der bald nach dem Eingreifen der NATO in der ehemaligen jugoslawischen Republik geschlossen worden war - von der NATO als »einzig wirksamer « Sicherheitsorganisation gesprochen. Andere Organisationen wie die Europäische Union, die Vereinten Nationen und die OSZE galten Vielen als Versager. (Vgl. Bernauer/Brem/Suter I995; Calic 1997) Die Realität ist jedoch nicht nur, dass bis heute weder das Problem Bosnien-Herzegowina noch das Problem Kosovo militärisch und politisch gelöst ist, abgesehen davon, dass die Vertreibungen in Kosovo auch nach der NATO-Intervention 
weitergingen - nun quasi unter >Aufsicht< der NATO und unter ethnisch umgekehrten Vorzeichen. (Vgl. Mutz 2000) Sondern der Kosovo-Krieg war aus verschiedenen Gründen auch ein Katalysator für zentrifugale Tendenzen in der NATO und für die Auseinandersetzung über die Identität der Organisation. Auch für die Allianz stellte sich heraus, dass sie - genauso wenig wie die Europäische Union oder die OSZE - eine erfolgreiche Bürgerkriegsschlichtungs- oder Nation-building-Regulierungsinstanz darstellt. Tatsächlich haben internationale Organisationen - bei allen Fehlern, die gemacht worden sind - eine positive Rolle im Versuch gespielt, dämpfend auf die Konfliktparteien im ehemaligen Jugoslawien einzuwirken. Als Fazit des postkommunistischen Nation-building lässt sich ziehen, dass die Wahl des »tschechoslowakischen Weges« - die friedliche Trennung von Volksgruppen - oder des »bosnischen Weges« - die versuchte Trennung mit Gewalt - weniger von externen Faktoren als von den Akteuren vor Ort abhängig ist.

Nach dem II. September 200I wurde partiell erwartet, partiell gehofft, dass die NATO nun ihre neue gemeinsame Aufgabenstellung im Kampf gegen den internationalen Terror finden würde. (Vgl. Kamp 2002) Die Organisation erklärte den Bündnisfall (vgl. Nato 200I), und es schien einen Augenblick, als rücke die Allianz ins Zentrum der sich formierenden internationalen Front gegen den Terrorismus. Bekanntlich war das Gegenteil der Fall. Vordergründig wurde die NATO durch die Politik der Administration in Washington marginalisiert. Diese zog unilaterale Entscheidungen und bilaterale Absprachen der Multilateralisierung des Kampfes gegen den Terror in internationalen Organisationen und auch in der NATO vor. Auch dies bewirkte, dass in der NATO von Anfang an divergierende Auffassungen über den Kampf gegen den Terrorismus herrschten. Die zuerst noch verhalten geführte Auseinandersetzung über die Sinnhaftigkeit eines Regimewechsels in Afghanistan oder aber eine Beschrän- 
kung des Einsatzes militärischer Kräfte auf die Zerschlagung terroristischer Stützpunkte verschärfte sich ab Ende Januar 2002, als US-Präsident George W. Bush die Zerschlagung der »Achse des Bösen« ankündigte. (Vgl. Whitehouse 2002a) Die Proklamation des Krieges gegen Irak, die Fixierung einer Strategie stotaler militärischer Überlegenheit und die Beanspruchung eines Präventivkriegsrechts in der neuen US-Sicherheitsdoktrin vom September 2002 (vgl. Whitehouse 2002b) sowie die Tatsache, dass sich einige europäische Politiker an die Seite der Administration in Washington stellten, während andere eine ablehnende Haltung einnahmen, vertieften die Spaltung in der NATO zusehends. Der Prager Gipfel im November 2002 war so sehr vom Zerwürfnis über die Irak-Frage geprägt, dass eine Debatte hierüber erst gar nicht geführt wurde. Der Streit über die Forderung Washingtons, die Allianz möge ihren Bündnisverpflichtungen gegenüber der Türkei im Falle eines Angriffs aus Irak in Folge der beabsichtigten Intervention der USA gerecht werden - was eine Pervertierung von Artikel 5 des NATO-Vertrags bedeutete war ein Schlaglicht an der Oberfläche jener grundsätzlichen Auseinandersetzung darüber, was die NATO heute sein soll.

Diese Auseinandersetzung hängt mit teilweise konträren Antworten auf die Frage zusammen, was in der Zeit nach dem Kalten Krieg unter Verteidigung zu verstehen sei und wie Sicherheit hergestellt werden könne. Die Diskrepanzen in der Wahrnehmung der Bedrohung und in der Strategieentwicklung sind darauf zurückzuführen, dass die klassische Bedrohung nationaler Souveränität sich weitgehend aufgelöst hat und die so genannten neuen Bedrohungen mit den Mitteln und Instrumenten der NATO nur mehr unzureichend zu bewältigen sind. Die Krise, in der sich die NATO befindet, resultiert aber nicht nur aus den divergierenden Wahrnehmungen, sondern ist auch institutionell bedingt. Der Entscheidungsprozess in der NATO funktioniert im Prinzip nicht anders als im Sicherheitsrat der Verein- 
ten Nationen. Sobald Differenzen auftreten, ist der Entscheidungsfindungsprozess genau so schwierig: Wenn eines der Mitglieder sein Veto einlegt, ist die Organisation »blockiert«. Beschlüsse über militärische Aktivitäten müssen die Zustimmung aller (oder wenigstens nicht die Ablehnung auch nur eines der) Mitglieder finden.

\section{Hysterisierung der Internationalen Politik}

Die Krise der NATO ist aber auch eine Krise der politischen Kultur im Bündnis. Die Zeiten der Transformation erzeugen eine Unsicherheit und eine Kontingenz, die vielfach eine verzerrte Wahrnehmung von Realität zur Folge hat. Objektiv gesehen ist unsere Sicherheit durch das Ende des Ost-West-Konflikts, der Bipolarität und der wechselseitigen Bedrohung mit ungeheuren Zerstörungspotenzialen noch nie so groß gewesen wie heute. Seit dem Ende der jugoslawischen Nachfolgekriege hat sich das Sicherheitsniveau in Europa noch erhöht. Die bislang erfolgreiche Kooperations- und Integrationsstrategie der Europäischen Union und der NATO gegenüber dem postkommunistischen Ostteil des Kontinents hat diesen Zustand noch weiter erheblich verbessert. Die militärische Überlegenheit der NATO-Staaten durch den Zusammenbruch des gesamten >Ostblocks< ist in einer Weise gegeben, dass kein Staat und keine Staatenkoalition der Welt ernsthaft den Gedanken zu fassen wagt, ein NATO-Mitglied anzugreifen. Umso höher ist zu werten, dass die kollektive Sicherheitsfunktion der Allianz - in ihr kooperiert der größte Teil der ökonomisch und militärisch potentesten Staaten der Welt miteinander, anstatt, wie bis zum Zweiten Weltkrieg, die größte globale Bedrohung für den Weltfrieden darzustellen dieser günstigen Lage ein stabiles institutionelles Fundament verleiht. Mit dem Zusammenbruch des sowjetischen Imperiums 
hat sich das marktwirtschaftliche System global durchgesetzt mit seiner Infragestellung ist höchstens zu rechnen, wenn seine Protagonisten es selbst delegitimieren. Die Demokratie hat sich weltweit als überlegenes politisches System und als Priorität auf der internationalen politischen Werteskala durchgesetzt. Im Vergleich zur ideologischen, politischen, militärischen, institutionellen und völkerrechtlichen Situation über weite Strecken im 20. Jahrhundert und zu den gegeneinander in Stellung gebrachten und tatsächlich eingesetzten Zerstörungspotenzialen sind die Gefährdungen durch den internationalen Terrorismus und durch die mögliche Proliferation von Massenvernichtungswaffen heute realiter gering.

Diese Beschreibung steht im krassen Gegensatz zur Wahrnehmung von Gefährdungen durch terroristische Verbrecher und fanatisierte Radikale, die vor allem Israel und die USA treffen wollen. In einem Großteil der Medien und in der Deskription durch eine Reihe von Politikern erscheint dieser Sachverhalt wie umgekehrt: Nie sei die Gefährdung so groß gewesen, nie hätten wir in einer anarchistischeren und apokalyptischeren Welt gelebt als heute. Dass der Kampf gegen den Terrorismus und gegen die Proliferation von Massenvernichtungswaffen intensiviert werden muss, steht außer Frage. Aber aufgrund des ungeheueren Abschreckungspotenzials, über das die USA, die NATO und Israel sowie eine große Zahl anderer anti-terroristischer Mächte wie Japan, Russland oder China verfügen, existiert real in sehr geringem Maße eine Gefährdung durch staatliche Akteure (»Schurkenstaaten«). Gleichzeitig wird die Gefahr der Proliferation durch derartige staatliche Akteure stark übertrieben. Diesbezüglich sind bislang sowohl in Bezug auf zeitweise von US-Führungen als »strategische Konkurrenten « gehandelte Akteure wie Russland oder China als auch auf »Schurkenstaaten« wie Irak, Nordkorea, Libyen und andere wenig stichhaltige Beweise erbracht worden. Der Umfang der Unterstützung für subversive 
antiwestliche Aktivitäten war in der Zeit des Kalten Krieges von Seiten der Sowjetunion und Chinas wie einer Reihe anderer Staaten - u.a. der DDR - in unvergleichlich höherem Maße gegeben als dies heute mit Bezug auf »Schurkenstaaten « und terroristische Organisationen der Fall ist. Einige Regime, die versuchen, sich atomare Waffen oder andere Massenvernichtungsmittel zu beschaffen, können heute in noch viel effizienterer Weise abgeschreckt werden, als dies in Zeiten des Kalten Krieges gegenüber der Sowjetunion der Fall gewesen ist.

Nicht nur im Osten Europas sind mit dem Wegbrechen von alten Ordnungsprinzipien, von Sicherheiten und eingespielten mentalen Schemata auch paranoide Deutungsmuster und radikale Ideologien in den Vordergrund getreten. Der Wegfall bipolarer Strukturierungsfaktoren und die Verschärfung negativer Auswirkungen der Globalisierung auf einige Regionen der Welt sowie das verschärfte >zu Tage treten< negativer Konsequenzen von >bad governance $<$ und unterbliebener Modernisierung haben in einem Staatengürtel, der von Peru und anderen Teilen Südamerikas über Afrika, den Nahen und Mittleren Osten bis nach Indonesien reicht, in einem gewissen Ausmaß eine Re-Ideologisierung und neue Gewaltpotenziale hervorgebracht, die sich allerdings vor allem endogen zerstörerisch auswirken. Aber auch >der Westen< befindet sich in einer Umbruchs- und Neuorientierungsphase. Auch hier wird partiell mit paranoiden Reaktionen und hysterischem Verhalten auf das Wegbrechen gewohnter Ordnungsmuster reagiert. Seit dem II. September 200I verbinden sich insbesondere bei den >Neokonservativen « in den USA Allmachtsphantasien und imperiale Ordnungsvorstellungen und -strategien mit solchen hysterischen Interpretationen und politischen Reaktionen. (Vgl. Pradetto 2003)

Besonders virulent wird diese Verbindung aufgrund personeller, situativer und struktureller Faktoren: Mit George W. Bush ist Ende 2000 ein Präsident an die Spitze der Vereinigten Staa- 
ten gewählt worden, dessen Persönlichkeit, mentale Befindlichkeit und Problemlösungskapazität mit dem diesbezüglichen Potenzial seiner neokonservativen Vordenker, Strategen und Politiker kongruiert. Mit dem terroristischen Verbrechen vom II. September 200I ist ein Ereignis eingetreten, das die Möglichkeiten zur Erzeugung von Phobien und zur Plausibilität neokonservativer Interpretationen und Strategien in einer Weise gesteigert hat, wie dies durch die zuvor verübten Terroranschläge nicht der Fall gewesen war. Schließlich verfügen die USA über ein militärisches Potenzial, das sie in die Lage versetzen, tatsächlich in globalem Maßstab Vergeltungs- und Neuordnungspläne mit militärischen Mitteln in Angriff zu nehmen. ${ }^{.}$Die Wahrnehmung dieses terroristischen Anschlages als globalen Krieg gegen die USA und die Schlussfolgerung einer Notwendigkeit globaler Kriegsführung gegen »das Böse« korrespondiert mit einem integralen Bestandteil der politischen und strategischen Kultur der Vereinigten Staaten, der als >hysterisches Syndrom werden kann: Übersteigerte Ängste (»das Böse« will >Amerika< zerstören), übersteigerte Feindbilder (Osama bin Laden, Slobodan Milosevic, Saddam Hussein als die >Hitler des 2r. Jahrhunderts $<$ ), apokalyptische Zustandsbeschreibungen.

Die vor allem von den >Neocons < vertretene Wahrnehmung, nach der der internationale Terrorismus als äußerer Feind die Hauptgefahr und eine existenzielle Bedrohung darstelle, differiert von der Gefahrenperzeption vieler europäischer Politiker. Zwar müsse der Terrorismus mit verbesserten Mitteln bekämpft und die Proliferation von Massenvernichtungswaffen verhindert werden. Aber die größten Gefahren für Stabilität und Sicherheit in Europa gingen neben dem internationalen Terrorismus und Massenvernichtungswaffen von einer Reihe negativer Binnenund Globalisierungsfaktoren aus, die zum größten Teil unterhalb der Schwelle von Gewalt, geschweige von Kriegen, angesiedelt sind: nämlich von sozialen Verwerfungen und ökonomischen 
Diskrepanzen, von Arbeitslosigkeit, Migrationsbewegungen, organisierter Kriminalität, Nation-building, nicht funktionierenden Zivilgesellschaften usw. Das heißt: Die unterschiedliche Wahrnehmung von Sicherheitsproblemen bei den US-Neokonservativen und der Bush-Administration, die die Bedrohung von außen in den Vordergrund stellen, sowie einer Reihe vor allem westeuropäischer Politiker und von Führern in der »Dritten Welt«, deren Gefahrenwahrnehmung stärker binnenorientiert ist, erschwert eine Verständigung über gemeinsam wahrzunehmende internationale Sicherheitspolitik. Die in unterschiedlichen politischen Milieus angesiedelten divergenten politischen und strategischen Kulturen, die innerhalb der NATO polarisiert von der Bush-Administration auf der einen Seite repräsentiert werden, vom französischen >gaullistischen Konsens $<$ und von der multilateral-legalistischen Einstellung der deutschen rot-grünen Regierung auf der anderen Seite, führen mit der andersartigen Bedrohungswahrnehmung auch $\mathrm{zu}$ unterschiedlichen Zielvorstellungen über die Rolle der NATO. Während die Bush-Administration auf eine Transformation der Allianz drängt, die unter Führung der USA beim globalen Krieg gegen »das Böse« helfen soll (vgl. U.S. Department of State 2003), wird die Funktion der NATO in gaullistischer und rot-grüner Sicht defensiver und politischer wahrgenommen. Abgesehen vom Abschreckungscharakter der NATO wird von Letzteren die sicherheitspolitische Kooperation und der institutionalistische Aspekt der Verbreiterung der Zone von Sicherheit und Frieden in Europa durch Integration osteuropäischer Staaten und Kooperation mit Nordafrika und Nahost betont - also der politische Stabilitätstransfer und die Stabilitätsprojektion weiter nach Osten und Süden. (Vgl. Alliot-Marie 2003; zur deutschen Position vgl. Kamp 2003) 


\section{NATO und Europäische Union als konkurrierende Sicherheitsproduzenten?}

Dass Europa und die Europäische Union in Sicherheitsfragen von der NATO und den USA independenter werden, entspricht der neuen historischen Lage. Während des Kalten Krieges war der Westteil Europas von der Sicherheitsgarantie der USA abhängig. Dies ist nach der Auflösung von Sowjetunion und Warschauer Pakt bei weitem nicht mehr im gleichen Maße der Fall. Das Selbständigwerden Europas drückt sich nicht zuletzt in der Fähigkeit aus, für die eigene Sicherheit in ausreichendem Maße Sorge $\mathrm{zu}$ tragen. Dies beinhaltet den Aufbau entsprechender capabilities bis hin zur Fähigkeit, möglicherweise erforderliche Einsätze robuster Kräfte zur Rechtsdurchsetzung bereitstellen zu können. Realisierbar ist dies, wenn der entsprechende politische Wille vorhanden und die europäischen militärischen Kapazitäten für diese Aufgabe ausgerichtet und gebündelt werden; die Ressourcen sind im Prinzip vorhanden. Die politische Notwendigkeit hierfür ergibt sich daraus, dass es auf Dauer weder sinnvoll noch akzeptabel ist, dass die europäische Sicherheit von Entscheidungen im Weißen Haus oder im US-Kongress abhängig ist. Die Bemühungen, die Europäische Union mit den entsprechenden Fähigkeiten und Kompetenzen auszustatten, gehen indes nur langsam voran. Auch wenn längerfristig absehbar ist, dass die Europäische Union einen relevanten Teil der Aufgaben, die die NATO gegenwärtig für den Kontinent leistet, übernehmen wird, ist gleichzeitig deutlich, dass bis zu einer ausreichenden und befriedigenden Lösung die NATO und die USA als Sicherheitsproduzenten in Europa unabdingbar bleiben. Dies stellt schon insofern keine Einbahnstraße dar, als auch die USA ein vitales Interesse an einem stabilen Europa haben, wennschon (oder gerade weil) sich der Schwerpunkt der US-Sicherheitspolitik im internationalen Bereich in andere Räume verlagert. Global 
betrachtet bleibt Europa ökonomisch, politisch und sicherheitspolitisch der wichtigste Partner der Vereinigten Staaten, genau wie dies umgekehrt für die Europäer mit Nordamerika der Fall ist.

Allerdings: Insofern die NATO in den Augen aller US-Administrationen - unabhängig von der politischen Färbung - gegenüber Europa eine dominante Stellung Washingtons in sicherheitspolitischen Fragen sicherstellen soll, steht die sicherheitspolitische Verselbständigung Europas durch einen entsprechenden Ausbau der Europäischen Union dazu in Konkurrenz. Die Aufnahme des Beistandsartikels in die Europäische Verfassung und die Bereitstellung entsprechender Kapazitäten, um diesem Anspruch gerecht $\mathrm{zu}$ werden, relativiert die Bedeutung der NATO in ihrer Abschreckungsfunktion für Europa weiter. Die Übernahme der Makedonien-Mission durch die Europäische Union von der NATO und Überlegungen zu einer analogen Vorgehensweise in Bosnien-Herzegowina und anderen Teilen des ehemaligen Jugoslawien sind Indizien für den oben genannten Trend der sicherheitspolitischen Selbstverantwortung.

In dieser Konkurrenz und in dem beschriebenen Tauziehen ist die NATO selbst Objekt spezifischer sicherheitspolitischer Begierden geworden. Die mit massiven militärischen Fähigkeiten, zahlreichen Ressourcen, hoher Autorität und damit auch erheblichem sozialen Kapital ausgestattete Institution weckt auf beiden Seiten des Atlantiks Begehrlichkeiten; die unterschiedlichen Wünsche wurden oben beschrieben. Die Akteure befinden sich darüber in einem intensiven Bargaining-Prozess, bei dem Kompromisse geschlossen werden, weil keiner den anderen verlieren möchte. Dabei liegt der Unterschied zwischen den USA und Europa nicht nur in unterschiedlichen Bedrohungswahrnehmungen, sondern auch - Bestandteil der strategischen Kultur - in einem strukturell unterschiedlichen globalen commitment, nämlich dem weltweiten Stützpunktsystem und der globa- 
len Rolle, die sich die außenpolitischen Eliten der USA zuschreiben. Dieses Stützpunktsystem ist nach dem Ende des Kalten Krieges nicht wesentlich reduziert worden, sondern soll im Gegenteil vor allem nach den Plänen der >Neokonservativen< erheblich ausgebaut werden, während genau dies in zunehmend geringerem Maße in verschiedenen Teilen der Welt akzeptiert wird. Nicht zuletzt deshalb wächst die Terrorgefahr für US-Truppen, die im Ausland stationiert sind. Vor diesem Hintergrund ist das Anliegen der US-Führung zu sehen, die NATO auch als Instrument der Absicherung dieses globalen Systems zu nutzen, das in Washington als zugleich im Interesse der Europäer liegend erachtet wird.

\section{Die Nato - irrelevant, marginalisiert, nützlich oder notwendig?}

Die vorstehenden Ausführungen zeigen: Eine Bewertung der gegenwärtigen und künftigen Rolle der NATO hängt im Wesentlichen von den Erwartungen ab, die mit der Allianz und ihren Aktivitäten verbunden werden. Wegen des Interesses an einer wechselseitigen Bündnisverpflichtung - auch wenn diese nicht mehr die existenzielle Bedeutung wie zu Zeiten des Kalten Krieges hat -, an fortbestehender enger sicherheitspolitischer Kooperation und Konsultation sowie an einer integrierten Zone der Gemeinsamkeit in wirtschaftlichen, politischen und Verteidigungsfragen scheint eine wesentliche Grundlage für das Weiterbestehen der Allianz nach wie vor existent. Nach wie vor ist die Funktion der Abschreckung vor allem an der Peripherie des Bündnisses nicht obsolet. Die NATO vermag aufgrund ihrer Magnetwirkung die transatlantische Werte- und Sicherheitszone weiter auszudehnen. Sie befähigt zu einem produktiven sicherheitspolitischen Dialog nach außen, wie nicht nur das Beispiel 
Russlands, sondern auch Chinas zeigt, dessen Führung sich um eine engere sicherheitspolitische Konsultation mit Brüssel bemüht. Sowohl die USA als auch die Europäer sind in ihrer großen Mehrzahl an einem Fortdauern der US-Präsenz in Europa - wenn auch mit abnehmender Tendenz - interessiert und erachten zumindest noch mittelfristig diese Präsenz als einen Sicherheitsfaktor, der reale und potenzielle binneneuropäische Rivalitäten und Befürchtungen austariert. Solcherart werden von einem Großteil der außenpolitischen Eliten in Europa wie in Nordamerika die NATO und die beschriebenen Funktionen der Organisation als wesentlicher Faktor von Stabilität und Sicherheit in der Welt erachtet.

Dieser Sachverhalt ist in der Auseinandersetzung über die Strategien des Kampfes gegen den internationalen Terrorismus nach dem ir. September 200I und im Zuge des Zerwürfnisses über den völkerrechtlich illegalen und sicherheitspolitisch umstrittenen Krieg der USA gegen den Irak in den Hintergrund gedrängt worden. Wie sich 2002/2003 gezeigt hat, wird die geschilderte gemeinsame Interessenbasis für das Fortbestehen der Organisation durch eine Überbetonung partikularer Zielsetzungen und die Überforderung diverser Mitglieder beeinträchtigt. Das Interventionskonzept der zurzeit im Weißen Haus dominierenden neokonservativen Richtung sprengt den Konsens, der das politische Fundament der Organisation darstellt - würde mit aller Macht versucht werden, dieses Konzept für die NATO verbindlich zu machen. Der Versuch, die Allianz in eine US-geführte internationale Interventionsmacht $\mathrm{zu}$ transformieren, wäre gleichbedeutend mit dem Zerfall der Organisation.

Mit der divergenten Bedrohungsanalyse einher geht die Unterschiedlichkeit in den Strategien, die als Antwort auf die »neuen Bedrohungen « gegeben werden. Die gegenwärtige US-Administration zielt bei der Bekämpfung des internationalen Terrorismus nicht zuletzt auf militärisch durchzusetzende Transfor- 
mations- und regionale Neuordnungskonzepte, die von anderen NATO-Mitgliedern als gefährlich und teilweise kontraproduktiv eingeschätzt werden. Die Debatte geht darüber, wie der zunehmend asymmetrischen Kriegführung adäquat zu begegnen ist. Militärisch induzierten Neuordnungsplänen stehen stärker auf geheimdienstliche und polizeiliche sowie auf ein Spektrum politischer Maßnahmen zielende Strategien gegenüber, die dem asymmetrischen Charakter der Auseinandersetzung zwischen dem internationalen Terrorismus und westlichen Staaten nach Auffassung ihrer Protagonisten eher gerecht werden. Demgegenüber zielt das Konzept der Bush-Administration, die europäischen Streitkräfte durch entsprechende Auf- und Umrüstungsmaßnahmen mit den US-Streitkräften kompatibel und weltweit einsatzfähig zu machen sowie eine gemeinsame NATO-Interventionsmacht zu schaffen, eher auf >klassischeく Szenarien - nämlich eben auf Intervention sowie militärische Eroberung und Besetzung.

In den Augen derer, die diese Strategie für ein antiquiertes Konzept erachten, weil es der asymmetrischen Kriegführung nicht gerecht werde, zeigt sich die Kontraproduktivität schon jetzt in Afghanistan und Irak: In beiden Ländern herrschten nicht mehr, sondern weniger Stabilität und Sicherheit; die Rekrutierungsbasis für Terroristen habe sich durch die Besetzung der beiden Länder nicht verschmälert, sondern verbreitert; nach Umfragen halten immer mehr Menschen in dem Gürtel zwischen Marokko und Indonesien Osama bin Laden für einen Akteur in der internationalen Politik, der die richtigen Konzepte verfolge. (Vgl. Rüb 2003) Auch die Anschläge in verschiedenen Teilen der Welt nach dem Regimewechsel in Irak zeigten, dass die klassische Kriegführung ungeeignet sei, dem Problem des Terrorismus beizukommen. Tatsächlich besteht die Gefahr, dass der Einsatz überlegener militärischer Macht zu einer >Palästinisierung< der asymmetrischen Kriegführung in Richtung Selbst- 
mordattentate führt, die die gewaltsame Auseinandersetzung noch weniger kalkulier- und beherrschbar macht als bisher.

Eine Rolle in der Auseinandersetzung über adäquate Strategien und Instrumente spielen auch unterschiedliche Wahrnehmungen darüber, was machbar ist und was nicht. Der >Optimismus< von Teilen der >strategischen Eliten< in Washington beschränkt sich nicht auf die Überzeugung, dass den USA die führende Rolle in der Bekämpfung »des Bösen« in der Welt zugefallen sei. Vielmehr sei man berufen, eine »gute Weltordnung « zu etablieren. Diese Prämisse steht hinter Vorstellungen, man müsse und könne den gesamten »Greater Middle East « von Nordwest-Afrika über Zentralasien bis nach Indonesien in Demokratien transformieren, und zwar unter anderem, indem die US-Truppenpräsenz in der Region massiv verstärkt wird, »Zentren des Bösen« wie Afghanistan, Irak, Iran und Nordkorea notfalls auch militärisch zur Transformation gezwungen und diese Länder zu »Musterstaaten der Demokratie« gemacht werden, in der Hoffnung, hiermit jeweils zugleich abschreckend und demokratisierend auf die Nachbarschaft einzuwirken. (Vgl. Asmus/ Pollack 2002) Konsequenterweise drückt sich dieses Konzept in einer Militärreform aus, die vor allem auf den Ausbau von Interventionsstreitkräften sowie auf eine massive Erhöhung des Verteidigungsbudgets setzt - von etwa 280 Milliarden Dollar im Jahre 1999 auf geplante 450 Milliarden Dollar im Jahre 2007, was einer Steigerung von etwa 60 Prozent entspricht. Die Vorstellungen der Bush-Administration über die künftige Entwicklung der NATO ordnen sich logisch in dieses Konzept ein.

Selbstredend darf die gegenwärtige Dominanz dieser Politik nicht zur Annahme verleiten, diese sei >US-Politik < an sich. Nicht nur befinden sich die schärfsten Kritiker dieser Politik nicht in Europa, sondern in den USA selbst. Sie werfen dem Weißen Haus nicht nur eine verfehlte Politik gegenüber den Verbündeten, sondern auch ein Versagen im Kampf gegen den internatio- 
nalen Terrorismus vor. Schon die nächste Administration kann eine ganz andere Politikrichtung einschlagen. Und ebenso wenig ist aus, in Europa formulierten, Vorbehalten zu schließen, es gäbe eine seuropäische Position< in diesen Fragen. Die Spaltung existiert nicht nur auf staatlicher Ebene zwischen dem, was USVerteidigungsminister Rumsfeld als »altes « und »neues« Europa wahrnimmt. Auch in denjenigen Ländern, in denen die Regierungen eine US-kritische Position eingenommen haben, gibt es - wie die Debatte in 2002/2003 gezeigt hat - eine Reihe von Politikern und Experten, die bereit sind, den Argumenten und Vorstellungen der >Neocons $<$ in den USA zu folgen. Der Typus des »crusader ${ }^{2}$ ist nicht nur in den Vereinigten Staaten von Amerika verbreitet, sondern auch in Europa existent. Das gleiche gilt für den Typ des vorwiegend an machtpolitischen Gegebenheiten orientierten Opportunisten. Viele hätten mit gleicher Inbrunst die Argumente der Bush-Administration vertreten, wenn diese sich nicht zum Krieg gegen Irak, sondern gegen Saudi-Arabien entschlossen hätte: wegen der dort herrschenden diktatorischen Zustände, des religiösen Fundamentalismus, der finanziellen Unterstützung terroristisch-extremistischer Organisationen und Religionsschulen, sowie wegen der Tatsache, dass I5 der I9 an dem Anschlag auf das World Trade Center und das Pentagon beteiligten Terroristen aus Saudi-Arabien stammten. »Crusaders« wie Tony Blair, »Machiavellisten« wie Silvio Berlusconi oder »Missionare« wie Václav Havel sind - aus unterschiedlichen Motiven - durchaus bereit, militärische Macht außerhalb völkerrechtlicher Restriktionen einzusetzen. Der Unterschied zwischen den USA und Europa besteht also keineswegs in einer prinzipiellen Divergenz politischer Überzeugungen, sondern in zwei strukturellen Unterschieden, die das Verhalten politischer Führungspersönlichkeiten und die Optionen, die ihnen zur Verfügung stehen, determinieren: Europäer verfügen nicht über das militärische Potenzial, das eine Erfolg versprechende Umset- 
zung globaler Neuordnungspläne ermöglichen würde; und die europäischen Staaten und ihre politischen Führungen sind eingebunden in einen multilateralen, institutionalisierten Kontext, der eine solche Politik als >Gemeinschaftspolitik< kaum zulässt. Tatsächlich sind die europäischen »crusaders«, Machtopportunisten und »Missionare « auf eine selektive Beteiligung an den US-geführten >Allianzen à la carte< angewiesen, um ihre Vorstellungen wenigstens partiell machtpolitisch umzusetzen. Und folgerichtig sind vor allem sie es, die einen zunehmenden politischen und militärischen >gap < zwischen >Amerika< und >Europa< beklagen und eine massive Aufrüstung und Vereinigung der europäischen Armeen fordern, weil sie sonst sich und >Europa< marginalisiert sehen.

Während ihre, im Vergleich zu den USA, militärische Schwäche die Europäer im Allgemeinen zu einer militärisch eher zurückhaltenden Außen- und Sicherheitspolitik determiniert, ist in den USA ein eher gegenteiliger Effekt zu beobachten. Die Größe US-amerikanischer Militärmacht bedingt eine >positivere Disposition zum Gebrauch militärischer Gewalt. Dass die USA mehr Geld für militärische Angelegenheiten ausgeben als die nächsten fünfzehn größten Industrieländer der Welt zusammen, verlangt eine Legitimierung und den Nachweis der Wirksamkeit militärischer Macht. Der Einsatz militärischer Kräfte wird nicht nur deswegen politisch >optionaler<, weil diese Ressource in überreichem Maße vorhanden ist und weil keine Gefahr besteht, dass irgendein Akteur in der internationalen Politik dieser totalen militärischen Überlegenheit etwas entgegensetzen könnte, sodass die Gefahr eigener Verluste relativ gering ist. Vielmehr müssen sich die Aufwendungen von 340 Milliarden Dollar (2002) und die beabsichtigte weitere Steigerung des Verteidigungsbudgets rechtfertigen. Es liegt in dieser Logik, die den Protagonisten und Profiteuren militärischer Stärke erfolgreiche 
Kriege wie gegen einen, zum >Hitler unserer Zeit< stilisierten, Saddam Hussein attraktiv erscheinen lassen.

Welche Bedeutung simultan mit den strukturellen Rahmenbedingungen der >Persönlichkeitsfaktor « aufweist, wurde gerade in der Irak-Problematik deutlich. Eine andere personelle Konstellation im Weißen Haus hätte sich sowohl in der Frage des Kampfes gegen den internationalen Terror als auch des Verhältnisses zu Europa und damit in Bezug auf die NATO niedergeschlagen. Umgekehrt hätte sich die >europäische Politik < anders dargestellt, wenn in Großbritannien nicht Tony Blair, sondern der ehemalige Außenminister Robin Cook, der wegen der Irak-Politik von Premier Blair als Fraktionsvorsitzender der Labour-Party zurückgetreten ist, Regierungschef gewesen wäre. Das gleiche gilt für Spanien und Italien, wenn statt Aznar und Berlusconi Linksliberale die Regierung gestellt hätten. Unter diesen Voraussetzungen wäre es wohl auch nicht in gleichem Maße zu Unterstützungsaktionen osteuropäischer NATO- und EU-Beitrittskandidaten für die Politik von US-Präsident Bush gekommen.

Andererseits gilt ebenso, dass wenn in Deutschland nicht eine Regierung Schröder/Fischer, sondern Stoiber - hypothetisch - mit einem Außenminister Schäuble die Regierung gestellt hätte, die Position der USA im Sicherheitsrat der Vereinten Nationen bei der im Oktober/November 2002 von den USA gewünschten Abstimmung über eine kriegslegitimierende Resolution anders verlaufen wäre und - was die Europäische Union und die NATO betrifft - Frankreich in die völlige Isolation oder zu einer anderen Position gedrängt worden wäre. ${ }^{3}$ Wie wahrscheinlich eine Pro-Bush-Positionierung der CDU in der IrakFrage gewesen wäre, verdeutlichen auch die neuen außenpolitischen Leitlinien, die der Vorstand und das Präsidium der Partei am 28. April 2003 verabschiedeten (vgl. Beschluss des Bundesvorstands 2003). Sie beinhalten de facto eine Übernahme der 
politischen Strategie der so genannten Bush-Doktrin, wie sie in der im September 2002 verabschiedeten National Security Strategy fixiert worden ist: Ein Ja zu Präventivkriegen und damit zur Aufhebung des Kerns geltenden Völkerrechts, nämlich des Aggressionsverbots ${ }^{4}$, und die Proklamation einer »engen Verbundenheit« mit den USA nicht nur als Werte- und Interessen-, sondern auch als »Schicksalsgemeinschaft«.

\section{Geostrategisierung der NATO?}

Im US-Verständnis stellt Washington in der NATO die eindeutige Führungsmacht dar und bestimmt den Kurs der Allianz. Schon unter Clinton wurde zunehmend die nach dem Ende des Kalten Krieges relativierte Verteidigungsfunktion mit der Forderung verknüpft, die NATO auf »neue Bedrohungen« auszurichten. Außerdem wurde ebenfalls bereits unter Clinton die Auffassung einer Bringschuld Europas deutlich: Nachdem während des Kalten Krieges die USA für die Sicherheit Europas gesorgt hätten, sei es nach dem Ende des Kalten Krieges an den Europäern, die USA in ihrer globalen Führungsrolle zu unterstützen. Diese Einstellung spielte bei der Enttäuschung der Bush-Administration über die Widersetzlichkeit europäischer Staaten gegen die Irak-Politik der USA eine verstärkende Rolle. Dies galt umso mehr gegenüber Deutschland, da es seine Einheit im Jahre I990 nicht zuletzt dank amerikanischer Unterstützung wiedergewonnen habe. Schon unter Clinton wurden die traditionellen Fundamente der NATO - Verteidigung des NATO-Gebietes auf Grundlage von Artikel 5I der Charta der Vereinten Nationen (Recht auf Selbstverteidigung bei einem Angriff von außen) - als überholt erachtet. Die Neuausrichtung auf internationale Interventionen spiegelte sich im (erfolgreichen) Bemühen Washingtons wider, im neuen strategischen Konzept von I999 - wie 
bereits angesprochen -, diesbezügliche Beschränkungen aufzuheben. Unter George W. Bush, insbesondere nach den Terroranschlägen vom II. September 200I, wurde die von seinem Vorgänger noch relativ moderat und multilateralistisch geforderte Transformation erheblich forciert. Die Bush-Administration verband das Drängen auf Aufrüstung und Umbau der NATO zum Zwecke globaler Interventionsfähigkeit mit massiver politischer Druckausübung (Bush: »Wer nicht für uns ist, ist für die Terroristen«; Rumsfeld: »altes und neues Europa«, Darstellung Deutschlands und Frankreichs als ein »Problem«; Androhung der »Bestrafung« von Ländern, die die USA nicht unterstützen etc.). Ein Teil der Strategie bestand darin, Wünsche nach Unterstützung der USA an die NATO insgesamt heranzutragen und gleichzeitig mit Unilateralismus, >Allianzen à la carte< und der Marginalisierung des Bündnisses zu drohen.

In diesen Kontext gehört die Reorientierung US-amerikanischer Politik in der Osterweiterungs-Frage. Für die meisten Allianzmitglieder kam die Entscheidung der Bush-Administration im Frühsommer 200I, eine große Erweiterungsrunde zügig durchzusetzen (»vom Baltikum bis zum Schwarzen Meer« [Bush 200I]), überraschend. Dies entsprach einer Verschiebung von eher institutionalistischen Motiven (Stand der Demokratisierung, Handlungsfähigkeit der Allianz) hin zu >realistischen $<$ und strategischen Nützlichkeitserwägungen. Mit der zu Recht angenommenen US-Affinität des größten Teils der politischen Eliten in den postkommunistischen Ländern westlich Russlands verband sich die Erwartung, sowohl innerhalb der Allianz als auch mit Blick auf die globale Rolle der USA das power projection $\mathrm{zu}$ verbessern. US-Parade-> Realist< Zbigniew Brzezinski sprach die diesbezüglich geltenden neuen Parameter am deutlichsten aus: Auch die Ukraine, Georgien und Aserbaidschan müssten in die NATO aufgenommen werden, weil dies unter geostrategischen und sicherheitspolitischen Aspekten vorteilhaft sei: Überflug- 
rechte, Stationierung von US-Truppen in den entsprechenden Ländern, hierüber Sicherung bzw. bessere Einflussnahme auf die unter dem Aspekt der Ressourcenzufuhr, insbesondere von Öl, bedeutsamen Regionen Naher Osten, die Kaspische See und Zentralasien. Der II. September 200 erleichterte den Strategen in Washington auch in dieser Frage eine Neuausrichtung. Die Terroranschläge, der nachfolgende Krieg gegen Afghanistan und die Vorbereitung dazu gegen Irak ließen die Diskussion über Probleme und Modalitäten der NATO-Osterweiterung in den Hintergrund treten. Die Verabschiedung der Aufnahme sieben neuer Staaten aus Nordost-, Zentral- und Südosteuropa erfolgte praktisch ohne Diskussion auf dem Gipfel in Prag im November 2002. (Vgl. NATO 2002)

Zieht man diese Veränderungen in Betracht, gewinnt die NATO zeitgleich mit ihrer Marginalisierung als multilateraler politischer Mechanismus eine stärkere strategisch-militärische Dimension. Im Zuge der Militarisierung der US-Außenpolitik traten die logistische Stützpunktfunktion und die kontinentale Infrastruktur des NATO-Gebietes mit Blick auf seine militärische Nutzbarkeit für die Pläne Washingtons in Nahost und Zentralasien in den Vordergrund. Weniger bedeutsam wurden die Kriterien, die andere ventilierte Optionen einer neuen NATO-Ausdehnung hinsichtlich des gesellschaftspolitischen Transformationsprozesses durch die Benennung von Kriterien für die Demokratisierung, den ökonomischen und administrativen Umbau, die Stärkung der Rechtsstaatlichkeit, die Zivilisierung der Kontrolle der Armee usw. sowie die Überprüfung dieses Prozesses im Zuge der Annäherung an die Allianz in den Vordergrund stellten. In gewisser Weise kann also von einer Revision der NATO-Politik der USA analog zu Zeiten des Kalten Krieges gesprochen werden: Auch die Aufnahme Griechenlands und der Türkei Anfang der 5oer Jahre entsprach weniger den demokratischen Kriterien, die die >Wertegemeinschaft< NATO für sich 
beanspruchte, als ihrer strategisch-militärischen Bedeutung bei der Positionierung gegenüber der Sowjetunion.

Gerade für die nordost-, ost- und südosteuropäischen Länder wie auch für die postsowjetischen Staaten des Kaukasus und Zentralasiens ist von einer besonderen politischen Nähe zu den USA auszugehen, wenn diese Staaten im Zuge ihrer Annäherung oder Integration in die NATO sicherheitspolitisch und militärisch stärker von den Vereinigten Staaten abhängig sind. Dazu kommt die Bedeutung der USA in der Rüstungs- und Militärkooperation für diese Länder sowie die Rolle als Wirtschaftsfaktor, wenn US-Truppen in diesen Ländern stationiert sind. Die für die Bush-Administration positiven Implikationen dieser Politik zeigten sich in der Irak-Krise deutlich. Damit aber steigt nicht nur der Einfluss der USA innerhalb der NATO, sondern auch weil diese Länder entweder neue oder prospektive Mitglieder sind - auf die Europäische Union.

\section{Schlussbemerkung}

Hinsichtlich der künftigen Rolle der NATO werden folgende Optionen genannt: ${ }^{5}$

I. Der Kampf gegen den internationalen Terrorismus wird eine zentrale Funktion der Allianz, wobei freilich die Frage offen bleibt, was dies bedeutet und ob die Herstellung eines Konsenses in dieser Frage möglich ist.

2. Als Abschreckungsinstrument und als Dialogpartner nimmt die NATO für die transatlantische Gemeinschaft und global eine stabilisierende Rolle in der internationalen Politik ein.

3. Die NATO wird zu einer multifunktionalen Organisation, die über die beiden vorgenannten Punkte hinausgehend eine sicherheitspolitisch integrierende und gesellschaftspolitisch 
stabilisierende und demokratisierende Rolle im postkommunistischen Raum spielt.

4. Die NATO tritt in ihrer Bedeutung als politisches, sicherheitspolitisches und militärisches Instrument immer mehr in den Hintergrund und mutiert zu einem Auslaufmodell. Sich dergestalt verändernd, ist die NATO nicht mehr eine >transatlantische Konsensmaschine<, sondern wird zu einem >Werkzeugkasten $<$ für verschiedene Zwecke und Koalitionen.

Einigkeit herrscht darüber, dass die zukünftige Ausgestaltung der Allianz vorrangig von der Perzeption ihrer Bedeutung durch Washington und vom Engagement der USA abhängig ist. Unterstellt man ein gemeinsames Interesse, weiterhin eine minimale Abschreckungsfunktion und Bündnisverteidigung auf der Basis von Artikel 5 des NATO-Vertrags (Bündnisverpflichtung) und die Stabilisierung, Demokratisierung und sicherheitspolitische Anbindung Osteuropas weiter zu verfolgen sowie gegenüber Dritten in sicherheitspolitischen Fragen als Dialogpartner aufzutreten, dann ist vom weiteren Bestand des Bündnisses auszugehen. Streit wird sich, wie schon in der Vergangenheit, an Anforderungen entzünden, über die Verteidigungsfunktion der NATO hinausgehend international tätig zu werden bzw. >Verteidigung< und >Sicherheitsproduktion $<$ neu im Sinne der National Security Strategy der USA vom September $2002 \mathrm{zu}$ definieren. Unterstellt man weiter, dass versucht wird, in einem Bargaining-Prozess widerstrebende Interessen miteinander $\mathrm{zu}$ verbinden und über Zugeständnisse das Interesse aller Beteiligten an der Organisation zu erhalten, dann ist von einigen Kompromissen auszugehen, wie sie sich bereits auf dem Prager Gipfel im November 2002 sowie nach dem Irak-Krieg angedeutet haben: Die Einrichtung einer NATO-Response-Force (die indes unter der Kautel steht, dass alle Mitglieder einem Einsatz zustimmen müssen und die Möglichkeit einer Nutzung durch die Europäische Union 
ermöglicht werden soll); die (beschränkte) Nutzung der NATO bei der Nachkriegsstabilisierung z.B. in Afghanistan und in Irak u.a. All diese Kompromisse sind aber in ihrer praktischen Umsetzung umstritten.

Längerfristig scheint eine Relativierung der NATO indes eher von europäischer als von US-amerikanischer Seite determiniert. Es handelt sich um den schon angesprochenen >natürlichen Prozess, dass Europa bzw. die Europäische Union sich sicherheitspolitisch und militärisch autonomer organisieren. Eine auch nach dem Ende des Kalten Krieges fortdauernde massive Abhängigkeit der europäischen Sicherheit von den USA würde dem europäischen Emanzipationsprozess, der ein Prozess der Übernahme von Selbstverantwortung für den europäischen Kontinent ist, zuwiderlaufen. Wie erwähnt ist die Diskussion über die Aufnahme einer Beistandsverpflichtung in eine europäische Verfassung Ausdruck und Indiz für diese Entwicklung. Die hypothetisch nutzbaren militärischen Potenziale in Rechnung gestellt, ist die Möglichkeit einer eigenständigen Verteidigung des Kontinents im Sinne klassischer militärischer Abschreckungspolitik durchaus gegeben.

Dass diese Perspektive einen längerfristigen Übergangsprozess voraussetzt, scheint indes ebenfalls evident. Die politischen Kosten einer schnellen Auflösung der NATO werden von allen Beteiligten als wenig akzeptabel eingeschätzt. Dies ändert nichts an einer schrittweisen Verminderung der realen Bedeutung des Bündnisses. In einer solchen Entwicklung würde der NATO zunehmend die Rolle einer sicherheitspolitisch-militärisch determinierten OSZE zukommen: Kollektive Sicherheitsproduktion durch Kooperation und Konsultation im Inneren, Dialogpartner zwischen Europa, den USA, Kanada, Russland und China nach außen. Diese Entwicklung entspräche sowohl aus >realistischer als auch >institutionalistischer< Sicht den veränderten Gegebenheiten und Entwicklungsbedingungen nach dem Ende des Kal- 
ten Krieges. Die Allianz wurde im Jahre 1949 gegründet, um, wie es der erste Generalsekretär der NATO ausdrückte, »to keep Russia out, the U.S. in, and Germany down«. Die Aufgabe, das Potenzial Deutschlands einzubinden, ist sukzessive von der Europäischen Union übernommen worden und wird mit der sicherheitspolitisch-militärischen Integration Europas immer stärker wahrgenommen. Die beiden anderen Aufgaben charakterisierte eine Reziprozität, die mit dem Ende der Sowjetunion und des Warschauer Pakts im Prinzip weggefallen ist. Die sicherheitspolitische Aufgabe Europas besteht heute vielmehr darin, die Institutionen $\mathrm{zu}$ formen, die Europa sicherheitspolitisch selbständig und selbstverantwortlich werden lassen, Russland nach Möglichkeit anzukoppeln und die Vereinigten Staaten als engen Partner mit Europa zu verkoppeln.

Es findet also nolens volens eine Transformation der NATO und des bestehenden Geflechts internationaler Organisationen sowie der Rolle der NATO in diesem Geflecht statt, wobei der Entwicklungsprozess selbst und seine konkrete Ausformung von einer ganzen Reihe von Umständen und Bedingungsfaktoren abhängig ist: Gravierende Ereignisse wie Naturkatastrophen oder die Terroranschläge vom II. September 200I, darauf basierende Bedrohungsperzeptionen und Strategien, welche wiederum von politischen Konstellationen in den beteiligten Ländern determiniert sind. Somit gewinnt nicht nur in ökonomischer, sondern auch in sicherheitspolitischer Hinsicht die sog. Triade deutlicher an Konturen: Nordamerika, Europa inklusive Russland sowie Ost- und Südostasien. Die parallele Entwicklung von Globalisierung und Regionalisierung dürfte sich längerfristig in einer Verstärkung, nicht in einer Verminderung der Rolle der Vereinten Nationen ausdrücken: Sie sind die Institution jenes "globalen Dorfes «, in dem sich die vernetzten Probleme nur durch gemeinsame Anstrengungen und die Schaffung von Konsens auf der Grundlage eines als global legitim angesehenen Entschei- 
dungsprozesses regulieren lassen. Die NATO dagegen transformiert in einem solchen Szenario von einem zentralen Instrument des militärisch-politischen Krisenmanagements des >Westens $<$ in einer bipolaren Welt zu einem US-europäischen Dialogund Konsultationsforum unter Einbeziehung Russlands nach innen und nach außen, was einem weiteren Entwicklungstrend in den internationalen Beziehungen entspräche, nämlich dem »Interregionalismus « (Roloff 200I) in seiner sicherheitspolitischen Dimension.

Diese Beschreibung genereller Entwicklungstrends bedeutet selbstredend nicht, wie bereits betont, dass unvorhersehbare Ereignisse (wie es die plötzliche Implosion des sowjetischen Imperiums und der Sowjetunion selbst an der Wende zu den 9oer Jahren des vergangenen Jahrhunderts gewesen war) Verwerfungen induzieren, die Faktoren ins Spiel bringen, die den genannten Trends zuwiderlaufen oder sie modifizieren. Politische Erdbeben in China, ein Krieg zwischen Pakistan und Indien, die Ausbreitung tödlicher Seuchen oder eine Weltwirtschaftskrise können den jetzt absehbaren oder angenommenen Verlauf der Entwicklung erheblich verändern.

Aber einige Grundlinien der internationalen Entwicklung sind doch vorgezeichnet. Dies betrifft nicht zuletzt die Multipolarisierung von Macht und von Potenzialen im internationalen System und damit die Relativierung der gegenwärtig als Hypermacht erscheinenden USA. Während in Europa - erzwungenermaßen durch den Zusammenbruch des riesigen kommunistischen Raumes im Osten des Kontinents - der Transformationsprozess mit Vehemenz eingesetzt hat, breitet sich dieser Prozess in Wellen auf andere Teile der Welt und auf das internationale Institutionengefüge aus.

Sollte sich indes unter fortgesetztem Druck aus Washington im Zusammenspiel mit politisch korrespondierenden Kräften in Westeuropa und unter den neuen Mitgliedern im Osten die 
NATO zu einem >Werkzeugkasten < entwickeln, aus dem sich diverse und wechselnde Koalitionen zu unterschiedlichen Zwecken zu bedienen suchen, könnte dies schneller zur Auflösung der Allianz führen als allen Akteuren lieb ist. Eine Überforderung der politischen und militärischen Kapazitäten der NATO für Partikularinteressen würde die Legitimität der Organisation vermutlich unter jenen Punkt sinken lassen, mit dem die Erwartung des Nutzens aus Zugehörigkeit und Beteiligung positiv stimuliert wird. Soll also die NATO in ihren zentralen, von einem Konsens getragenen Funktionen über einen zumindest mittelfristigen Zeitraum erhalten bleiben, dürfen an sie nicht unrealistische oder konsenssprengende Aufgaben und Anforderungen gestellt werden. Werden diese Spielregeln eingehalten, die die NATO 50 Jahre lang getragen haben, dann wird ihr für einen längeren Übergangszeitraum noch eine wichtige stabilisierende und integrierende Funktion und damit eine wichtige sicherheitspolitische Rolle im globalen Geschehen zukommen.

\section{Anmerkungen}

I Zu den Kapazitäten der USA siehe SIPRI Yearbook (2002). Für eine negative Einschätzung des >go-it-alone siehe Kupchan (2002).

2 Stoessinger unterscheidet bei den Präsidenten und Außenministern der USA zwischen »crusaders « und »pragmatists«. (Vgl. Hermann I986: I74)

3 Siehe das Interview mit Helmut Kohl in Frankfurter Allgemeine Zeitung, I4.06.2003. Kohl betonte in dem Interview allerdings seine Überzeugung, dass auch Gerhard Schröder eine andere Haltung eingenommen hätte, wenn seine oppositionelle Haltung in der Irak-Frage nicht entscheidend gewesen wäre, um der rot-grünen Regierung bei den 
Bundestagswahlen im September 2002 das Überleben zu sichern. (Vgl. Kohl 2003)

4 Was in dem unter Federführung von Wolfgang Schäuble erarbeiteten Papier unter notwendiger »Weiterentwicklung« des Völkerrechts firmiert.

5 Siehe NATO after Prague (2003); Struck (2003); Alliot-Marie (2003); Talbott (2002); Pradetto/Timmermann (2002); Beck (2003); Kamp (2003); Hodge (2002); Schmidt (2003); Bertram (2003).

\section{Literatur}

Alliot-Marie, Michèle (2003): Die zukünftige Rolle der NATO, Rede der französischen Ministerin für Verteidigung auf der Münchner Konferenz für Sicherheitspolitik am 08.02.2003, online unter: http://www.bundesregierung.de/Anlage4698io /Sonderausgabe+2003.pdf, besucht am I5.I2.2003.

Asmus, Ronald D./Pollack, Kenneth M. (2002): »Transformation des Mittleren Ostens. Das neue transatlantische Projekt«, in: Blätter für deutsche und internationale Politik, I2/O2, S. I457I466.

Beck, Thomas (Hg.) (2003): Sicherheitspolitik im Wandel: NATO und Bundeswehr vor neuen Herausforderungen: auf Spurensuche in Berlin und Brandenburg; ein Tagungsbericht, Brühl/Rheinland.

Bernauer, Thomas/Brem, Stefan/Suter, Roy (I995): »Traum und Wirklichkeit kollektiver Sicherheit: Uno und OSZE am Anfang eines Umdenkprozesses«, in: Neue Züricher Zeitung vom I3.I2.I995.

Bertram, Christoph (2003): Was soll aus der Nato werden?, online unter: http: / / www.swp - berlin .org / pdf / brennpunkte / jour_ nato_030319_Bertram.pdf, besucht am I5.I2.2003. 
Beschluss des Bundesvorstandes (2003): Die außenpolitischen Interessen Deutschlands: Stabilität durch Partnerschaft und Vertrauen, online unter: http://www.cdu.de/tagesthema/beschluss 240403.pdf, besucht am I5.I2.2003.

Bush, George (200I): Transcript: President Bush speech in Warsaw vom 15.06.2001, online unter: http://www.cnn.com/200I/ WORLD/europe/06/15/bush.warsaw.trans/, besucht am I5. I2.2003.

Calic, Marie-Janine (1997): »Friedensstrategien in komplexen Konfliktfeldern: Lehren aus dem zerfallenen Jugoslawien«, in: Dieter Senghaas (Hg.): Frieden machen, Frankfurt a.M., S. I66-I86.

Gordon, Philip H. (200I): »NATO After II September«, in: Survival, vol. 43 (4), S. 89-106.

Gordon, Philip H./Steinberg, James B. (200I): NATO Enlargement: Moving Forward, Policy Brief No. 90, Washington, online unter:http:/ / www. brook. edu / dybdocroot/comm / policybriefs/ pb9o.pdf, besucht am I5.I2.2003.

Hermann, Margaret G. (I986): »Ingredients of Leadership«, in: Political Psychology. Contemporary Problems and Issues, San Francisco/London, S. I67-192.

Hodge, Carl C. (Hg.) (2002): NATO for a new century: Atlanticism and European security, Westpoint, Conn. [u.a.].

Kamp, Karl-Heinz (2002): »Die NATO nach dem Prager Gipfel. Eine globale und >präventive< Allianz?«, online unter: http: //www.legamedia.net/legamall/2003/03-03/0303_kamp_karlheinz_nato-allianz_or.php\#, besucht am I5.I2.2003.

Kamp, Karl-Heinz (2003): Die NATO nach dem Prager Gipfel: eine globale und "präventive« Allianz?, Sankt Augustin.

Kohl, Helmut (2003): »Wir sind Freunde, nicht Untergebene«, Fragen von Georg Paul Hefty, in: Frankfurter Allgemeine Zeitung vom I4.06.2003. 
Kupchan, Charles (2002): The End of the American Era. US Foreign Policy and the Geopolitics of the Twenty-First Century, New York.

London Declaration On A Transformed North Atlantic Alliance. Issued by the Heads of State and Government participating in the meeting of the North Atlantic Council, London 5-6 July I990, online unter: http://www.nato.int/docu/comm/49-95/ c900706a.htm, besucht am I5.12.2003.

Mutz, Reinhard (2000): »Den Krieg gewonnen, den Frieden verfehlt - Das Debakel der Kosovo-Intervention«, in: Frankfurter Rundschau vom 07.06.2000.

NATO after Prague (2003): New Members, New Capabilities, New Relations. NATO Office of Information and Press. Brussels.

Nato Press Release (200I): Statement by the North Atlantic Council vom I2.09.200I, online unter: http://www.nato.int/docu/pr/ 200I/poi-I24e.htm, besucht am I5.12.2003.

NATO Press Release (2002): Prague Summit Declaration. Issued by the Heads of State and Government participating in the meeting of the North Atlantic Council in Prague vom 2I.II. 2002, online unter: http://www.nato.int/docu/pr/2002/po2I27e.htm, besucht am I5.I2.2003.

Pradetto, August (2003): »Instrumenteller Multilateralismus und servile Rezeption: der Irak, die USA und Europa«, in: Blätter für deutsche und internationale Politik, 2/03, S. I63-I74.

Pradetto, August/Timmermann, Heiner (Hg.) (2002): Die NATO auf dem Weg ins 21. Jahrhundert, Münster/Hamburg/London.

Roloff, Ralf (200I): Europa, Amerika und Asien zwischen Globalisierung und Regionalisierung: das interregionale Konzert und die ökonomische Dimension internationaler Politik, Paderborn.

Rüb, Matthias (2003): »Misstrauen gegen Amerika gewachsen«, in: Frankfurter Allgemeine Zeitung vom 06.06.2003.

Schmidt, Peter (2003): »NATO-Politik: Das Bündnis im Wechselbad amerikanischer Politik« in: Peter Rudolf et al.: Zwei 
Jahre Präsident Bush. Beiträge zum Kolloquium der Stiftung Wissenschaft und Politik in Berlin am 13. Februar 2003, Berlin.

SIPRI Yearbook (2002): armaments, disarmaments and international security, Oxford.

Struck, Peter (2003): Die zukünftige Rolle der NATO, online unter: http://www.bundesregierung.de/Anlage469810/

Sonderausgabe+2003. pdf, besucht am I5.I2.2003.

Talbott, Strobe (2002): »From Prague to Baghdad: NATO at Risk«, in: Foreign Affairs, November/December 2002, S. 4657.

The Washington Declaration Signed and issued by the Heads of State and Government participating in the meeting of the North Atlantic Council in Washington D.C. on 23rd and 24th April I999, online unter: http://www.nato.int/docu/pr/1999/ p99 063e. htm, besucht am 15.12.2003.

U.S. Department of State, International Information Programs (2003): Bush Urges NATO Nations to Unite in Fight Against Terrorism, online unter: http://usinfo.state.gov/topical/pol/ nato/03053103.htm, besucht am I5.12.2003.

Whitehouse (2002a): The President's State of the Union Address vom 29. Januar 2002, online unter: http://www.whitehouse.gov/ news/releases/2002/0I/20020129-II.html, besucht am I5. I2.2003.

Whitehouse (2002b): The National Security Strategy of the United States, online unter: http://www.whitehouse.gov/nsc/nss.pdf, besucht am I5.I2.2003. 


\title{
Was ist neu an den neuen Kriegen?
}

\author{
HeRFRIED MÜNKLER
}

Ich spreche von »neuen Kriegen« (vgl. Münkler 2002a), um damit ganz unterschiedliche Formen der Gewaltanwendung in den letzten beiden Jahrzehnten des 20 . Jahrhunderts zusam-

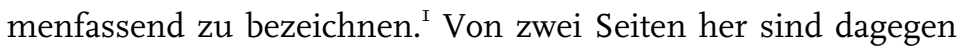
Zweifel und Widerspruch vorgebracht worden.

I. Kann man wirklich das diffuse Gewaltgeschehen, vom Auftreten raubender und mordender (Kinder-)Banden, etwa in Sierra Leone oder Liberia, über die jahrzehntelangen Bürgerkriege in Angola und Somalia bis zu den Terroranschlägen des II. September und schließlich dem jüngsten Golfkrieg, sinnvoll unter dem Begriff des Krieges zusammenfassen? In dieser Frage hat vor allem Erhard Eppler widersprochen. (Vgl. Eppler 2002a; Eppler 2002b)

2. Gibt es wirklich etwas wesentlich Anderes, substanziell Neues an den Kriegen der letzten beiden Jahrzehnte, das im präzisierenden Adjektiv »neu « als Charakterisierung zusammengefasst und herausgestellt werden kann? In diesem Punkt sind unter anderem von dem langjährigen Leiter der Hamburger 
Arbeitsgemeinschaft Kriegsursachenforschung (AKUF) KlausJürgen Gantzel Zweifel geltend gemacht worden. (Vgl. Gantzel 2000)

Zur Beantwortung der ersten Frage schlage ich den Rückgriff auf die Theorie von Clausewitz vor, freilich nicht auf das vielzitierte Epigramm von der Fortsetzung des Krieges mit anderen Mitteln, sondern auf Überlegungen am Schluss des I. Kapitels des I. Buches von Vom Kriege, wo Clausewitz den Krieg als »ein wahres Chamäleon« bezeichnet hat (Clausewitz I980: 212). Will heißen: Mit der Veränderung der Umwelt verändert auch der Krieg seine Erscheinungsform. Krieg ist demnach nicht über seine jeweiligen Erscheinungsformen identifizierbar, sondern über Wesensmerkmale, die diesen Erscheinungsformen zugrunde liegen. Viele meinen, Krieg sei prinzipiell so etwas wie der Erste oder Zweite Weltkrieg, weswegen sie den Dritten Golfkrieg vom Frühjahr 2003 (vgl. Münkler 2003) sofort als Krieg zu bezeichnen bereit sind, aber nicht die Bürgerkriege in West- oder Ostafrika, und schon gar nicht die Attentate vom II. September 200I. Diejenigen, die so denken, sind in die Falle des kollektiven Gedächtnisses einer politischen Gemeinschaft innerhalb einer bestimmten Epoche gegangen. Sie haben keinen Begriff des Krieges, sondern nur eine bestimmte historische Anschauung. Um diese Falle zu vermeiden, hat Clausewitz, der über den Krieg und seine unterschiedlichen Erscheinungsformen in einer Epoche nachdachte, als sich diese im Gefolge der Französischen Revolution tiefgreifend verändert hatten, vorgeschlagen, den Krieg als eine »wunderliche Dreifaltigkeit« zu denken, bestehend aus

- der Gewaltsamkeit als dem ursprünglichen Element des Krieges,

- dem Spiel der Wahrscheinlichkeiten und des Zufalls im Kriege sowie 
- dem Charakter des Krieges als politisches Instrument. (Vgl. Clausewitz I980: 213)

In heutiger Sprache könnte dies heißen, dass sich der Krieg zusammensetzt aus Gewaltsamkeit, strategischer Kreativität und politischer Rationalität, die ihm einen den jeweiligen politischen, sozialen und ökonomischen Verhältnissen angepassten Charakter geben. Je tiefgreifender sich diese Verhältnisse ändern, desto stärker verändern sich auch die Formen, in denen Kriege ausgetragen werden. ${ }^{2}$ Das Auftreten neuer Formen der Gewalt ist darum kein Grund, auf den Kriegsbegriff zu verzichten. Im Gegenteil: es geht darum, den veränderten Erscheinungsformen organisierter Gewalt gerade vermittelst eines umfassend angelegten Kriegsbegriffs nachzuspüren.

Zur Beantwortung der zweiten Frage muss man sich die verfügbaren Daten über das Kriegsgeschehen nach 1945 vergegenwärtigen:

- Von den nach 1945 weltweit geführten Kriegen waren nur noch ein Drittel zwischenstaatliche Kriege im klassischen Sinn und die Tendenz ist unübersehbar: dass sie weiter abnehmen. Der Staatenkrieg ist offenbar ein historisches Auslaufmodell. Oder pointiert: der europäische Sonderweg, Krieg als symmetrischen Staatenkrieg zu führen, scheint an sein Ende gekommen zu sein.

- Von den im Rahmen von Kriegshandlungen Getöteten und Verwundeten waren zu Beginn des 20. Jahrhunderts 90 Prozent Kombattanten und Io Prozent Zivilisten; am Ende des 20. Jahrhunderts hatte sich dieses Verhältnis in etwa in sein Gegenteil verkehrt. ${ }^{3}$ Das heißt: in den früheren Kriegen wuchsen die Überlebenschancen eines jungen Mannes in dem Maße, wie er sich als nicht fronttauglich erwies. In den neuen Kriegen ist dagegen der Eintritt in die Gefolgschaft 
eines Warlords lebensverlängernd, weil auf diese Weise das

Risiko, Opfer von Gewalt zu werden, vermindert wird.

Ganz offensichtlich haben sich hier fundamentale Veränderungen vollzogen, die es berechtigen, von >neuen « Kriegen zu sprechen. Die skizzierten Veränderungen sollen nachfolgend genauer und detaillierter dargestellt werden.

\section{Privatisierung und Kommerzialisierung des Krieges}

I. Dass nur Staaten Kriege führen, diese gewissermaßen das Monopol der Kriegführung und des Rechts zum Kriege besitzen, ist ein auf Europa beschränkter Vorgang, und der hat auch hier erst im I6./I7. Jahrhundert eingesetzt. Zuvor hatten beispielsweise die italienischen Condottieri militärische Arbeitskraft für begrenzte Zeit und definierte Aufgaben an- und verkauft, an Fürsten und Städte, die selbst Krieg zu führen nicht in der Lage oder nicht willens waren. Die Condottieri haben das auch im Mittelalter schon anzutreffende Söldnerwesen in großem Stil entwickelt und den Krieg in eine regelrechte Form der Erwerbsarbeit überführt. (Vgl. Baumann I994) Der Dreißigjährige Krieg bildet den Endpunkt jener Epoche einer privatisierten und kommerzialisierten Kriegführung in Europa. Die mit dem Dreißigjährigen Krieg verbundenen Gräuel sind nicht zuletzt eine Folge der kommerziellen Dimension dieser Art des Krieges. Alle Kriegsparteien versuchten den Krieg durch die wirtschaftliche Ausplünderung der eroberten und besetzten Gebiete zu finanzieren. Als sie schließlich nicht mehr in der Lage waren, die Soldaten zu bezahlen, nahmen die das Geschäft des Brandschatzens und Plünderns selbst in die Hand.

Die Verstaatlichung des Krieges gelang, weil die Kriege aus 
militärtechnologischen und militärorganisatorischen Gründen immer teurer wurden. Durch seine Verteuerung entzog sich der Krieg zunehmend der Amortisationslogik des Kapitals, und die in Europa entstehenden Territorialstaaten bemühten sich darum, die Kontrolle über den Krieg zu erlangen. Dass ihnen dies im Verlauf des I6. und I7. Jahrhunderts gelang, hatte vor allem mit waffentechnischen und militärorganisatorischen Faktoren $\mathrm{zu}$ tun; die rechtliche, insbesondere die völkerrechtliche Regelung dieser Entwicklung war eher ein Begleitphänomen als deren Ursache. ${ }^{4}$ Der Krieg wurde teurer durch die Entwicklung der Artillerie, ohne die schon bald keine Belagerung, aber auch keine offene Feldschlacht mehr zu gewinnen war. Kanonen, das militärische Großgerät der Frühen Neuzeit, aber waren kostspielig, und einen umfassend angelegten Geschützpark konnten sich bald nur noch die Staaten, nicht aber private Kriegsunternehmer leisten. Der Einsatz von Artillerie wiederum hatte zur Folge, dass die taktische Formation des »Gewalthaufens «, die tiefgestaffelt aufgestellten Lanzenträger, in denen die Fußtruppen bislang in die Schlacht geschickt wurden, extrem verwundbar war und durch die langgezogenen Reihen der Infanterie ersetzt werden musste. Die Entwicklung der neuen Lineartaktik aber setzte voraus, dass die Truppen über lange Zeit sgedrillt‘ wurden, um unter Gefechtsbedingungen ihre Formation zu halten. Sie konnten nicht länger kurzfristig angeworben, sondern mussten kaserniert und diszipliniert werden. Auch das konnte sich kein privater Unternehmer, sondern nur der Staat leisten. Es waren die immensen Kosten der Herstellung von Kriegführungsfähigkeit, die den Staat zum faktischen Monopolisten des Krieges haben werden lassen. Nur weil er auf dem Weg zum faktischen Kriegsmonopolisten war, konnte der Staat schließlich auch zum rechtlichen Kriegsmonopolisten werden.

Im Gefolge der Verstaatlichung des Krieges kam es zu einer klaren Trennung von Krieg und Frieden. Krieg und Frieden wur- 
den durch Kriegserklärung und Friedensschluss voneinander getrennt und als aparte Rechtszustände begriffen. Dabei wurden Kriegserklärung und Friedensschluss selbst als Rechtsakte konzipiert. Gleichzeitig wurden Kombattanten und Nonkombattanten immer präziser voneinander getrennt, aber dass diese kriegsvölkerrechtlichen Regelungen auch Folgen zeitigten und tatsächlich keine Gewalt gegen Nonkombattanten angewandt wurde, war zunächst die Folge der Kriegsentwicklung selbst, die das Gewaltgeschehen immer stärker auf dem Schlachtfeld konzentrierte und die Zivilbevölkerung verschonte. Das freilich war nur in Europa so, nicht jedoch an den weichen Grenzen der Imperien, wo >wilde Völker weiterhin in ihrer Gesamtheit und ohne jede Hegung Kriege führten und die Truppen der Imperien dies in ähnlicher Weise taten. Hier blieben auch die Grenzen zwischen Krieg und Frieden fließend. Die staatliche und die imperiale Kriegsgeschichte folgt nicht denselben Imperativen. Dementsprechend unterschiedlich konturiert sind die Vorstellungen vom Völker- und Kriegsrecht.

2. Die entscheidende Entwicklung, die in den letzten Jahrzehnten des 20. Jahrhunderts das Kriegsgeschehen fundamental verändert hat, ist die Verbilligung des Krieges, denn die meisten der neuen Kriege werden nicht mehr mit militärischem Großgerät und regulären Truppen geführt, sondern mit eilends rekrutierten Kämpfern (nicht selten so genannten Kindersoldaten) und billigen Waffen: automatischen Gewehren, leichten Raketenwerfern, Pick-ups. Kinder und Jugendliche sind für die regionalen Kriegsherrn nicht zuletzt darum so billig, weil sie mit ein paar Drogen und dem Versprechen auf Plünderung dazu gebracht werden können, sich den größten Risiken auszusetzen. Die automatischen Handfeuerwaffen schließlich machen sie ohne längere Ausbildung gefechtsfähig. Man kann sagen, dass die Warlords Armut und Abenteuerlust der Kinder ausbeuten, um ohne größeren finanziellen Aufwand zur Führung eines Krieges 
in der Lage zu sein. Die so erreichte Verbilligung des Kriegs hat die Eintrittsschwellen des Krieges gesenkt, so wie diese vormals durch die Verteuerung angehoben worden waren. Für Warlords und Milizenführer ist die Herstellung von Kriegführungsfähigkeit aber auch darum ein einfacher und billiger Vorgang, weil sie die Folgekosten des Krieges nicht in ihrer Bilanz haben: Sie plündern den natürlichen Reichtum eines Gebiets oder die Ressourcen der Bevölkerung aus, bereichern sich und ihren Anhang und bekümmern sich nicht um das, was am Ende übrig bleibt. ${ }^{5}$ Hier gilt die Devise von der Privatisierung der Gewinne und der Sozialisierung der Verluste. Der Krieg ernährt den Krieg; er ist wieder zu einem Geschäft geworden. Die, die von ihm profitieren, sind darum selten an seiner Beendigung interessiert. ${ }^{6}$

3. Dass der Krieg (wieder) zu einem Geschäft und einer Form des Lebensunterhalts geworden ist, liegt neben der Verbilligung der Kriegsvorbereitungs- und Kriegführungskosten vor allem an den offenen Bürgerkriegsökonomien, die über die Kanäle der Schattenglobalisierung mit den Friedensökonomien der OECD-Welt verbunden sind. Der Handel mit Bodenschätzen und illegalen Gütern, nicht selten aber auch die Ausbeutung der Hilfsbereitschaft der Menschen im reichen Norden, halten diese Kriege am Schwelen, wobei vom Handel die profitieren, die in einem bestimmten Gebiet die Gewalt ausüben. (Vgl. Medico International 2002) Die lokalen und regionalen Kriegsherren sind dabei mit der internationalen Kriminalität eine enge Verbindung eingegangen. Viele von ihnen sind mit der Fortdauer des Krieges immer reicher geworden. Dies erklärt auch, warum diese Kriege so lange dauern: Angola, Somalia, Kongo, Afghanistan sind Beispiele für Kriege, die sich über Jahrzehnte hinziehen. Es gibt in ihnen keine militärische Entscheidung, weil keine der beiden Seiten die militärische Entscheidung sucht. Viele Kriege des 2I. Jahrhunderts werden darum wohl dem Modell des Dreißigjährigen Krieges im Europa des I7. Jahrhunderts ähneln: 
Kommerzielle Motive für die Fortsetzung des Krieges zehren die politischen Gründe, die am Anfang gestanden haben, schnell auf. Immer wieder kommt es zu Interventionen in die Kriegsgebiete, bei denen unentwirrbare Motivbündel eine Rolle spielen: von reiner Machtpolitik bis $\mathrm{zu}$ wertgebundenen, nicht selten humanitären Beweggründen. Das macht, dass diese Kriege so schwer durch einen Interessenausgleich beendet werden können. Wenn überhaupt, so enden sie nicht durch einen Friedensschluss, sondern durch einen Friedensprozess, in dem die verschiedenen Parteien allmählich von der Kriegs- auf die Friedensdividende >umgestellt< werden. Der Westfälische Frieden, der den Dreißigjährigen Krieg beendete, war im Übrigen auch eher ein Friedensprozess als ein Friedensschluss. Die Verhandlungen zogen sich über Jahre hin, und als eine der schwierigsten Fragen erwies sich die Kostenübernahme für die Demobilisierung der Soldaten, also deren Umorientierung von der Kriegs- auf die Friedensdividende. Wo dies misslingt, ist an einen dauerhaften Frieden nicht zu denken.

\section{Die Asymmetrie der neuen Kriege}

Offensichtlich sind in weltgeschichtlicher Perspektive asymmetrische Gewaltkonstellationen sehr viel häufiger als symmetrische - schon darum, weil letztere sehr viel voraussetzungsvoller und damit unwahrscheinlicher sind. Die europäischen Staatenkriege waren in ihrem Kern symmetrische Kriege, insofern sich die von beiden Seiten aufgebotenen Streitkräfte von der Art ihrer Rekrutierung, ihrer Bewaffnung sowie ihrer Ausbildung her ähnlich waren. Mögen sie sich hinsichtlich ihrer Größe auch deutlich unterschieden haben, so waren sie doch stets wesentlich gleichartig. Diese Gleichartigkeit der Streitkräfte war die Voraussetzung der gegenseitigen Anerkennung der Kriegsparteien, und 
auf der wiederum fußte das System des Kriegsvölkerrechts. Militärische Asymmetrien erwachsen aus der Ungleichartigkeit beider Seiten. Beispiele dafür sind der Zusammenprall wandernder Völker mit dem professionalisierten Militär von Großreichen, Kleinkriege an den weichen Grenzen imperialer Herrschaftsbereiche, Verwüstungskriege, die durch Kostenerhöhung den Gegner zum Einlenken bringen sollen, usw. Eine gegenseitige Anerkennung der Konfliktparteien als Gleiche ist hier nicht möglich, und demgemäß folgen diese Kriege durchweg auch anderen Prinzipien als den im europäischen Völkerrecht entwickelten. Was verstärkt zu beobachten ist, ist die Verteufelung oder Kriminalisierung des Gegners. Asymmetrische Kriege sind auf der Basis von Reziprozitätsannahmen nicht zu verrechtlichen. An diesen Problemen laboriert das Völkerrecht seit dem Ende der bipolaren Weltordnung. Beispiele für asymmetrische Kriege sind:

I. Offene Gewaltregime von Warlords, Milizenführern oder Clanchefs über die Zivilbevölkerung einer Region zwecks Ausplünderung der natürlichen Ressourcen oder des gesellschaftlichen Reichtums; insbesondere die Kriege im subsaharischen Afrika und in Zentralasien folgen diesem Modell. Die Wahrscheinlichkeit von Kriegen steigt hier in dem Maße, wie Bodenschätze bekannt sind oder entdeckt werden, aus denen der, der das Gebiet kontrolliert, Einnahmen erzielen kann.

2. Die klassischen Formen des Partisanenkrieges, bei denen die Strategie der Konzentration der Kräfte in Raum und Zeit durch eine Strategie der Verstreuung der Kräfte im Raum und der Ausdehnung des Kriegsgeschehens in der Zeit konterkariert wird. Mao Tse-tung hat dafür den Begriff des lange auszuhaltenden Krieges geprägt. Die gesteigerte Opferbereitschaft einer Bevölkerung ist hier die wichtigste Ressource, aus der asymmetrisch unterlegene Akteure ihre Durchhaltefähigkeit gewinnen. Der Kampf richtet sich hierbei wesentlich gegen die einge- 
schränkte Opferbereitschaft der gegnerischen Gesellschaft, die allmählich ermatten wird. So wird die Verfügbarkeit von Zeit zur Ressource des Erfolgs. (Vgl. Münkler 2002b: I94ff.)

3. Das Ausspielen waffentechnischer Überlegenheit, wie es etwa die Briten in der Schlacht von Omdurman taten, als sie mit Hilfe ihrer Maxim-Maschinengewehre die Truppen des Mahdi von Khartum zusammenschossen, bevor die ihre eigenen Waffen einsetzen konnten, oder die Luftwaffe der Nato im Kosovokrieg von I999, die aus einer für die serbische Luftabwehr unerreichbaren Höhe den Gegner attackierte und zermürbte. Solche Asymmetrien werden dort dramatisch, wo die überlegene Macht neue Sphären für die Kriegführung zu erschließen bzw. zu nutzen vermag: das Meer, den Luftraum, den Weltraum. Die amerikanische Überlegenheit in den jüngsten Kriegen beruht auf der tendenziellen Alleinverfügung über diese Sphären, und sie ist inzwischen so groß, dass für die Gegner der USA keinerlei Aussicht besteht, durch entsprechende Nachrüstung zu einer Resymmetrierung des Kriegsgeschehens zu gelangen. (Vgl. Münkler 2003b: I7f.)

4. Schließlich der Terrorismus als eine Strategie der systematischen Kostenerhöhung. Terrorismus wird dabei verstanden als eine moderne Variante des Verwüstungskrieges, dessen strategische Direktive darin besteht, dem Gegner einen so großen wirtschaftlichen Schaden zuzufügen, dass er in seinen politischen Zielen resigniert.7 Angriffsziele sind zentrale Symbole, Aktienkurse und das Sicherheitsgefühl von Touristen, also die labile psychische Infrastruktur der westlichen Welt. 


\section{Asymmetrie der Stärke und Asymmetrie aus Schwäche}

Symmetrische Kriegführung ist dadurch gekennzeichnet, dass in ihr für jeden Soldaten die Chancen zu töten oder getötet zu werden tendenziell gleich verteilt sind. Eine solche Form der Kriegführung eignet sich für entsprechende Ethisierungen, die komplementär zu den kriegsvölkerrechtlichen Hegungen der Gewaltanwendung und Zielauswahl fungieren. In der Regel wird ethisierte Symmetrie als Ritterlichkeit bezeichnet. Die Gleichverteilung der Chancen zu töten oder getötet zu werden gilt für asymmetrische Kriege jedoch gerade nicht: Der Kosovo-Krieg war der erste Krieg, in dem eine der kriegführenden Parteien keinen einzigen Mann im Rahmen von Kampfhandlungen verloren hat; gegen diese Entwicklung steht die Figur des so genannten Selbstmordattentäters, dessen Aktionsmöglichkeit aus dem Verzicht auf jede Chance des Überlebens erwächst. (Vgl. Schröder 2002) Im ersten Fall werden eigene Opfer systematisch minimiert, im zweiten Fall werden sie gezielt und demonstrativ produziert. Beides ist die Folge der spezifischen Kriegführungsfähigkeit unterschiedlicher Gesellschaften und der Mobilisierung ihrer jeweiligen Möglichkeiten.

Westliche Demokratien sind im Kern postheroische Gesellschaften. Sie sind auf Arbeit und Tausch, nicht auf Opfer und Ehre begründet. Infolge demokratischer Rückkoppelungen der politischen Entscheider sind sie nur bei geringen eigenen Opfern kriegführungsfähig. Die Kriegführungsfähigkeit von Demokratien gründet sich auf technologische Überlegenheit, also auf Seestreitkräfte, die Luftwaffe und auf Marschflugkörper. Sie müssen ihre waffentechnologische Überlegenheit stets weiterentwickeln, weil sie keine opferreichen Kriege führen können und auf Überlegenheit zwecks Opferminimierung angewiesen sind. 
Nichtwestliche Gesellschaften haben seit dem Zerfall der Sowjetunion nicht die Möglichkeit zur Führung symmetrischer Kriege gegen westliche Gesellschaften, weil ihnen dazu die technologischen, militärorganisatorischen und ökonomischen Voraussetzungen fehlen. Die Relevanz des Zweiten Golfkrieges, als eine US-geführte Koalition I99I die Iraker aus Kuwait vertrieb, lag in der an alle anderen gerichteten Botschaft: Ihr habt keine Chance, also gebt auf! Der Dritte Golfkrieg hat dies noch einmal verstärkt. Daraus erwächst für die Unterlegenen ein Zwang zur Asymmetrie, und dies erst recht bei noch schwächeren Staaten als dem Irak, bei Warlords etwa, und vor allem natürlich bei entterritorialisierten Netzwerken. Netzwerke können sich den Reziprozitätsbedingungen der Territorialstaaten entziehen, weswegen sie asymmetrische Strategien besonders effektiv zu handhaben vermögen. Netzwerkstrukturen und asymmetrische Strategien aus Schwäche gehören zueinander, so wie Staatlichkeit und Symmetrie zueinander gehören.

Die beiden Richtungen der Asymmetrisierung werden symbolisiert durch moderne Kampfflugzeuge und lasergesteuerte Bomben auf der einen Seite und durch Selbstmordattentäter auf der anderen Seite. Sie sind einander funktionsäquivalent: Was für die einen Tomahawk-Marschflugkörper sind, sind für die anderen Selbstmordattentäter. Aber die Funktionsäquivalenz beider >Waffensysteme < begründet keine Reziprozität, das heißt eine Hegung der Gewaltanwendung durch gegenseitige Anerkennung ist nicht möglich. Dabei kommt es auch zu einer Verlagerung des Kampfgeschehens auf die symbolische Ebene: die Unerreichbarkeit moderner Kampfflugzeuge für die gegnerische Luftabwehr auf der einen, die demonstrative Verachtung für das eigene Leben, mit der Selbstmordattentäter die Werte der angegriffenen Gesellschaft zu dementieren versuchen, auf der anderen Seite. In den neuen Kriegen hat die Symbolik der Gewaltmöglichkeiten neben der Instrumentalität der Waffenwirkung 
erhöhtes Gewicht erlangt. Natürlich haben auch in früheren Kriegen Symboliken eine wichtige Rolle gespielt, aber sie blieben wesentlich an die Instrumentalität der Waffen gebunden. In den neuen Kriegen hat sich die Symbolik verselbständigt. Es kommt dadurch zu einer schleichenden Entmilitarisierung des Krieges und auch das ist ein Grund, von »neuen« Kriegen zu sprechen.

\section{Anmerkungen}

I Systematisch entfaltet hat das Theorem der neuen Kriege erstmals Mary Kaldor (2000). Dagegen hat Martin van Creveld in Die Zukunft des Krieges von einer »Transformation des Krieges « gesprochen, worunter er das Verschwinden des klassischen Staatenkrieges und die Entwicklung so genannter »low intensity conflicts « verstanden hat.

2 Die Geschichte des Krieges kann darum auch nicht als eine Abfolge von Manövern und Schlachten, sondern nur als Bestandteil der politischen Geschichte sowie der Sozial- und Wirtschaftsgeschichte geschrieben werden. Hinter diese im Prinzip breit akzeptierte Einsicht fällt jede enge Fassung des Kriegsbegriffs zurück.

3 Die einschlägigen Daten $\mathrm{zu}$ beiden Trends sind zusammengestellt bei Gantzel (2000) und bei Kaldor (2000: I60).

4 Hier liegt die zentrale Differenz der hier vorgetragenen Überlegungen zu denen Carl Schmitts, der in seinem Werk Der Nomos der Erde (I950) die Regelungsleistung der Juristen als ursächlich für den spezifischen Gang der europäischen Staaten- und Kriegsgeschichte herausgestellt hat. Bei allem Respekt vor der Jurisprudenz: damit wird der Einfluss von Texten und Paragraphen dramatisch überschätzt. In gewisser Hinsicht begehen diejenigen denselben Fehler, die gegenwärtig darauf vertrauen, durch rechtliche Regelungen 
die verändernde Kraft neuer waffentechnischer wie militäroganisatorischer Entwicklungen domestizieren zu können.

5 In jüngster Zeit erst sind die veränderten Formen der Kriegsökonomie von der Wissenschaft genauer in Augenschein genommen worden. $\mathrm{Zu}$ nennen sind hier vor allem Jean/Rufin (1999) sowie Berdal/Malone (2000). Die deutschen Friedens- und Konfliktforscher haben in ihrer großen Mehrheit über ein ganzes Jahrzehnt den Wandel der Kriegsökonomie übersehen; offensichtlich auch, weil sie mit einem zu engen Kriegsbegriff arbeiteten.

6 Die Dynamik solcher Kriege ist zusammenfassend analysiert worden von Genschel/Schlichte (1997).

7 Hierbei sind die älteren Formen des sozialrevolutionären und ethno-separatistischen Terrorismus, die auf Provokationsstrategien beruhen (vgl. Waldmann I998), von den jüngsten Formen des internationalen Terrorismus zu unterscheiden, in denen an die Stelle der Provokation die Strategie der Verwüstung getreten ist.

\section{Literatur}

Baumann, Reinhard (1994): Landsknechte. Ihre Geschichte und Kultur vom späten Mittelalter bis zum Dreißigjährigen Krieg, München.

Berdal, Mats/Malone, David (Hg.) (2000): Greed and Grievance. Economic Agendas in Civil Wars, Boulder [u.a].

Clausewitz, Carl von (1980): Vom Kriege, I9. Aufl., hg. von Werner Hahlweg, Bonn.

Creveld, Martin van (1998): Die Zukunft des Krieges, München.

Eppler, Erhard (2002a): »Privatisierte Gewalt«; in: tageszeitung vom 9.10.2002. 
Eppler, Erhard (2002b): Vom Gewaltmonopol zum Gewaltmarkt? Die Privatisierung und Kommerzialisierung der Gewalt, Frankfurt a.M.

Gantzel, Klaus-Jürgen (2000): »Über die Kriege nach dem Zweiten Weltkrieg: Tendenzen, ursächliche Hintergründe, Perspektiven«, in: Bernd Wegner (Hg.): Wie Kriege entstehen. Zum historischen Hintergrund von Staatenkonflikten, Paderborn [u.a.], S. 299-318.

Genschel, Philipp/Schlichte, Klaus (1997): »Wenn Kriege chronisch werden: der Bürgerkrieg«, in: Leviathan, 25. Jg., Heft 4, S. 50I-5I7.

Jean, François/Rufin, Jean-Christophe (Hg.) (1999): Ökonomie der Bürgerkriege, Hamburg.

Kaldor, Mary (2000): Neue und alte Kriege. Organisierte Gewalt im Zeitalter der Globalisierung, Frankfurt a.M.

Medico International (2002): Ungeheuer ist nur das Normale: zur Ökonomie der »neuen Kriege«, Frankfurt a.M.

Münkler, Herfried (2002a): Die neuen Kriege. Reinbek bei Hamburg.

Münkler, Herfried (2002b) »Die Kriege des 2I. Jahrhunderts«, in: Gewerkschaftliche Monatshefte 4/2002, S. 193-204.

Münkler, Herfried (2003a): Der neue Golfkrieg, Reinbek bei Hamburg.

Münkler, Herfried (2003b): »Die Privatisierung des Krieges. Warlords, Terrornetzwerke und die Reaktion des Westens«, in: Zeitschrift für Politikwissenschaft (ZPol), I3. Jg., Heft I, S. 7-22.

Schmitt, Carl (I950): Der Nomos der Erde im Jus Publicum Europaeum, Köln.

Schröder, Christoph (2002): Mein Leben ist eine Waffe. Selbstmordattentäter - Psychogramm eines Phänomens, München.

Waldmann, Peter (1998): Terrorismus. Provokation der Macht, München. 



\section{Wo liegst du, Europa?}

\section{Europäische Identität als Konstrukt}

JÜRGEN KOCKA

Für Gustav Schmidt zum 65. Geburtstag

In Artikel I-I des am I3. Juni 2003 vom Europäischen Konvent mit großer Mehrheit verabschiedeten Verfassungsentwurfs heißt es: »Die Union steht allen europäischen Staaten offen, die ihre Werte achten und sich verpflichten, ihnen gemeinsam Geltung zu verschaffen.« Auf welche Werte die Union sich gründet, sagt Artikel I-2: die Achtung der Menschenwürde, Freiheit, Demokratie, Gleichheit, Rechtsstaatlichkeit und die Wahrung der Menschenrechte. (Europäischer Konvent 2003: Art. I-I u. I-2) Was >europäisch< ist, sagt der Text dagegen nicht, setzt es vielmehr voraus. Aber was ist >europäisch ?

Die Frage hat ihre praktisch-politische Bedeutung. Die Europäische Union (EU) befindet sich bekanntlich in einem rasanten Prozess der Erweiterung. Aus den ehemals sechs beteiligten Staaten wurde längst der heutige Club der fünfzehn, der seine 
Erweiterung auf 25 beschlossen hat. Weitere Expansion ist auf dem Weg. Man hat anderen osteuropäischen Staaten Hoffnung gemacht: Rumänien, Bulgarien, Kroatien. Serben, Bosnier, Mazedonier und Albaner kämen auch gern dazu. Die Frage der Türkei wird kontrovers diskutiert; auch ihr ist der Beitritt in Aussicht gestellt, wenn sie denn die genannten Werte demnächst erfüllen kann (worum sie sich zunehmend bemüht). Aber ist die Türkei ein europäischer Staat?

Seit den 7oer Jahren hat die EG, seit 1993 die EU, die Neigung entwickelt, sich auf ihre europäische Identität zu berufen und sie zu stärken. Identität hat aber mit Inklusion und Exklusion, mit einem selbst und mit anderen zu tun. Für ein staatsähnliches Gebilde wie die EU ist damit die Frage nach den Grenzen in grundsätzlicher Weise gestellt. Die Frage: »Wo liegst du, Europa? « ist auch eine Frage nach Grenzen und eine Frage nach den anderen, die nicht zu Europa gehören - und warum.

Ich gebe im ersten Kapitel einen sehr selektiven und kursorischen Überblick über Antworten, die in den letzten zweieinhalb Jahrtausenden auf diese Fragen angeboten worden sind. Es wird sich zeigen, dass Geschichte und Geographie zwar wichtige Fingerzeige bieten, aber keine klaren und eindeutigen Antworten bereithalten. Wo Europa liegt und was es ist, lässt sich weder aus Geographie- noch aus Geschichtsbüchern eindeutig ablesen, sondern hing und hängt immer auch von den wechselnden Entwürfen und den politischen Entscheidungen der jeweiligen Gegenwart ab. Die Frage muss also schließlich lauten: Wo sollen die Grenzen Europas gezogen werden (2. Kapitel) und wie sollen sie beschaffen sein (3. Kapitel)? Und generell: Wohin soll der historisch einmalige Prozess der politischen Integration Europas führen? 


\section{Historische Antworten}

I. Europa war bei den griechischen und lateinischen Schriftstellern der Antike und des frühen Mittelalters kein zentraler Begriff. Er kam nur gelegentlich und nur am Rande vor. Die Geschichte des Begriffs beginnt mit zwei Gründungsmythen. (Vgl. Plessen 2003: 47-6I) Seit dem 4. Jahrhundert vor Christus taucht das Motiv vom Raub der phönizischen Königstochter Europa durch den griechischen Götterkönig Zeus auf, der zu diesem Zweck die Gestalt eines Stieres annahm. Zeus entführte Europa nach Kreta, wo aus der Verbindung zwischen ihnen die minoische Herrscher-Dynastie hervorgegangen, also ein Reich gegründet worden sein soll. Diese Erzählung ist in zahlreichen Texten und bildlichen Darstellungen überliefert.

In der frühchristlichen Literatur des 4. Jahrhunderts nach Christi Geburt beginnt man den Mythos des Japhet auszudeuten. Der biblische Noah habe drei Söhne gehabt, unter denen die Welt aufgeteilt worden sei. Sem habe Asien, Ham Afrika und Japhet Europa erhalten, das zunehmend christlich wurde. Diese Legende war noch im I8. Jahrhundert so weit verbreitet, dass sich der Aufklärer Voltaire bemüßigt sah, sie mit empirischen Argumenten zu widerlegen.

Diese Gründungsmythen bieten zum einen ein gewaltsames, sinnliches, heidnisches Bild und zum andern den Versuch, Europa biblisch zu grundieren und die Erinnerung an die anrüchigen Liebschaften des Königs der heidnischen Götter mit einem Mädchen aus Kleinasien vergessen zu machen. Ich will hier nur auf die räumlichen Dimensionen der beiden Mythen aufmerksam machen: Einerseits wird Europas Verflechtung mit Asien betont - von dort kommt die Königstochter und dorthin wirkt, was sie aufbaut, zurück. Für beide Mythen ist andererseits die Differenz zwischen Europa und Asien zentral; eine Differenz, die auch in anderen antiken Aussagen über Europa präsent war. Für 
Hippokrates zum Beispiel waren im 5. Jahrhundert vor Christus - kurz nach den Perserkriegen, die für die Griechen gut ausgegangen waren - die Bewohner Europas geistig lebhafter, rühriger und auch kriegerischer als die Asiaten. Diese hielt er für langsamer, weicher und folgsamer, weil sie unter fremder Herrschaft, in großen Reichen und nicht unter der Herrschaft eigener Gesetze lebten, wie das bei den Europäern (den Griechen) oftmals der Fall war.

Es gab offenbar frühzeitig Grund, die Grenzen Europas zu thematisieren. Der Hellespont, der Bosporus und weiter nördlich das Schwarze Meer galten als östliche Grenze Europas. Nach Süden grenzte deutlich das Mittelmeer ab. Nach Westen und Norden blieb die Abgrenzung noch lange unklar. Immerhin, eine länderübergreifende Vorstellung von Kontinenten bildete sich früh, und sie bildete sich in Europa. Begrifflich waren Asien und Afrika mithin europäische Erfindungen, wie später auch Amerika.

2. Im europäischen Mittelalter sprach man weniger von $>$ Europa<, sondern eher von »christianitas«. Die Abgrenzungen stellten nicht den Unterschied zwischen Europäern, Asiaten oder Afrikanern ins Zentrum, sondern den zwischen Christen und Heiden. Das christliche Europa des Mittelalters war aber tief zwischen dem katholischen Westen und dem byzantinischen Osten gespalten. Und es gab immer auch Christen außerhalb Europas, zum Beispiel in Abessinien, wie es auch immer Nicht-Christen in Europa gab, so seit dem 7./8. Jahrhundert auf der Iberischen Halbinsel, wo unter arabischer Herrschaft Christen, Muslime und Juden spannungsvoll und variantenreich zusammenlebten. Noch bevor die christliche Rückeroberung der Halbinsel abgeschlossen war, geriet seit dem I4. Jahrhundert ein großer Teil des Balkans und - vorübergehend - Russlands unter islamische bzw. osmanisch-türkische Herrschaft. Es gab überdies immer die 
jüdische Minderheit: geduldet, verfolgt, Europa mitprägend. In den Kulturen der Völker überlebten zudem viele heidnische Elemente. Doch insgesamt wurde das Gebiet, das zunächst vereinzelt, später häufiger als Europa bezeichnet wurde, tief durch die christliche Zivilisation geprägt.

Differenzen und Konflikte mit den anderen trieben die Entstehung eines christlich-europäischen Zusammenhangsbewusstseins voran - und umgekehrt. Die Vorstellung >Europa < tauchte damals am ehesten in Berichten über Kriege mit Nicht-Europäern auf. 732 besiegte der Frankenkönig Karl Martell die Araber beim französischen Poitiers. Die Chronik nennt seine Krieger »Europenses«, Europäer. Diese entdeckten am Morgen des achten Tages der Schlacht, dass die arabischen Feinde ihre Zelte in der Nacht aufgegeben hatten. Sie konnten also, nach der üblichen Plünderung, frohen Mutes nach Hause zurückkehren, jeder ins eigene Land. >Europäisch < stand hier für eine Gemeinschaft von Völkern nördlich der Pyrenäen und der Alpen, die sich im Krieg gegen die nicht-europäischen, vom Süden andrängenden Araber zusammenschlossen.

Karl der Große, im Jahr 800 vom römischen Papst zum Kaiser gekrönt, ist von Zeitgenossen vereinzelt als »Vater Europas« bezeichnet und sein Reich mit Europa gleichgesetzt worden: Europa vel regnum Caroli. Das war ein Europa ohne England und Skandinavien und ohne den östlichen Teil, der byzantinisch beherrscht und orthodox-christlich geprägt war, also vor allem ohne den Balkan. Entsprechend rief Papst Gregor IV. 843 in seiner Auseinandersetzung mit dem Patriarchen von Konstantinopel »alle Kirchen Europas« zur Hilfe auf.

Den so genannten >Kreuzzügen $<$ seit dem II. Jahrhundert lagen sehr unterschiedliche Antriebe zugrunde. Aber zweifellos waren sie ein christliches, vom römischen Papst gestütztes Unternehmen mit anti-islamischer, zum Teil anti-jüdischer und bisweilen anti-oströmischer Stoßrichtung, unter anderem im 
Kampf um den Zugang zum Heiligen Land, das allen drei Religionen heilig war, so sehr sie sich im Übrigen befeindeten. Die Kreuzzugserfahrung beförderte den innerchristlich-innereuropäischen Zusammenhang und brachte ihn zur Sprache, allerdings wohl primär für den lateinischen Westteil der Christenheit und ohne das Schisma zu überbrücken.

Und als 1453 Konstantinopel nach langer Belagerung an die vordringenden Türken gefallen war, klagte Enea Silvio Piccolomini, einer der führenden Humanisten der Zeit und späterer Papst:

»In der Vergangenheit wurden wir in Asien und Afrika, also in fremden Ländern, geschlagen. [Er spielte wohl auf die Kreuzzüge an.] Jetzt aber trifft man uns in Europa, unserer Heimat, unserem Zuhause. Man wird einwenden, dass die Türken früher schon von Asien nach Griechenland eingedrungen waren, die Mongolen sich in Europa festsetzten und die Araber einen Teil Spaniens besetzten, nachdem sie die Meerenge von Gibraltar überwunden hatten. Aber noch nie haben wir eine Stadt oder Festung wie Konstantinopel verloren.« (Zitiert nach Cardini 2003: I7I)

Bis ins I8. Jahrhundert hinein brachte die Furcht vor den vordringenden Türken das im Übrigen äußerst uneinige Europa bisweilen dazu, tatsächlich zusammenzurücken und sich in den Schriften seiner Intellektuellen als zusammengehörig zu denken. Mit einigem Recht kann man den Propheten Mohammed und die Kalifen Arabiens wie auch die Sultane der Osmanen, besonders Mehmed II. und Süleyman, als die »gewalttätigen Geburtshelfer« Europas bezeichnet. (Vgl. ebd.: I3)

Trotz dieser Kämpfe entwickelte sich im I2. und I3. Jahrhundert ein intensiver islamisch-christlicher Kultur- und Wissensaustausch, wobei im Wesentlichen die Araber die Gebenden und die Europäer die Nehmenden waren. Über die Araber in Spanien, Sizilien und anderswo erhielt Europa das Papier, die 
arabischen Ziffern einschließlich der Null, die Kenntnis der griechischen Philosophen, die arabische Mode. Es gab viele Kontakte durch Übersetzungen, Handel und Reisen, und es gab viel Bewunderung für Arabien - bei Herrschern wie dem Staufer Friedrich II. in Palermo oder dem Philosophen und Theologen Albertus Magnus in Köln. Andere Beispiele ließen sich nennen, auch für spätere Jahrhunderte und mit Blick auf die komplizierte europäische Rezeption von türkischen Dingen weit über Kaffee und Kaffeehaus hinaus, besonders seitdem im I6./I7. Jahrhundert die Orientalistik als europäische Wissenschaft entstand. So waren die anderen nicht nur Fremde und Feinde, gegen die man sich in Europa absetzte und zusammenschloss, sondern auch Quellen neuer Erfahrungen und Anregungen, neuen Wissens und Lernens. Über Differenz und über Verflechtung entstand europäische Identität.

3. Vom I5. bis zum I8. Jahrhundert überlagerte im Denken der Gebildeten die Idee eines völker- und staatenumspannenden $>$ Europa< nach und nach die ältere Idee einer völker- und staatenumspannenden >Christenheit<. Als Wille und Vorstellung ist Europa vor allem ein Produkt der Neuzeit. Wie kam es dazu?

Es lag zum einen am Aufstieg der zunehmend souveränen Territorialstaaten seit dem späten Mittelalter und ihren blutigen Kriegen, gegen die ein europäischer Frieden gesucht und beschworen wurde. Es lag zum anderen an der Konfessionalisierung, der Spaltung der westlichen Kirche im I6. Jahrhundert und den folgenden blutigen Religionskriegen, in denen die Hoffnung auf die einheitsstiftende Kraft eines alles umspannenden Christentums verloren ging. Es lag drittens an der europäischen Expansion in nicht-europäische Teile der Welt, im Vergleich zu denen und im Spiegel von denen sich Europa als Europa identifizierte. Es lag schließlich viertens an einer sich seit der Renaissance allmählich herausbildenden und in der Aufklärung kulmi- 
nierenden, säkularisierten europäischen Kultur der Gebildeten an den Höfen, Universitäten und in den Bürgerstädten des Kontinents und der britischen Inseln.

Dies waren gemeinsame europäische Erfahrungen trotz extrem ausgeprägter innereuropäischer Vielfalt. Aber an dieser gemeineuropäischen Erfahrung partizipierte der große, unter osmanischer Herrschaft stehende Teil des Balkans ebenso wenig wie das seit dem i6. Jahrhundert wieder christlich-orthodoxe Russland. Die Moskowiter sahen sich als die wahren, der Orthodoxie treu gebliebenen Christen, die sich unter der Herrschaft des christlichen Zaren von den Katholiken im Westen (Polen), von den Protestanten im Norden (Schweden) wie von den sungläubigen Tataren und Osmanen im Osten und Süden trotzig abhoben. Erst nachdem der Zar die Hauptstadt von Moskau I702 ins westwärts blickende St. Petersburg verlagert hatte, nahm das gleichzeitig nach Osten expandierende Reich mit dem nun zunehmend europäisch orientierten Teil seiner Eliten und mit autokratischer Modernisierung von oben ein Stück weit an der gemein-europäischen Entwicklung teil.

In den utopischen Ideen vom europäischen Frieden durch europäischen Zusammenschluss, mit denen einige Gebildete seit dem späten i6. Jahrhundert auf die vielen Kriege zwischen den europäischen Staaten und Konfessionen reagierten, hatte Europa unterschiedliche Grenzen. Der französische Herzog von Sully entwarf z.B. I638 einen Plan, der zahlreiche gemeinsame Institutionen und Verträge zur innereuropäischen Konfliktlösung vorsah. Er wünschte sich Ungarn mit einem Teil des Balkans als Bollwerk gegen die Türken und Polen als Vorwerk gegen Moskowiter und Tartaren. William Penn, der englische Quäker, der die Kolonie Pennsylvania mit einer freien Verfassung gründete, entwarf als Antwort auf die Kriege Ludwigs XIV. den Plan eines europäischen Fürsten- und Staatenbundes. Darin schloss er ausdrücklich nicht aus, dass auch Russland und die Türkei zum 
Zwecke der Verhinderung von Krieg zu Europa gehören könnten. Der aufgeklärte Kleriker Abbé de Saint Pierre wiederum rechnete in seinem »Traktat zum ewigen Frieden « (I7I2) Russland zwar zu Europa, nicht aber die Türkei. Umgekehrt wandte sich der französische Revolutionär und Konsul der Republik Delaunay I794 in seinem »Plan zur Wiederherstellung des allgemeinen Friedens in Europa « gegen jeden anti-türkischen Kreuzzug und vertrat die Auffassung, dass man den Türken helfen und sie für Europa gewinnen müsse - gegen die Russen, die er nach ihrer Machterweiterung im I8. Jahrhundert als ernste Bedrohung Europas ansah.

Der preußische König Friedrich II. hatte für solche Pläne nur Sarkasmus übrig:

»Der Abbé von Saint Pierre [...] hat mir ein schönes Werk über die Art und Weise, wie in Europa der Friede wieder hergestellt werden könnte, zugesandt. Die Sache ist sehr praktisch - um ihr zum Erfolg zu verhelfen, bedarf es nur der Zustimmung Europas und einiger anderer Kleinigkeiten.«

In der Tat wurde aus den Plänen nichts. Aber sie zeigen, wie und aus welchen Motiven Europa-Ideen entstanden und wie die Abgrenzung Europas nach Osten mit dem jeweiligen Zweck und der sich ändernden politischen Einschätzung schwankte. (Nach Rougemont I962: 83-III)

4. An der Entdeckung der anderen Weltteile, ihrer Ausbeutung und Kolonisierung nahmen die europäischen Völker im I6., I7. und I8. Jahrhundert sehr unterschiedlich teil, die Deutschen relativ wenig. Vermittelt über die Intellektuellendiskussionen und die öffentliche Meinung war die Expansion trotzdem ein gesamteuropäischer Prozess, durch den die europäische Selbstbeschreibung zum Thema wurde und sich veränderte. Einerseits 
beschrieben europäische Intellektuelle ihren Weltteil aufgrund seiner Wissenschaft, seiner wirtschaftlichen Tüchtigkeit, seiner militärischen Mittel, seiner politischen Verhältnisse als überlegen. Das führte bisweilen zu extremer Selbstüberheblichkeit und zu gewagten historischen Konstruktionen vom Aufstieg Europas und Abstieg Asiens bis hin zu rassistischen Thesen bereits im I8. Jahrhundert. Asien und Afrika (oder Teile davon) wurden zu negativ besetzten Gegenbildern: als zurückgeblieben bemitleidet oder exotisiert.

Andererseits gab es auch nüchterne Varianten des Selbstvergleichs, in denen beispielsweise durch Kontrast mit Asien die politische Vielfalt und die Begrenzung politischer Herrschaft durch die Trennung von staatlicher und geistlicher Gewalt, Repräsentationsorgane und öffentliche Meinung als Eigenarten der europäischen Entwicklung herausgearbeitet wurden. Solche Selbstvergleiche konnten auch zu ironischen Ergebnissen führen, wie das zum Beispiel beim Schweden Carl von Linné (I7I8) der Fall war:

»Homo europäeus: weiß, sanguinisch, fleißig, mit gelblichen Haaren, bläulichen Augen. Leicht beweglich, scharfsinnig, erfinderisch; bedeckt mit anliegenden Kleidern; regiert durch Gesetze.« (Ebd.: II8)

Aber der vergleichende Blick konnte auch in europäische Selbstzweifel und Selbstkritik münden, wie es im Medium der Literatur in den »Lettres persanes« von Montesquieu (I72I) der Fall war: Der scharfe Blick eines fiktiven Besuchers aus Amerika, Asien oder Afrika deckte europäische Schwächen auf, etwa europäische Künstlichkeit, brutalen Kolonialismus und europäische Dekadenz oder auch mangelndes Raffinement. Spiegelbildlich erschienen dann die Bewohner der anderen Erdteile als edel, natürlich und jung, oder als verfeinert und zivilisiert. (Vgl. Montesquieu I988: 326, 330) 
Und manchmal verbanden sich Selbstbewusstsein und Selbstkritik: wie bei Condorcet zum Beispiel. Bissig konfrontierte der französische Aufklärer des I8. Jahrhunderts die edle Zivilisierungsrhetorik der Europäer mit dem brutalen Eigennutz ihrer Kolonialpolitik. Er rief sie auf, ihre Grundsätze ernst zu nehmen und die Rechte, Freiheiten und Interessen der fremden Völker zu respektieren. Er verlangte von ihnen, in Afrika, Amerika und Asien »das Beispiel der Freiheit, die Aufklärung und die Vernunft Europas auszubreiten«. (Condorcet I963: 353) Keine schlechte Argumentation! Nach diesem Muster sah sich Europa als Ausgangspunkt universaler Modernisierung, als Region, von der die Menschenrechte, die moderne Wissenschaft, der moderne Staat und manche andere Errungenschaft ausgegangen waren, die mittlerweile weltweite Geltung beanspruchten. Umgekehrt zwang dies aber dazu, die eigene Praxis an jenen Normen $\mathrm{zu}$ messen und zu kritisieren.

So trat im Zeichen der Aufklärung die Frage nach den europäischen Grenzen zurück. Der universalistische Anspruch des Projekts Europa wurde in den Vordergrund gerückt und als Kritik an den realen europäischen Verhältnissen auf den Erdteil zurückgelenkt. Aus den sich emanzipierenden nordamerikanischen Kolonien schallte das Echo unter konsequenter Betonung der Europakritik bald zurück. So schrieb Alexander Hamilton im »Federalist« I787/88, Europa habe die anderen Weltteile, sehr zu ihrem Schaden, Schritt für Schritt seiner Herrschaft unterworfen, mit Waffen und durch Verhandlungen, mit Gewalt und Betrug.

»Afrika, Asien und Amerika sind nacheinander in seine Hände gefallen. Die Überlegenheit, die Europa so lange behalten hat, ist der Grund dafür, dass es sich als Herrscher über die Welt betrachtet und meint, der Rest der Menschheit sei nur zu seinem Vorteil geschaffen [...] Es ist an uns (in Amerika), die Ehre des Menschengeschlechtes wieder herzustel- 
len und diese unsere usurpatorischen Brüder Bescheidenheit zu lehren [...] O dass doch die Amerikaner endlich aufhörten, der Größe der Europäer zu dienen!« (Hamilton/Madison/Jay I993: I06)

Es sollte noch mehr als hundert Jahre dauern, bis ähnlich entschiedene Worte aus anderen Weltteilen kamen, die von Europäern kolonisiert worden waren.

5. Seit dem Ende des i8. Jahrhunderts nahm die Neigung zu europäischer Selbstgerechtigkeit und Selbstüberheblichkeit kräftig zu, wobei weiterhin das Osmanische Reich, häufiger aber Asien insgesamt als negatives Gegenbild dienten. Entsprechende Äußerungen finden wir bei vielen kleinen und selbst noch bei den größten Geistern.

So freute sich Schiller (I798), nachdem er sich mit Berichten über Reisen nach Syrien und Ägypten beschäftigt hatte,

»in Europa geboren zu sein. Es ist doch wirklich unbegreiflich, dass die belebende Kraft im Menschen nur in einem so kleinen Teil der Welt wirksam ist, und jene ungeheuren Völkermassen für die menschliche Perfektibilität ganz und gar nicht zählen.«

Goethe, dem er diese Sätze schrieb, begnügte sich mit einer lakonischen Antwort: »Lassen Sie uns denn also, wenn es auch in Europa noch etwas bunter zugehen sollte, gern in diesem Weltteile verweilen.« (Goethe I950: 506, 5II)

Hegel meinte in seinen »Vorlesungen über die Geschichtsphilosophie«, »die Orientalen« hätten nur gewusst, dass Einer frei sei; die griechische und römische Welt habe gewusst, dass Einige frei seien; »wir aber« wüssten, dass alle Menschen frei sind,

»alle Menschen an sich, das heißt der Mensch als Mensch.«»Die Welt- 
geschichte geht von Osten nach Westen, denn Europa ist schlechthin das Ende der Weltgeschichte, Asien der Anfang.« (Hegel I992: 32, I34)

Und als der späte Ranke sich fragte, warum das Osmanische Reich so sehr im Niedergang begriffen sei, fand er den Grund darin, dass es

»einer anderen Weltmacht gegenübersteht, die ihm unendlich überlegen ist. [...] Es ist der Genius des Occidents. Es ist der Geist, der die Völker zu geordneten Armeen umschafft, der die Straßen zieht, die Canäle gräbt, alle Meere mit Flotten bedeckt und in sein Eigenthum verwandelt, die entfernten Continente mit Colonien erfüllt, der die Tiefen der Natur mit exacter Forschung ergründet und alle Gebiete des Wissens eingenommen und sie mit immer frischer Arbeit erneuert [hat] [...] In ungeheurem Fortschritt sehen wir diesen Geist begriffen. Er hat Amerika den rohen Kräften der Natur und unbildsamen Nationen abgewonnen und durchaus umgewandelt; auf verschiedenen Wegen dringt er in das entfernteste Asien vor, und kaum China verschließt sich ihm noch; er umspannt Afrika an allen Küsten; unaufhaltsam, vielgestaltig, unnahbar, mit Waffen und Wissenschaft unwiderstehlich ausgerüstet, bemeistert er sich der Welt.« (Ranke I879: 5I8f.)

Andererseits gab es auch Pessimismus und Untergangsprognosen. Sowohl Napoleon auf St. Helena wie Tocqueville und Jakob Burckhardt sagten voraus, dass die Zukunft den außereuropäischen Mächten Amerika und Russland gehören werde. Nietzsche beklagte wortreich die »Vermittelmäßigung « Europas, und nach dem Ersten Weltkrieg trafen die europapessimistischen Niedergangsprognosen z.B. eines Oswald Spengler auf große Resonanz.

6. Zweifellos hat die nationale Rhetorik des I9. Jahrhunderts den Europa-Diskurs in den Hintergrund gedrängt. Doch die gro- 
ßen Kriege des 19. und 20. Jahrhunderts bewirkten auch das Gegenteil. Sie führten zur Stärkung des europäischen Bewusstseins und zu flammenden Aufrufen für die Einigung Europas im Dienst des Friedens. Beispiele dafür sind Saint-Simon nach den napoleonischen Kriegen, Victor Hugo nach dem deutsch-französischen Krieg von I870-7I, Graf Coudenhove-Kalergi nach dem Ersten Weltkrieg und auf zahlreichen Kongressen nach 1945. (Vgl. Rougemont i962: I93ff., 243ff., 333f., 40If.)

Wie änderte sich dabei die Vorstellung von den Grenzen Europas? Lässt man Spezialdiskussionen, z.B. über Island oder Malta beiseite, bestand viel Einigkeit über Europas Grenzen im Süden, Westen und Norden. Doch die Unsicherheit über Europas östliche und südöstliche Grenzen dauerte an. Zwar nahm die Furcht vor dem immer schwächeren Osmanischen Reich ab man sprach im späten I9. Jahrhundert eher vom >kranken Mann am Bosporus $<$. Doch kaum jemand war bereit, die Türkei als Teil Europas zu sehen. In ihrem Kampf um Selbständigkeit beriefen sich dagegen Griechen, Serben und andere Balkanvölker immer häufiger auf ihre historische Zugehörigkeit zu Europa und fanden auf dieser Ebene im übrigen Europa viel Zustimmung man denke an die Philhellenische Bewegung für griechische Unabhängigkeit im vormärzlichen Europa. In ähnlicher Weise beschwor man in den 7oer und 8oer Jahren des 20. Jahrhunderts in der Tschechoslowakei, Ungarn und Polen die eigene Zugehörigkeit zu Europa. Indem man sich als >mitteleuropäisch kategorisierte und die $>$ Rückkehr nach Europa< forderte, rüttelte man an der Hegemonie der Sowjetunion: Europa wurde zum antidiktatorischen Erwartungsbegriff, wenngleich es im 20. Jahrhundert die schlimmsten Diktaturen selber hervorgebracht hatte.

Umstritten blieb im I9. und frühen 20. Jahrhundert die Zugehörigkeit Russlands zu Europa. Auf der demokratischen Linken wurde sie glatt verneint. Auch Ranke meinte I824: »In 
der Tat stehen uns New York und Lima näher als Kiew und Smolensk.« (Ranke I824: 39; vgl. Schulin I958: I60) Nietzsche sprach von Russland als »jenem ungeheuren Zwischenreiche, wo Europa gleichsam nach Asien zurückfließt.« (Nietzsche I988: 139) Andere prognostizierten ein furchtbares Erwachen des russischen Riesen und sahen Europa als seine zukünftige Beute.

Der russische Historiker und Geograph Wassilij Tatischtschew soll im I8. Jahrhundert den Ural als Grenze Europas vorgeschlagen haben. Er wollte damit das Stereotyp entkräften, nach dem der Moskauer Staat und seine Erben zu Asien gehörten. Der Vorschlag hat sich in vielen Darstellungen durchgesetzt. Doch im I9. und 20. Jahrhundert haben russische Intellektuelle lange darüber gestritten, ob ihr Land zu Europa gehört oder nicht. Jene großen Teile der russischen Oberschicht, die sich fest an Europa orientierten, flüchteten nach der Oktoberrevolution häufig aus dem Land. Dass unter den Bolschewisten die Hauptstadt nach Moskau zurückverlegt wurde, konnte als Distanzierung von Europa verstanden werden, und bisweilen wurde entsprechend der sowjetische Stalinismus polemisch als >asiatischer Despotie interpretiert. Erst seit dem Ende der Sowjetunion wird der europäische Charakter Russlands wieder stärker betont.

\section{Differenz, Verflechtung und das Problem der Grenzen}

Ich fasse meine Ausführungen in vier Punkten zusammen und beziehe sie auf die gegenwärtige Situation und Diskussion über die europäische Integration.

I. Es ist auffällig, wie wichtig Kriege für die Herausbildung eines europäischen Selbstverständnisses und für europäische Einigungsbestrebungen gewesen sind - von den Perserkriegen 
über den Zweiten Weltkrieg bis hin zum Kalten Krieg. Es handelt sich dabei erstens um Kriege an den europäischen Rändern, in denen über die Jahrhunderte hinweg die Auseinandersetzung mit islamischen Mächten im Vordergrund stand. Es handelt sich aber zweitens und vor allem um die zahlreichen innereuropäischen Kriege, auf die im Gegenzug die europäischen Einigungsbestrebungen jeweils antworteten. Kein Zweifel: Europa ist bis vor kurzem ein ausgesprochen kriegerischer Kontinent gewesen.

Aber nicht nur durch Kämpfe und Absetzung von anderen veränderte sich Europa, sondern auch durch Verflechtung. Europa nahm vieles von anderen in sich auf: durch Ausbeutung und Raub, durch Lernen und Anverwandlung, durch Tausch und Transfer, Migrationen und Reisen - vom südamerikanischen Silber und von der indischen Baumwolle über den Kompass, das Schießpulver und das Porzellan aus China bis zu den Bildern, Moden und Träumen aus Kulturen, die als fremd wahrgenommen und als exotisch imaginiert wurden, mit tiefen Einflüssen auf europäische Musik, Literatur, Architektur und Kunst. Europas Neugier war unersättlich, Europas Habgier auch. Europas schier unbegrenzte Aufnahmefähigkeit gehörte zu seinen größten Stärken.

2. Auf Kriege wird die weitere Einigung Europas hoffentlich verzichten können, auf die Differenz und die Bestimmung der Differenz aber sicherlich nicht. Europa-Bewusstsein kann sich nur im Selbstvergleich mit anderen herausbilden, das heißt durch Betonung der Unterschiede zwischen Europa und den nichteuropäischen Teilen der Welt.

Mit Hartmut Kaelble lassen sich dabei verschiedene Typen der Argumentation unterscheiden: Zum einen die Behauptung vom überlegenen Europa, die im I9. und frühen 20. Jahrhundert verbreiteter war als heute und vor allem von der Unterlegenheit 
Asiens und Afrikas überzeugt war. Zum anderen die Rede vom bedrohten Europa, das sich durch die Überlegenheit eines anderen herausgefordert und in Frage gestellt sah. Im I9. und 20. Jahrhundert betraf das vor allem die technische, wissenschaftliche und kommerzielle Übermacht Amerikas. Drittens und besonders interessant ist die These von Europa als dem Ausgangspunkt universaler Modernisierung. Hier wurde Europa als die Region angesehen, von der die Menschenrechte, die moderne Wissenschaft, der moderne Staat und manche andere neuzeitliche Errungenschaft, die mittlerweile weltweite Geltung beanspruchen, ausgegangen sind. Diese Art europäischen Selbstvergleichs muss nicht unbedingt in Überheblichkeit enden, sondern war und ist mit europäischer Selbstkritik durchaus verbindbar. (Vgl. Kaelble 200I: 25-39)

Für die Bildung und Stärkung europäischen Bewusstseins ist der Selbstvergleich jedenfalls zentral. Man muss allerdings dafür sorgen, dass er ohne Stereotype und Feindbilder auskommt. Aber mit wem soll oder will Europa sich vergleichen? Zwei Referenzregionen sind dafür früher wie heute zentral: die islamische Welt und das nördliche Amerika. Die ausgeprägte Differenz zwischen Europa und der islamischen Welt ist nach wie vor nicht zu leugnen und durch Wegsehen nicht aus der Welt zu schaffen. Die Differenz zu Amerika ist subtiler. Zwar besteht in Bezug auf die grundsätzlichen Werte Übereinstimmung, und die enge Partnerschaft mit den USA hat lange die politische Integration Europas gefördert und ermöglicht. Ohne sie wird die weitere Integration schwierig sein. Aber zur Befestigung europäischer Identität und gesamteuropäischer Handlungsfähigkeit ist zugleich die Unterscheidung von Amerika wichtig.

An relevanten amerikanisch-europäischen Unterschieden fehlt es nicht. Europa hat auf dem Weg zu seiner Einheit mit erheblich mehr eingeschliffener und institutionalisierter Vielfalt von Nationen und Traditionen zurechtzukommen. Die europäi- 
sche Einigung ist überdies stark durch die Erfahrung vorangehender Katastrophen geprägt. Sie ist der Versuch, aus diesen Katastrophen zu lernen. Ferner wird das Verhältnis von individueller Freiheit und Solidarität, von Konkurrenz und Wohlfahrt in Europa anders bestimmt als in den USA. Durch den Sozialstaat unterscheiden wir uns von den Amerikanern. Die gegenwärtige Krise des Sozialstaats gefährdet nicht nur Wachstum und Wohlstand, sondern auch das sich mühsam herausbildende europäische Selbstbewusstsein. Umso dringlicher ist die Reform.

3. Europa war und ist ein Konstrukt. »Europa, wo liegst du?« Die Antwort lautet: vor allem in unseren Köpfen. In der Beschreibung Europas mischten und vermischen sich fast immer Befunde mit Absichten, Bestandsaufnahmen mit Entwürfen. Auch deshalb wechseln sie je nach Standort und verändern sich mit der Zeit.

Europa ist ein Konstrukt - das gilt erst recht für die Argumente, mit denen die Gemeinsamkeit Europas begründet und seine Grenzen definiert werden. Wirksam waren und sind vor allem zwei Argumente. Erstens das Argument der gemeinsamen Kultur: Religion, Geschichte, Sitte, Recht, politische Kultur und übereinstimmende Werte gelten zu Recht als verbindende Elemente. Dabei dürfen allerdings die zahlreichen und tiefgreifenden kulturellen Unterschiede innerhalb Europas nicht übersehen werden. Diese Vielfalt ist kein Widerspruch zur Einheit Europa, sondern bezeichnet eine ihrer Qualitäten. Zweitens das Argument der Verbindung durch Kommunikation: Der Austausch zwischen Herrschenden, Wissenschaftlern, Künstlern und Gebildeten, aber auch das Wandern der Handwerksgesellen, der Verkehr zwischen den Kaufleuten und der öffentliche Austausch der politischen Argumente waren für Europa charakteristisch. Mit unterschiedlicher, aber insgesamt zunehmender Dichte ha- 
ben diese Kommunikationen die Teile Europas miteinander verbunden.

So tragfähig diese Argumente sind, wenn man den inneren Zusammenhang Europas begründen will - zu einer scharfen Grenzziehung, vor allem im Osten Europas, führen sie nicht. Im Laufe der Jahrhunderte hat die Bestimmung der Grenzen erheblich variiert. Dabei spielten politische Einschätzungen, Bündnisse und Gegensätze immer eine große Rolle. Die Türkei wurde allerdings nur in Ausnahmefällen als Teil Europas angesehen.

4. Die Autoren des Entwurfs einer Verfassung für Europa können sich also nicht auf einen allgemein geteilten, ein für allemal festliegenden Begriff >europäisch < beziehen. Letztlich müssen sie die Grenzen selber bestimmen. Die Grenzen werden das Produkt einer politischen Entscheidung sein, allerdings unter Beachtung der realen Verhältnisse und orientiert an plausiblen Kriterien. Wie kann, wie sollte man argumentieren?

Wichtig ist erstens der Bezug auf die Werte der Europäischen Union. Der Verfassungsentwurf zählt sie auf: Menschenwürde, Freiheit, Demokratie, Gleichheit, Rechtsstaatlichkeit und die Wahrung der Menschenrechte. Nur wer sie teilt, gehört zu Europa. Das Argument leuchtet ein; es steht in der Tradition der Aufklärung, in der sich die Vorstellung von Europa vor allem formte.

Aber die genannten Werte sind universalistischer Art. Sie gelten nicht nur für Europa, sondern auch in anderen Teilen der Welt. Deshalb folgen aus ihnen Abgrenzungen nur hic et nunc, nicht aber auf Dauer und prinzipiell. Auf sie gestützt kann man nur sagen, was man ja auch in den gegenwärtigen Verhandlungen über den Beitritt neuer Mitglieder tatsächlich oft sagt: Dieses oder jenes Land erfüllt die Voraussetzungen der Zugehörigkeit derzeit nicht. Und die so beurteilten Ländern antworten: noch 
nicht - und versprechen Abhilfe. Mit anderen Worten: Nach diesem Kriterium könnte Europa ständig wachsen und immer größere Teile der Welt umfassen, sofern sie nur ihre Verhältnisse und Verhaltensweisen an jenen Werten ausrichten. So sehr das politisch zu wünschen wäre, so ungute Konsequenzen hätte dies für die Gestalt Europas, das dann prinzipiell grenzenlos wäre. Das Kriterium >Wertebezug < reicht nicht aus, wenn man räumliche Grenzziehungen begründen will.

Es muss deshalb in der Praxis ein zweites Kriterium berücksichtigt werden: das Kriterium >demokratische Handlungsfähigkeit<. Damit ein politisches Gebilde handlungsfähig und zugleich demokratisch ist, braucht es einen Fundus von innerer Kommunikation und von Gemeinsamkeit in relevanten Hinsichten, das heißt, es darf nicht zu heterogen und unbalanciert sein. Manche sprechen von Vertrauen, das zwischen denen vorhanden sein muss, die im Gemeinwesen handeln; andere vom sozialen Kapital, wieder andere von politischer Kultur. Welchen Begriff man auch favorisiert, sie alle gehen über den Bezug auf universale Werte deutlich hinaus und haben viel mit gemeinsamer Kultur und gemeinsamer Geschichte zu tun. Wenn das auf dem Weg der europäischen Integration nicht beachtet wird, übernimmt man sich. Es würde dann ein Gebilde ohne hinreichenden inneren Zusammenhang und ausreichende Handlungsfähigkeit entstehen, das alsbald zerfiele. Allenfalls entstünde eine Freihandelszone oder ein Bündnis, aber keine Union. Und manche plädieren gegenwärtig wohl auch deswegen für rasche Erweiterung, weil sie keine weitere Vertiefung wollen. Mir dagegen erscheint es dringend erforderlich, dass auf die Phase der Expansion eine Phase der Konsolidierung folgt, wenn man denn wirklich eine Union, ein politisch handlungsfähiges Gebilde will, das eine Verfassung verdient und benötigt.

Der Verfassungsentwurf präjudiziert die zukünftige Entwicklung nicht. Er verzichtet richtigerweise darauf, sich auf eine ein 
für allemal feststehende Grenze festzulegen und sie essentialistisch zu definieren. Er sieht stattdessen die Möglichkeit späterer Eintritte und Austritte vor. Die Hürden dafür liegen freilich hoch, besonders für jede spätere Erweiterung. Nach Artikel I-57 des Entwurfs erfordert sie den einstimmigen Beschluss des Europäischen Rates, die Zustimmung des Europäischen Parlaments und die »Ratifikation durch alle Vertragsstaaten gemäß ihren verfassungsrechtlichen Vorschriften«. Und nur »europäische Staaten« können den Antrag auf Aufnahme stellen. Was >europäisch< heißt, wird allerdings nicht weiter spezifiziert, sodass im Prinzip politischer Spielraum offen bleibt. Im Interesse demokratischer Handlungsfähigkeit ist jedoch eine restriktive Auslegung dringend zu empfehlen. Die EU übernähme sich jetzt und auf absehbare Zeit, wenn sie Länder wie die Türkei und Russland voll einbezöge.

\section{Grenzziehung abgestuft}

Es geht nicht nur darum, wo die Grenzen zu ziehen sind, sondern auch darum, wie sie gestaltet werden. Europa hat immer von seiner Weltoffenheit gelebt; es darf und wird sich auch zukünftig nicht abschotten, es darf und wird keine Festung werden. Entsprechend werden die einschlägigen Politikbereiche zu gestalten sein, die Zoll- und Außenwirtschaftspolitik, die Einwanderungspolitik, die Außen- und erst recht die Militärpolitik, denn Europa muss auch außerhalb seiner Grenzen militärisch handeln können. All dies kann hier nicht ausgeführt werden.

Sehr zu begrüßen ist, dass Artikel I-56 des Verfassungsentwurfs Bestimmungen für möglich erklärt, »die besondere Beziehungen zu den Staaten in der Nachbarschaft« festlegen und besonders enge Zusammenarbeit vorsehen. (Europäischer Konvent 2003: Art. I-56) Wie die besonderen Beziehungen zu den 
Nachbarstaaten zu gestalten sind, ist im Einzelfall auszuhandeln und zu entscheiden. Es wäre gut gewesen, ausdrücklich die Möglichkeit zu eröffnen, dass Abgeordnete der Nachbarländer im Europäischen Parlament Gastrecht erhalten und umgekehrt. Denn was in Europa beschlossen wird, wirkt sich oft auf die Nachbarn aus, und das gilt auch in umgekehrter Richtung. Die Entwicklung besonderer Beziehungen $\mathrm{zu}$ den Nachbarn, die dadurch der Union assoziiert werden, kann die Ablehnung ihrer vollen Mitgliedschaft in ihren psychologischen Wirkungen entschärfen und ihren Druck auf Beitritt mindern.

Einer solchen Abstufung des Außenverhältnisses sollten Abstufungen im Innern der Union entsprechen. Dass die Integration Europas, je nach Fähigkeit und Neigung der einzelnen Mitglieder, eine Integration mit unterschiedlichen Geschwindigkeiten werden muss und nicht homogen im Gleichschritt erfolgen kann, ist seit dem Lamers-Schäuble-Papier von 1994 im Grunde klar und teilweise bereits Realität. Je weiter sich die Union ausdehnt, desto heterogener wird sie im Innern sein und desto größer ist die Notwendigkeit, jeweils einzelnen Gruppen von Mitgliedsländern die Möglichkeit zu bieten, in bestimmten Politikbereichen - beispielsweise der Geld-, der Militär- oder der Sozialpolitik - enger miteinander zu kooperieren als mit den anderen Mitgliedsstaaten. Entsprechende Instrumente sehen die EU-Verträge längst vor, der jetzige Verfassungsentwurf erkennt sie an (ebd.: Art. I-43), und sie sollten in Zukunft ausgebaut werden. Sonst droht in der größer und heterogener werdenden Union aufgrund gegenseitiger Blockade die Gefahr politischer Unbeweglichkeit. Sieht man die variablen Abstufungen im Innern und im Außenverhältnis zusammen, dann ergibt sich daraus, dass die Unterscheidung zwischen innen und außen keine schroffe Entgegensetzung mehr darstellt. Eine Gradualisierung der Grenze ist die Folge, eine Grenzziehung neuer Art, in der Differenz und Verflechtung zusammengehören. 


\section{Literatur}

Böhlke, Effi (2002): »Russlandbilder aus dem I8. und I9. Jahrhundert. Entworfen in der deutschen und französischen politisch-philosophischen Literatur«, in: Osteuropa 5, S. 576-597.

Cardini, Franco (2000): Europa und der Islam. Geschichte eines Missverständnisses, München.

Cerutti, Furio/Rudolph, Enno (Hg.) (200I): A Soul for Europe, Leuven [u.a.].

Condorcet (1963): Entwurf einer historischen Darstellung der Fortschritte des menschlichen Geistes, Frankfurt a.M.

Delvaux, Peter/Papiór, Jan (Hg.) (I996): Eurovisionen. Vorstellungen von Europa in Literatur und Philosophie, Amsterdam.

Dunkerley, David et al. (2002): Changing Europe. Identities, Nations, and Citizens, London [u.a.].

Europäischer Konvent (2003): Vertrag über eine Verfassung für Europa (Entwurf), vom Europäischen Konvent im Konsensverfahren angenommen am I3. Juni und Io. Juli 2003, CONV $850 / 03$.

Faber, Richard (2002): Abendland. Ein politischer Kampfbegriff, Berlin.

Frevert, Ute (2003): Eurovisionen. Ansichten guter Europäer im 19. und 20. Jahrhundert, Frankfurt a.M.

Goethe, Johann Wolfgang (1950): Briefwechsel mit Friedrich Schiller, Zürich.

Hegel, Georg Wilhelm Friedrich (1992): Vorlesungen über die Philosophie der Geschichte, Frankfurt a.M.

Hobsbawm, Eric J.: »Welchen Sinn hat Europa?«, in: Die Zeit vom 4.Io.1996.

Kaelble, Hartmut (200I): Europäer über Europa. Die Entstehung des europäischen Selbstverständnisses im 19. und 20. Jahrhundert, Frankfurt a.M. [u.a.]. 
Kocka, Jürgen (2002): »Wo liegst du, Europa? Die Identität des Kontinents ist nicht eindeutig«, in: Die Zeit vom 28.II.2002.

Lützeler, Paul Michael (1997): Europäische Identität und Multikultur. Fallstudien zur deutschsprachigen Literatur seit der Romantik, Tübingen.

Hamilton, Alexander/Madison, James/Jay, John (I993): Die Federalist Papers, Darmstadt.

Mitterauer, Michael (2003): Warum Europa? Mittelalterliche Grundlagen eines Sonderwegs, München.

Mokre, Monika (Hg.) (2003): Europas Identitäten. Mythen, Konflikte, Konstruktionen, Frankfurt a.M./New York.

Montesquieu, Charles de (I988): Perserbriefe, Frankfurt a.M.

Nederveen Pieterse, Jan (I994): »Unpacking the West: How European is Europe?«, in: Ali Rattansi/Sallie Westwood (Hg.): Racism, Modernity and Identity. On the Western Front, Cambridge, S. I29-I49.

Nietzsche, Friedrich (1988): Jenseits von Gut und Böse. Zur Genealogie der Moral, München.

Osterhammel, Jürgen (1998): Die Entzauberung Asiens. Europa und die asiatischen Reiche im 18. Jahrhundert, München.

Plessen, Marie-Luise von (Hg.) (2003): Idee Europa. Entwürfe zum »Ewigen Frieden«. Ordnungen und Utopien für die Gestaltung Europas von der pax romana zur Europäischen Union. Eine Ausstellung als historische Topographie, Berlin.

Ranke, Leopold von (I824): Geschichten der romanischen und germanischen Völker von 1494-1514, Leipzig.

Ranke, Leopold von (1879): Serbien und die Türkei im I9. Jhd., in: Ders. (1879): Gesammelte Werke, Bd. 43/44, Leipzig.

Requate, Jörg/Schulze-Wessel, Martin (Hg.) (2002): Europäische Öffentlichkeit. Transnationale Kommunikation seit dem 18. Jahrhundert, Frankfurt a.M.

Rougemont, Denis de (1962): Europa. Vom Mythos zur Wirklichkeit, München. 
Schmidt-Gernig, Alexander (Hg.) (1999): Amerika erfahren, Europa entdecken. Zum Vergleich der Gesellschaften in europäischen Reiseberichten des 20. Jahrhunderts, Berlin.

Schulin, Ernst (1958): Die weltgeschichtliche Erfassung des Orients bei Hegel und Ranke, Göttingen.

Seton-Watson, Hugh (1985): »What is Europe, Where is Europe? «, in: Encounter $6_{5}$ (2), S. 9-I7.

Viehoff, Reinhold/Segers, Rien T. (Hg.) (I999): Kultur, Identität, Europa. Über die Schwierigkeiten und Möglichkeiten einer Konstruktion, Frankfurt a.M.

Walkenhorst, Heiko (I999): Europäischer Integrationsprozess und europäische Identität. Zur politikwissenschaftlichen Bedeutung eines sozialpsychologischen Konzepts, Baden-Baden.

Weißhaupt, Winfried (1979): Europa sieht sich mit fremdem Blick. Werke nach dem Schema »Lettres persanes« in der europäischen, insbesondere der deutschen Literatur des 18. Jahrhunderts, Frankfurt a.M. 



\section{Die Europäische Verfassung als "demokratisches Projekt"}

EMANUEL RichteR

Die europäische Einigung steht vor einer neuerlichen Reform von historischer Tragweite: Am I8. Juli 2003 hat der Präsident des Europäischen Konvents, Valéry Giscard d'Estaing, dem amtierenden Ratspräsidenten der Europäischen Union in Rom den Entwurf einer europäischen Verfassung überreicht. Kurz nach der Einführung des Euro und der Erweiterung der Europäischen Union um zehn Mitgliedstaaten vollzieht sich damit in rascher Folge ein weiterer, wegweisender Entwicklungsschub für die supranationale Integration, dieses Mal versehen mit dem Nimbus einer vollendeten politischen Formgebung für die Europäische Union. Jene Stufen der Koordination und Kooperation, die bescheiden auf den Trümmern der europäischen Nachkriegsphase in Europa begonnen hatten und sich mittlerweile auf einen Zeitraum von mehr als fünfzig Jahren intensiver Integrationsbemühungen erstrecken, kulminieren in einer eigenständigen Verfassung für das supranationale Gebilde. 
Haben sich damit die Homogenitätssehnsüchte und Finalitätsvisionen erfüllt, die die europäische Einigungsgeschichte durchgängig begleiten? Besteht Anlass, das Ende des Nationalstaats zu konstatieren, jener Zielvorstellung, die schon dem supranationalen Integrationsbeginn zu Grunde lag? Erhalten wir eine politische Ordnung auf europäischer Ebene, die den nationalstaatlichen Institutionenstrukturen und Identitätsressourcen ebenbürtig ist? Immerhin wird die Europäische Union durch ihre >Verfassung nicht mehr nur als wirtschaftspolitischer Zweckverband konturiert, sondern nimmt auch die Gestalt eines rechtspolitischen Herrschaftsverbandes an. Sie rückt also zumindest deklamatorisch in die größtmögliche Nähe eines Äquivalents zur Nationalstaatlichkeit.

Angesichts dieses Reformschubs in die Richtung der Staatsähnlichkeit erwartet man daher zumindest von Seiten der Mitglieder des Europäischen Konvents als den Systemkonstrukteuren einigungspolitische Euphorie und geschichtsmächtige Überschwänglichkeit. Aber im Vergleich zur immer wieder öffentlich lancierten Rhetorik der Jubeleuropäer kommt dieses Reformwerk eher auf leisen Sohlen daher. Das ist ein Indiz dafür, dass uns doch keine epochale Zäsur bevorsteht, die das Ende der Nationalstaatlichkeit einläutet und eine europäische Integrationsdichte hervorbringt, die uns alle zu einer europäischen Identitätsgemeinschaft zusammenschweißt. Die vergleichsweise verhaltenen Reaktionen zeigen einen heilsamen Reflex auf die zahlreichen Enttäuschungserfahrungen an, die mit hochtrabenden Einigungsplänen und deren kläglichem Scheitern aufgrund der Unterschätzung historischer, prägender Ordnungsprinzipien - wie dem Prinzip nationalstaatlicher politischer Selbstorganisation einhergingen. Vor allem aber ist die auffällige Nüchternheit rund um den Verfassungsentwurf ein Spiegel der konzeptionellen Bescheidenheit, die er inhaltlich zum Ausdruck bringt. Man hat in der rechtspolitischen Substanz des Vertragswerks offenkundig 
Abstand gewonnen zu zwanghaften Einheitsvisionen und dem selbst gesetzten Diktat von ehrgeizigen Finalitätsvorgaben. Stattdessen findet man sich auf einer konzeptionell mittleren, aber realitätsgerechten Stufe supranationaler Bindungstiefe ein.

Nach eineinhalb Jahren kontroverser Beratungen und schwieriger Verhandlungen hat der Europäische Konvent zweifelsohne ein wegweisendes Dokument der europäischen Integration erstellt. Es repräsentiert aber nicht so sehr den großen Sprung hinsichtlich der europäischen Einigungsgeschichte und damit die spektakuläre Richtungsweisung zu den, seit dem I8. Jahrhundert erträumten, >Vereinigten Staaten von Europa<. Es gibt vielmehr authentisch die an ihre Grenzen stoßende Konturenschärfe der Europäischen Union als politischen Herrschaftsverband wieder, die das Prinzip der Nationalstaatlichkeit nicht zu ersetzen, sondern nur zu ergänzen vermag. Die Europäische Union bietet keinen Ersatz für die traditionalistischen Sehnsüchte nach politischer Einheit in der späten Folge des zerfallenen Römischen Reiches; sie wird auch keine Kopie des modernen föderalen Großstaates der Vereinigten Staaten von Amerika sein. Sie bleibt ein wirtschaftspolitischer Zweckverband, der nun durch die rechtspolitische Formgebung deutlicher denn je partielle Staatsqualitäten erlangt.

Wie steht es im Zuge dieses beachtlichen Reformschubs um das >demokratische Projekt< im Rahmen der Europäischen Union? Genügt die rechtspolitisch verfasste supranationale Integration noch jenen demokratischen Standards, die Europa jenseits aller nationalen Sonderwege als kollektive Errungenschaft hervorgebracht, verinnerlicht und fortentwickelt hat? Die Frage lässt sich nicht mit einem kurzen Blick auf die neuen formalen Strukturen beantworten. Mit einem supranationalen Konstitutionalismus vollzieht sich nicht automatisch die Aufhebung des viel beschworenen europäischen >Demokratiedefizits<. Es kommt also die tiefer greifende Frage auf, inwieweit die Europäische 
Union mit ihren neuen institutionellen Strukturen und politischen Entscheidungsprozessen jenen demokratischen Wertbeständen genügen kann, die auf der Basis europäischer Traditionsbestände zu Recht als Basisausstattung jeglicher legitimer Herrschaftsordnung gelten. Jetzt, wo sie nicht mehr nur das Instrumentarium einer effizienten Kooperation liefert, sondern auch als politischer Herrschaftsverband Gestalt gewinnen soll, stellt sich die Demokratiefrage nachhaltiger und konkreter denn je. Die europäische Einigung hat sich zwar auf einer mittleren Stufe der politischen Kohärenz eingefunden und kann deshalb auch nur begrenzte Möglichkeiten einer demokratischen Gestaltungsfähigkeit aufbieten. Aber selbst noch diese limitierte Regelungskompetenz untersteht normativ einem reichhaltigen demokratischen Anforderungskatalog. Es besteht aller Anlass, die europäische Verfassungsgebung mit konzeptioneller Aufmerksamkeit zu verfolgen und sie einer kritischen demokratietheoretischen Bestandsaufnahme zu unterziehen.

Ich will in einem ersten Kapitel daher die demokratischen Strukturmerkmale der Verfassung ins Auge fassen und den demokratischen Zugewinn bewerten, der durch die europäische Verfassung in ihrem vorliegenden Entwurf für die europäische Integration erzielt wird. Im zweiten Kapitel überschreite ich den Fokus der demokratietheoretischen Analyse im engeren Sinn, um auf die übergreifende Fragestellung der zukünftigen Rolle Europas einzugehen: Ich werde die im Verfassungsentwurf mehr oder weniger deutlichen Positionsbestimmungen hinsichtlich des neuen Europas als weltpolitischen Mitspieler resümieren und bewerten - durchaus auch unter den Gesichtspunkten einer Verwirklichung von Demokratie für einen Akteur auf der Bühne der Weltpolitik. In einem Schlusswort fasse ich die Ergebnisse der demokratietheoretischen Bestandsaufnahme zusammen. 


\section{Die Demokratie im Entwurf einer Europäischen Verfassung}

Der Europäische Konvent hat einen in mehrfacher Hinsicht beachtlichen Entwurf einer europäischen Verfassung vorgelegt. Beachtlich ist er vor allem deshalb, weil er entgegen einer geradezu jahrhundertealten Tradition europäischer Einigungspläne nicht kühn den >großen Sprung< propagiert, der wegen seiner Überschätzung der Bereitschaft und Möglichkeiten zur Transformation nationalstaatlich dominierter Politik von vornherein zum Scheitern verurteilt wäre. Stattdessen propagiert er nüchtern kleine Schritte des Systemwandels, die bestenfalls auf mittlerer Stufe des Integrationsfortschritts anzusiedeln sind. Die Rahmenbedingungen einer Koexistenz von nationalstaatlicher Ordnung und supranationaler Integration werden zum ersten Mal in der Geschichte der europäischen Einigung konstitutionell anerkannt. Gleichzeitig bleibt aber in den Vorschlägen ein substanzieller Zugewinn an Demokratie zu verzeichnen. Diese Mischung aus politischem Realismus und idealistischer Politikgestaltung markiert schon eine konzeptionelle Leistung an sich. Ich will mich im Folgenden nur denjenigen Partien des - übrigens schon wieder viel zu umfangreich geratenen - Verfassungsentwurfs widmen, die sich im weiteren Sinne mit der Demokratie befassen. Dabei wähle ich eine Zweiteilung, die zunächst die demokratischen Elemente des Vertragswerks im Sinne des institutionellen Geflechts und der Gewaltenteilung aufgreift (г.), bevor die Elemente einer partizipativen Demokratie im engeren Sinne zur Sprache kommen (2.).

I. Die Verfassung weist eine deutlich markierte Zweiteilung auf: »Teil I« umfasst sämtliche grundlegenden Bestimmungen zu den Zielvorstellungen der Integration und zu den Institutionen und Funktionsweisen der Europäischen Union; »Teil II« 
umfasst die schon früher ausformulierte Charta der Grundrechte der Union. Die Ausführungen über die Grundrechte werden damit gegenüber den Funktionsmerkmalen der Union deutlich nachgeordnet, was einer möglichen Konkurrenz zu nationalen Verfassungen in Europa vorbeugen soll, die sämtlich in großem Umfang eigene Grundrechtsbestimmungen enthalten. Ich werde auf die Problematik spezifisch europäischer Grundrechte später noch einmal eingehen und widme mich zunächst den unter »Teil I« firmierenden Bestimmungen.

Überschrieben ist der Vertragsentwurf mit einem - sogar im griechischen Original wiedergegebenen - Zitat von Thukydides: »Die Verfassung, die wir haben [...] heißt Demokratie, weil der Staat nicht auf wenige Bürger, sondern auf die Mehrheit ausgerichtet ist«. Nun mag man darüber streiten, ob die Entgegensetzung von Aristokratie und Demokratie noch die demokratischen Strukturprobleme der Europäischen Union trifft. Aber ein Bekenntnis zur Antike als eine Berufung auf die europäischen Traditionsbestände der Demokratie hat doch eine konzeptionelle Signalwirkung: Es soll Ernst gemacht werden mit dem >Europa der Bürger<. Freilich hat der Europäische Konvent darauf geachtet, den Verfassungsentwurf nicht mit hochtrabenden Erwartungen hinsichtlich einer originären Erfüllung von Demokratie zu überfrachten. Demokratie in Europa heißt aus der Sicht des Europäischen Konvents: die Koexistenz von nationalstaatlich legitimierten und supranationalen politischen Institutionen und Verfahren. Die Europäische Union erlangt den Status der Staatsähnlichkeit, aber wird gegenüber weiterreichenden Integrationsvisionen auf die Koexistenz mit nationalstaatlichen Ordnungen festgeschrieben. Die Europäische Union erlangt >Rechtspersönlichkeit<, und es sollen Maßnahmen für »mehr Demokratie, Transparenz und Effizienz « getroffen werden - was die traditionellen Losungen einer Staatsordnung sind (Europäischer Konvent 2003: 2). Gleichzeitig mahnt der Europäische Konvent im 
Vorwort zum Vertragsentwurf zur »besseren Aufteilung der Zuständigkeiten der Union und der Mitgliedstaaten« und schlägt vor, dass »die nationalen Parlamente stärker an der Legitimierung des europäischen Projekts mitwirken« (ebd.: 2).

Europa soll laut Präambel »in Vielfalt geeint« sein - eine bedächtige Formulierung, an deren Stelle in bisherigen Dokumenten zur europäischen Einigung eher ehrgeizige integrationspolitische Finalitätsvisionen zu finden waren. Hier zeigt sich ein auffälliger Unterschied zum traditionellen europapolitischen Leitbild der Vereinigten Staaten von Amerika. Die entsprechende amerikanische Losung lautet: e pluribus unum - aus der Vielfalt die Einheit. Das deutet eine Dynamik an, die von der Vielstimmigkeit zur Einstimmigkeit hinführt. Die Europäer legen sich dagegen mit ihrer Formel wohlbegründet auf einen Fortbestand der Vielfalt fest und vermeiden die Hervorhebung jeglicher Dynamik, indem sie nicht mehr anbieten als eine leitmotivisch zugespitzte Lagebeschreibung.

Der erste Artikel des neuen Vertragswerks bringt die Spannung der verschiedenen Kompetenzkreise noch einmal deutlich zum Ausdruck: Die Europäische Union soll die Politik der Mitgliedstaaten »koordinieren«, sie soll aber auch »die ihr von den Mitgliedstaaten übertragenen Zuständigkeiten in gemeinschaftlicher Weise« ausüben (ebd.: 3). Es gibt eine abgeleitete Koordinationsfunktion, die unter der Hoheit von Nationalstaaten verbleibt, und es gibt eine genuine Herrschaftsfunktion unter den Prämissen der supranationalen Kompetenzzuteilung. Aber selbst die genuin supranationale Herrschaftsfunktion geht auf eine Zuteilungsformel unter der Kontrolle der Nationalstaaten zurück. Der Vertragsentwurf bekennt sich zur »begrenzten Einzelermächtigung « der Europäischen Union, also zur Einschränkung der Regelungskompetenz auf jene Zuständigkeiten, die ihr »von den Mitgliedstaaten in der Verfassung zur Verwirklichung der in ihr niedergelegten Ziele zugewiesen werden« (Art. I-9). 
Zum ersten Mal sieht ein Reformprojekt der Europäischen Union offiziell die »abgestufte Integration« vor: In Art. I-43 wird die »verstärkte Zusammenarbeit« spezifiziert, nämlich der Fall einer Bereitschaft zur Kooperation und Koordination unter einem kleinen Kreis von Mitgliedstaaten auf dem Gebiet der »nicht ausschließlichen Zuständigkeiten der Union«. Mit anderen Worten: Wenn die Union handeln kann, aber nicht muss, zugleich aber einige Mitgliedstaaten auf supranationale Regelungen drängen, können sie nun offiziell als kleine Gruppe von Entschlossenen im Rahmen des gesamten Mitgliederkreises voranschreiten. Die »abgestufte Integration « bedeutet noch nicht den Schritt zur »differenzierten Integration«, die nicht mehr auf die allmähliche Anpassung aller an den von einigen integrationsfreudigen Staaten schon vorweggenommenen Standard gerichtet ist, sondern unterschiedliche Integrationsniveaus als Dauerzustand festschreibt.

Die Sprengkraft der Differenzierung in Richtung einer zusammenhanglosen Diversifikation, die als status quo ante $\mathrm{zu}$ werten wäre, lässt sich nur abwenden, wenn »abgestufte Integration« ein vorübergehendes Integrationsniveau kennzeichnet, das durch >Sogwirkung< außenstehende Mitgliedstaaten zur Anschlussfähigkeit treibt. Darauf hoffen Jacques Derrida und Jürgen Habermas in einem geradezu verzweifelten Appell, der im Voranschreiten einiger integrationswilliger Staaten die einzige Chance ausfindig macht, Europa vor dem Auseinanderfallen bewahren zu können und es stattdessen allmählich zum dringend erforderlichen Widerpart der Hegemonialmacht USA zu erheben. Sie sind sich der gefährlichen Gratwanderung zwischen Vorreiterfunktion und ausgrenzender Dynamik bewusst: »Vorangehen heißt nicht ausschließen. Das avantgardistische Kerneuropa darf sich nicht $\mathrm{zu}$ einem Kleineuropa verfestigen; es muss - wie so oft - die Lokomotive sein.« (Derrida/Habermas 2003). 
Das supranationale Gegenstück zur »abgestuften Integration« bildet eine »Flexibilitätsklausel« (Art. I-I7), die auf der Grundlage eines einstimmigen Beschlusses im Ministerrat vorsieht, Befugnisse an die supranationalen Institutionen zu delegieren, wenn sie ein Verfassungsziel verwirklichen sollen, für die das neue Vertragswerk noch keine Rechtsgrundlage bietet. Diese Form der Flexibilität ist die größtmögliche subsidiäre Offenheit, die ein mehrstufiges Herrschaftssystem bieten kann.

Ist der Union allerdings eine Regelungshoheit erteilt worden, dann hat das damit gesetzte Recht Vorrang vor dem nationalen (Art. I-Io). In auffälliger Analogie zum deutschen Grundgesetz zählt der Vertragsentwurf enumerativ »ausschließliche« und »geteilte« Zuständigkeiten der Regelungskompetenz auf - ein Versuch der kontrastiven Konturierung der unterschiedlichen Herrschaftskreise.

Mittlerweile ist also das Subsidiaritäts-Prinzip authentischer in den Vertragstext eingeflossen, denn in den ersten Vertragsentwürfen war noch die Lagebeurteilung »von oben« ausschlaggebend dafür, in welchem Ausmaß die Zuteilung von Kompetenzen »nach unten« erfolgen soll (Richter 2003: 29). Es geht im Subsidiaritätsprinzip jedoch nicht um die Legitimation einer hoheitlichen »Kompetenzzuteilung«, sondern um eine von unten her ansetzende »Kompetenzöffnung« (Waschkuhn 1995). Nun hat sich im vorliegenden Vertragsentwurf die Zuteilungshoheit folgerichtig umgekehrt, denn zum Maßstab der Zuständigkeiten avancieren die Mitgliedstaaten einschließlich ihrer »regionalen oder lokalen Ebenen«. Hinzu kommt der bemerkenswerte Satz: »Die nationalen Parlamente achten auf die Einhaltung des Subsidiaritätsprinzips nach dem in diesem Protokoll vorgesehenen Verfahren« (Art. I-9: 8). Die Kontrolle über die authentische Einhaltung des Subsidiaritätsprinzips, das der bisherigen rechtspolitischen Konstruktion der Europäischen Union trotz wörtlicher Erwähnung merkwürdig entrückt oder missver- 
ständlich geblieben ist, wird nun konsequent im Sinne der Strategie des bottom up demokratisiert. Die unmittelbaren Repräsentanten aller Bürger in den Mitgliedstaaten wachen über eine $\mathrm{Zu}$ teilungsformel von Herrschaftskompetenz, in der die nationale Bezugsebene zwar selbst schon die mittlere Stufe der Machthierarchie darstellt, weil sie über der lokalen und regionalen Ebene steht, aber immerhin die machtvollste Stufe unterhalb der supranationalen Herrschaftskompetenz repräsentiert.

Die institutionelle Struktur der Europäischen Union bleibt weitgehend erhalten, aber es findet eine beachtliche Positionsstärkung des Europäischen Parlaments gegenüber der Kommission und mittelbar auch gegenüber dem Ministerrat statt, die in Richtung einer besser balancierten Gewaltenteilung zielt. Gleichwohl bleibt die Legislativgewalt durch die unmittelbare Einflussnahme von Ministerräten und Kommission nach wie vor in zu geringem Maße an direkt gewählte Volksvertreter gebunden. Das Parlament wählt jetzt aber immerhin den Präsidenten der Kommission - eine Analogie zur Einsetzung der Exekutive in parlamentarischen Regierungssystemen. Getrübt wird diese Analogie freilich durch eine Einschränkung im Bereich des Vorschlagsrechts: Das Europäische Parlament kann nur solche Kandidaten wählen, die vom Europäischen Rat vorgeschlagen worden sind (Art. I-26). Der Präsident der Kommission >benennt< seine Kommissare aus einer Vorschlagsliste der Mitgliedstaaten. Das gesamte >Paket an Amtsträgern - der Präsident der Kommission, alle Kommissare und der »Außenminister « der Europäischen Union - »stellen sich gemeinsam dem Zustimmungsvotum des Europäischen Parlaments« (Art. I-26). Diese Paketlösung stellt ein demokratisch bedenkliches Druckmittel dar, weil es das Europäische Parlament in die Alternative drängt, entweder alle zu bestätigen und damit die zügige Arbeitsaufnahme zu ermöglichen, oder alle zurückzuweisen und damit den 
gesamten Apparat zu lähmen, obwohl vielleicht nur einige wenige Personen Bedenken hinsichtlich ihrer Wahl aufwerfen. Am Ende bleibt nur das Mittel des nachträglichen Keulenschlags: Das Europäische Parlament hat weiterhin das Recht eines Misstrauensantrags gegen die Kommission insgesamt, was bei Annahme immerhin die erzwungene Amtsniederlegung aller Kommissare zur Folge hat.

Der Europäische Rat entscheidet durch Konsens - eine begrifflich kluge Formel für ein Abstimmungsverfahren und für deliberative Diskurse, denn >Konsens < bedeutet weder den Zwang zur Einstimmigkeit, noch eine formalisierte Mehrheitsregel, aber auch nicht eine völlige Übereinstimmung, sondern eben nur die nicht formalisierte Zustimmungsfähigkeit - gegebenenfalls wider die eigene Überzeugung, aber im Interesse der Handlungsbereitschaft aller. Das weist eine gewisse Nähe zur >Konkordanzdemokratie< auf, also zu einer Entscheidungsfindung unter konsensueller Zustimmungsbereitschaft möglichst großer Kreise von Verhandlungspartnern. Im Ministerrat sind dagegen allerhand Raffinessen der Mehrheitsregel zur Anwendung gekommen. Wie Art. I-24 bestimmt, bleibt die »qualifizierte Mehrheit«, die auf Stimmengewichtung je nach Mitgliedstaat beruht, zugleich an die Mehrheit der Mitgliedstaaten und an eine hinreichende Repräsentanz der Bevölkerungsmehrheit gebunden. Erstaunlich erscheint übrigens auch, dass der Europäische Rat laut Art. I-24 die erforderlichen Mehrheitsverhältnisse im Ministerrat durch einstimmige Beschlüsse ändern kann. Beschlüsse über die Änderung von Mehrheitsverhältnissen gehören unter demokratischen Gesichtspunkten der Gewaltenteilung in die Hand von parlamentarischen Institutionen, die als Legislativgremium in einer solch heiklen Angelegenheit wie der Verfahrensordnung für Abstimmungsprozeduren am unmittelbarsten den Willen der Souveräne zum Ausdruck zu bringen vermögen. 
Wenn die Exekutive völlige Autonomie über ihre Verfahrensordnung besitzt, fehlt ein wichtiges Element der demokratischen Kontrolle.

Eine bedenkliche institutionelle Konstruktion stellen die Ämter des »Präsidenten des Europäischen Rats« (Art. I-2I) und des »Außenministers der Europäischen Union« (Art. I-27) dar lässt man es nicht mit dem abwertenden Befund bewenden, dass es sich lediglich um eine aufgeblasene Nomenklatur handelt, mit der politisch bedeutungslose Repräsentativämter begrifflich hervorgehoben werden sollen. Falls es sich nur um eine Art >Geschäftsführer < der Europäischen Union handelte, der den bisher rotierenden Ratsvorsitz personell bündelt und durch die längere Amtszeit effektiver gestaltet, bliebe gegen die Konstruktion nichts einzuwenden. Wenn der neue Präsident aber als politischer Funktionsträger in Erscheinung tritt und, wie es Art. I-2I formuliert, die »Außenvertretung der Union in Angelegenheiten der Gemeinsamen Außen- und Sicherheitspolitik « wahrnimmt, dann ist damit eine Machtzuteilung in ehemals genuin nationalstaatlichen Hoheitsbereichen angezeigt, die in Analogie zu einem parlamentarischen Regierungssystem eigentlich einem vom Parlament gewählten >Premier< zukommen müsste. Die Suggestion einer >Staatsqualität< der Europäischen Union durch einen gemeinsamen Repräsentanten nach außen ist in Hinblick auf die demokratische Legitimation der Exekutive kontraproduktiv, denn durch eine Wahl im Europäischen Rat mit »qualifizierter Mehrheit« wird das Amt eines Superstaatschefs konstruiert, dessen Bezeichnung den Anschein eines genuinen Elements im Rahmen eines präsidentiellen Regierungssystems erweckt. Mit den jetzt vorliegenden Verfassungsbestimmungen wird jedoch eine schiefe Staatsqualität suggeriert, die den Bürger als demokratisch aufmerksamen Souverän gewissermaßen für dumm verkauft. Es handelt sich um einen pseudo-repräsentativen Etikettenschwindel. 
Noch bedenklicher ist das Amt eines »Außenministers« ein hochrangiger Ministerposten in den Kategorien der souveränen Territorialstaaten, aber ohne Regierungschef und ohne Kabinett? Er wird vom Europäischen Rat mit »qualifizierter Mehrheit« gewählt und trägt mit seinen Vorschlägen zur »Festlegung« der gemeinsamen Außenpolitik sowie der Sicherheits- und Verteidigungspolitik bei (Art. I-27). An späterer Stelle heißt es noch präziser und damit in gewissem Widerspruch zu diesen Formulierungen, dass die Gemeinsame Außen- und Sicherheitspolitik »vom Außenminister der Union und von den Mitgliedstaaten mit den einzelstaatlichen Mitteln und denen der Union durchgeführt« wird (Art. I-39). Zugleich ist der »Außenminister« Vizepräsident der Kommission. Hinter dieser Konstruktion kann man mit etwas Argwohn eine Perfidie des Europäischen Rats gegenüber der Kommission erkennen, denn der Europäische Rat behält nicht nur die personelle Auswahl in seiner Hand, sondern mit ihm hat auch die Abstimmung der politischen Leitlinien des Außenministers zu erfolgen. Zugleich redet der Außenminister an vorderster Front in der Kommission mit. Die vom einzelnen Bürger am weitesten entfernten Organe werden der Leitungsfunktion durch eine ausschließlich von den Staats- und Regierungschefs rekrutierte Person unterstellt - eine demokratische Provokation! Ist nicht eine >Entpersonalisierung < der Politik der erforderliche Reflex, um alle Verbundenheiten gegenüber dem absolutistischen Traditionalismus abzuschütteln? Personelle Führungspositionen müssen einem demokratischen Wahlmodus und demokratischer Kontrolle unterstellt werden. Ein nicht nur auf eine Person zugeschnittenes >Sekretariat< oder ein nach Schweizer Vorbild gestaltetes mehrköpfiges Präsidium, das in parlamentarische Verantwortlichkeit eingebunden bleibt, wäre die bessere Alternative gewesen. 
2. Ich komme nun zu den Ansätzen einer partizipativen Demokratie im Vertragsentwurf des Europäischen Konvents. Begrifflich wird die Demokratie als Leitprinzip der supranationalen Integration erst an fortgerückter Stelle des Vertragswerks erwähnt und blumig umschrieben. Art. I-44 geht auf die Demokratie als »Grundsatz der Gleichheit« ein, der die Europäische Union leiten soll. Er hebt hervor, dass es sich um eine Manifestation von Grundsätzen der »repräsentativen Demokratie« handele, da die Bürger unmittelbar durch das Europäische Parlament vertreten seien und mittelbar durch den Europäischen Rat und den Ministerrat. Die Bürger sollen aber »am demokratischen Leben der Union teilnehmen«, wie und wo auch immer dieses stattfindet. Die Rolle der nationalen Parlamente wird durch ein dem Vertragswerk angefügtes >Protokoll ausführlich gewürdigt. Sie sollen intensiv über alle Vorgänge unterrichtet werden, sie werden zu Anfragen an die supranationalen Institutionen ermuntert, und sie sollen eine enge Zusammenarbeit mit dem Europäischen Parlament praktizieren.

Die Volkssouveränität als Zuschreibung eines Bürgerstatus bleibt im Vertragsentwurf des Europäischen Konvents ohne Einschränkungen in den Nationalstaaten verankert: Die »Unionsbürgerschaft« ist an die Staatsangehörigkeit eines Mitgliedstaates gebunden und »tritt zur nationalen Staatsbürgerschaft hinzu, ohne diese zu ersetzen« (Art. I-8: 6). Das Nationalstaatsmonopol bleibt im Bereich der nationalen politischen Identität und im Bereich der »grundlegenden Funktion des Staates « unangetastet. Art. I-5 des Vertragsentwurfs schreibt den Nationalstaaten die »Wahrung der territorialen Unversehrtheit, die Aufrechterhaltung der öffentlichen Ordnung und den Schutz der inneren Sicherheit« zu. Es handelt sich um den Fortbestand des konventionellen Leitbilds staatlicher Souveränität im traditionellen Modus der zwischenstaatlichen Koexistenz, die schon seit der Westfälischen Friedensordnung des I7. Jahrhunderts existiert. 
Joseph Weiler plädiert folgerichtig dafür, sektorale Gemeinschaftlichkeit an die Stelle der unerreichbaren gesamtverbandlichen Kohärenz treten zu lassen.

»Is it mandated, we should ask, that Demos in general and the European Demos in particular be understood exclusively in organic cultural homogeneous terms? Can we not break away from that tradition and define membership of a polity in civic, non-organic-cultural terms? (Weiler I996: 525)

Wenn nun die Europäische Union nur noch Teile eines bürgerschaftlichen Selbstverständnisses entfaltet, dann darf sie auch nicht staatsähnlichen Zielorientierungen unterstellt werden, die auf eine umfassende Bürgerschaft fixiert sind. Das aber leistet wenigsten teilweise die Charta der Grundrechte der Union, die einen nachgeordneten Stellenwert in dem Vertragsentwurf einnimmt, weil sie - längst ausgearbeitet und bislang in ihrer Rechtswirksamkeit sowie in ihrem politischen Status unklar den Teil II als Komplementärstück zu dem geschilderten Institutionengefüge und den Verfahrensregeln in Teil I darstellt. Die jetzt integrierte Charta der Europäischen Grundrechte schießt in vielen Partien über das erforderliche Maß an europapolitischen Präzisierungen von Grundrechten hinaus, die ja größtenteils schon in den nationalstaatlichen Verfassungen hinreichend verankert und mit Sanktionsgewalt ausgestattet sind. Damit suggeriert die Charta eine Unmittelbarkeit von individueller Staatsangehörigkeit, die in den Nationalstaaten längst stabil verankert ist und ja - wie bereits erläutert - auch nicht zu den Grundsatzzielen des Verfassungsentwurfs passt.

Ich komme zur expliziten Bezugnahme im Verfassungsentwurf auf die partizipative Demokratie. Der wörtlich erwähnte »Grundsatz der partizipativen Demokratie« bleibt sehr vage und beinhaltet lediglich die Möglichkeit, dass Bürger, Verbände und 
die Zivilgesellschaft »in geeigneter Weise « ihre Ansichten zur Integrationsmaterie bekannt geben und austauschen können (Art. I-46). Dann aber folgt ein erstaunliches, geradezu als kühne demokratische Errungenschaft $\mathrm{zu}$ wertendes Element: Eine vermittelte Form der direkten Demokratie findet Eingang in die supranationale Integration. Eine Million Bürger »aus einer erheblichen Anzahl von Mitgliedstaaten« stellt das Quorum dar, auf dessen Basis die Bürger die Kommission auffordern können, Vorschläge zu Themen auszuarbeiten, die nach Meinung der Bürger eines supranationalen Rechtsakts bedürfen. Das ist fast unverstellt ein >Volksbegehren < auf europäischer Ebene, also das Recht des Volkes, eine Behandlung von drängenden politischen Themen in den Gesetzgebungsorganen zu forcieren. Es ist lediglich fast unverstellt, weil eine Spezifikation der Verbindlichkeit fehlt, die für die Gesetzgebungsorgane aus dem Volksbegehren resultieren. Ohne die aus der Initiative zwingend erfolgende Behandlung würde es sich lediglich um eine >Volksinitiative< handeln. Diese brächte nicht mehr als das Bemühen um politische Aufmerksamkeit für vernachlässigte Themen zum Ausdruck, beinhaltete aber keine Zwangsläufigkeit der offiziellen Befassung. Aber als direktdemokratischer Keil ist dieses partizipative Instrumentarium doch eine beachtliche demokratische Errungenschaft. Wenn nun auch noch Referenda über die Annahme der Verfassung in allen - oder zumindest in den meisten - Mitgliedstaaten zwingend vorgeschrieben würden, dann wären bereits alle zentralen Grundstufen der direkten Demokratie aktiviert. Davon unbenommen handelt es sich bei dieser Art des Volksbegehrens zweifelsohne um einen erstaunlichen Zugewinn an europäischer Demokratie.

Mit diesem hervorstechenden und für die supranationale Integration überraschenden Element einer partizipativen Demokratie lässt sich der Gesamtrahmen unmittelbarer demokratischer Gestaltungsmöglichkeiten in der neuen Europäischen 
Union treffend zusammenfassen: Es gibt einige außergewöhnliche Errungenschaften, die das Prinzip der repräsentativen Mittelbarkeit durchbrechen und tatsächlich ein basisnahes >Europa der Bürger $<\mathrm{zu}$ installieren versuchen. Aber es gibt insgesamt kein stimmiges System der kollektiven Willensbildung, in das sich die verstreuten Elemente der Demokratie modellgerecht einfügen können. So bleibt es auch hier bei einer Demokratie auf $>$ mittlerer Stufe $<$, die gegenüber dem supranationalen Gebilde in seiner bisherigen Gestalt eine normativ gehaltvolle Annäherung an traditionsreiche Standards der Mitbestimmung, Kontrolle und Transparenz vollzieht, die aber kein demokratisches System sui generis schafft, das als Ablösemodell für überkommene Muster nationalstaatlich verfasster Demokratie zu überzeugen vermag.

\section{Die Konstruktion der ,Weltmacht، Europa}

Schon die Erklärung von Laeken im Dezember 200I hatte mit aufwendigem Pathos und großen Worten die erforderliche Stärkung Europas als Weltmacht zum neuen Ziel europäischer Integration erhoben - kurz nach dem II. September 200I, aber bemerkenswerterweise noch vor dem Irak-Krieg 2003. Europa sollte demnach »eine führende Rolle in der Weltpolitik übernehmen « und zugleich »eine stabilisierende Rolle« ausüben (Erklärung von Laeken 200I: 2). Europa wurde in der Erklärung von Laeken nicht als Hegemon beschworen, sondern als Hüter von kollektiven Werten. Europa galt den Staats- und Regierungschefs als »Kontinent der humanitären Werte, der Magna Charta, der Bill of Rights, der Französischen Revolution, des Falls der Berliner Mauer«, als »Kontinent der Freiheit, der Solidarität, vor allem der Vielfalt«. Als einzige Grenze akzeptiere dieser Kontinent die der »Demokratie und der Menschenrechte« (ebd.: 2). Im Rahmen der Globalisierung solle Europa dafür kämpfen, die 
Weltlage zugunsten der ärmsten Länder sowie in Richtung einer »nachhaltigen Entwicklung « zu verändern. Europa soll eine Macht darstellen, »die der Globalisierung einen ethischen Rahmen « gibt (ebd.: 2).

Eine solche weltpolitische Positionsbestimmung erscheint in doppelter Hinsicht plausibel: Sie bringt ein genuin europäisches Erbe als zeitgemäßes Reservoir an Werten in Anschlag, und sie entwickelt eine bedächtige Alternative zu jenen kraftvoll polarisierenden Klischees, die der >westlichen Welt entweder das Selbstverständnis eines völlig zurückgenommenen Isolationismus anempfehlen oder ihr das einer offensiven globalen Hegemonie zuschreiben. Die von ethischen Maximen durchdrungenen Zielvorstellungen in der Erklärung von Laeken stehen vor allem im Kontrast zu konventionellen Leitbildern einer Weltmacht, die sich nur über ihre wirtschaftlichen Interessen oder über ihr militärisches Potenzial definiert. Es steht nicht das Orientierungsziel eines >global players < im Mittelpunkt, der sich im geltungssüchtigen Habitus eines >Spielers< an einem weltpolitischen Poker um Machtsphären und Einflusszonen beteiligt, sondern das einer >diskursiven Streitmacht<, die sondiert, abwägt, vermittelt, schlichtet. Ein solcher Akteur ist auf die Reflexion von weltpolitischen Handlungsmaximen ausgerichtet und darum bemüht, die globale Vielfalt an Werten, Interessen, widerstreitenden Prinzipien und antagonistischen Positionen zu registrieren, Betroffenenperspektiven und Akteurspositionen in abwägende Strategie-Überlegungen einzubringen und daraus das eigene weltpolitische Rollenverständnis abzuleiten. Die authentischen europäischen Beiträge zur Weltpolitik wären die einer diskursiv erzielten flexible response, die je nach Konfliktlage internationale Vermittlung, Verhandlung oder Schlichtung betreibt, die notfalls Sanktionen vorschlägt oder Intervention zum Zwecke der Gewaltprävention oder der Deeskalation ausübt. 
Dieses Selbstverständnis als Weltmacht stellt eine substantielle Alternative zu der wieder sehr stark hegemonial ausgerichteten Politik der USA dar und entspricht einem Europa, das sich nach außen nicht suggestiv zur handlungsmächtigen politischen Einheit stilisiert, sondern realistisch sein von vielfältigen Traditionen gespeistes Selbstverständnis zu einem wertbewussten öffentlichen Kommunikationsraum und zu einer davon inspirierten Diskursgemeinschaft weltpolitischer Handlungsoptionen ausbuchstabiert. Europa wäre der Impulsgeber eines pluralistischen Multilateralismus im Weltmaßstab. Die daraus gewonnene Handlungsmächtigkeit läge deutlich unterhalb der Fähigkeit zur Hegemonie, aber deutlich oberhalb des ethischen Legitimationspotenzials der herrschenden weltpolitischen Konstellationen.

In Entsprechung dazu erinnert der Europäische Konvent im Vorwort zum Verfassungsentwurf an seine durch die Erklärung von Laeken definierte Aufgabe, »die Union zu einem Stabilitätsfaktor und zu einem Vorbild in der neuen Weltordnung zu machen « (Europäischer Konvent 2003: 2). Natürlich wird kein Einverständnis darüber zu erzielen sein, unter welchen Maximen ein »Stabilitätsfaktor « agiert und welche politische Substanz eine »neue Weltordnung « aufweisen soll. Aber Vorbildfunktionen setzen ethische Reflexionen voraus, und so bestehen doch zumindest Anknüpfungspunkte an die progressiven Partien in der Erklärung von Laeken, die Europas Selbstverständnis als Kommunikationsraum und Diskursgemeinschaft hervorheben.

Freilich haben sich viele der bisherigen Bemühungen im Rahmen der Europäischen Union, ein konturiertes Verständnis als >Weltmacht< auszuprägen, eher in konventionellen Bahnen bewegt, die auf wirtschaftliche Dominanz, politische Entscheidungsvollmacht und militärisches Drohpotenzial ausgerichtet sind. Das zeigt sich an der Gemeinsamen Außen- und Sicherheitspolitik (GASP), die ehrgeizige Weltmachtsansprüche Europas 
begründen sollte, aber schon an inneren Strukturschwächen scheiterte. Die Europäische Union ist offenkundig vorerst zur Erfolglosigkeit von hochtrabenden, eine neue Staatlichkeit herstellenden Harmonisierungsbemühungen in den Arkanbereichen nationaler Herrschaftsmonopole verdammt. Bedauerlicherweise bleibt die GASP im neuen Vertragswerk als konventionelles weltpolitisches Leitbild erhalten. Sie wird aber - ein erneuter Ausweis eines umsichtigen Realismus - in entscheidenden Passagen in die Möglichkeitsform zurückgestuft: In Art. I-II wird die Union »für zuständig erklärt«, die »schrittweise Festlegung einer gemeinsamen Verteidigungspolitik « zu erarbeiten, während in noch entschiedenerer Abschwächung Art. I-I5 resümiert, dass die GASP zu einer gemeinsamen Verteidigung führen »kann«. Inhalte und Zielorientierungen werden nicht mehr apodiktisch vorgeschrieben, sondern tastend eruiert.

Die Demokratie kommt insgesamt in den Passagen zur weltpolitischen Rolle Europas zu kurz. Der Europäische Rat behält auf Basis von einstimmigen Beschlüssen das außenpolitische Heft in der Hand: »Der Europäische Rat bestimmt die strategischen Interessen der Union und legt die Ziele ihrer Gemeinsamen Außen- und Sicherheitspolitik fest« (Art. I-39). Das Europäische Parlament wird lediglich »regelmäßig gehört und über ihre Entwicklungen auf dem Laufenden gehalten«. Greifbarere Ansatzpunkte für eine demokratische Kontrolle bieten jene Abschnitte des Verfassungsentwurfs, die sich nicht unmittelbar mit der GASP im engeren Sinne befassen. In ihnen ist jene bedächtige Gestaltungsoffenheit wieder $\mathrm{zu}$ finden, die schon in einigen Partien des Entwurfs zum Ausdruck gekommen war. Die Formulierungen zum allgemeinen weltpolitischen Rollenverständnis für Europa sind klug gewählt, weil sie eine verfahrensbezogene Dynamik unterstellen, aber die Intensität und Finalität inhaltlicher Ziele offen lassen. Der begriffliche Ausdruck dieses abwägenden Vorgehens lautet: 
»Die Europäische Union verfolgt eine gemeinsame Außen- und Sicherheitspolitik, die auf einer Entwicklung der gegenseitigen politischen Solidarität der Mitgliedstaaten, der Ermittlung der Fragen von allgemeiner Bedeutung und der Erreichung einer immer stärkeren Konvergenz des Handelns der Mitgliedstaaten beruht.« (Art. I-39)

Die Kategorie der »Konvergenz « ist in dieser herausgehobenen Position ein integrationspolitisches Novum, das wohltuend von den konventionellen europapolitischen Festlegungen hinsichtlich der Integrationsgeschwindigkeit und der Zielvorgaben - wie »einer immer engeren Union der Völker Europas« oder dem »europäischen Bundesstaat « - abrückt. Die Mitgliedstaaten werden neben dem »konvergenten Handeln « zu gegenseitiger Konsultation und Solidarität verpflichtet. Sie behalten insbesondere im Bereich der Verteidigungspolitik das Recht, gegebenenfalls »den besonderen Charakter « ihrer jeweiligen verteidigungspolitischen Richtlinien und Bindungen zum Ausdruck zu bringen (Art. I-40). Der damit gesetzte Zwang zur Kommunikation ist ein Weg zum offenen Diskurs. Die Festlegung auf eine intensive Verständigung über die gemeinsamen Handlungsmaximen kann dann ein Element von deliberativer Demokratie werden, wenn die demokratischen Instrumente in den übrigen Partien des Verfassungswerks - die Entscheidungsvollmacht des Europäischen Parlaments, die Mitsprache nationaler Parlamente und die Hebel zur direkten Demokratie - auch in den außenpolitischen Themenfeldern folgerichtig zur Anwendung gelangen.

Die Vertragsbestimmungen zur gemeinsamen Verteidigungspolitik im engeren Sinn fallen dagegen hinsichtlich ihrer Verfahrensbestimmungen hinter das diskursive Potenzial des Konvergenzpostulats zurück. Sie erreichen auch inhaltlich nicht das Niveau des ethisch unterfütterten Weltmachtsverständnisses aus der Erklärung von Laeken. Jetzt heißt es nur noch, dass die Union »die auf zivile und militärische Mittel gestützte Fähigkeit 
zu Operationen « erlangt und dabei eng mit den Vereinten Nationen kooperiert (Art. I-40). Die Mitgliedstaaten werden aufgefordert, »ihre militärischen Fähigkeiten schrittweise zu verbessern«. Es soll gar ein »Europäisches Amt für Rüstung, Forschung und militärische Entwicklung« eingerichtet werden (Art. I-40). Solche Forderungen erinnern historisch mehr an militärpolitische Strategien in Hochrüstungsphasen anstatt an ein alternatives Weltmachtsverständnis in Zeiten amerikanischer Hegemonie und einem notorisch unsicheren Rollenverständnis der Vereinten Nationen. Fallen Friedensmissionen unter die Kategorie der »Verteidigungspolitik«, ist die Abwehr eines terroristischen Angriffs von den militärischen Fähigkeiten der Europäischen Union abhängig? Plakative Leitmotive ersetzen im Verfassungsentwurf differenzierte konzeptionelle Antworten auf diese Fragen. In Art. I-42 heißt es dann noch unverblümter, dass die Union »alle ihr zur Verfügung stehenden Mittel« ergreift, um Terroranschläge abzuwehren, »einschließlich der ihr von den Mitgliedstaaten bereitgestellten militärischen Mittel«. In nationalen Zusammenhängen erscheint mit gutem Grund noch immer höchst umstritten, was hier unvermittelt zur supranationalen Kollektivbefugnis erhoben wird: dass eine militärische Einheit der kollektiven Hoheitsgewalt unumwunden in die zivilen Schutzfunktionen eingreift. Eine solche >Militärmacht Europa < ist intern aus Gründen der Trennung zwischen zivilen und militärischen Aufgaben bedenklich und nach außen fragwürdig, weil sie andere Institutionen der sanktionsbewehrten Friedenssicherung, wie die Vereinten Nationen, nicht hinreichend in dem Zuschnitt ihres eigenen Rollenverständnisses berücksichtigt. Gerade das Verhältnis zwischen Europäischer Union und Vereinten Nationen hätte viel weiterreichender verfassungspolitischer Klärungen bedurft.

Es zeigt sich erneut, dass die vom Europäischen Konvent ausgearbeitete Verfassung nicht aus einem Guss gefertigt ist, sondern disparate inhaltliche und prozedurale Festlegungen 
trifft, die mal als kluger Mittelweg erscheinen, mal als widersprüchliche Strategie, mal als unangemessene Rollenzuschreibung. In der uneinheitlichen Modellierung der Europäischen Union als weltpolitischer Akteur kommen diese Strukturschwächen besonders schmerzhaft zum Ausdruck.

\section{Schluss}

Zusammenfassend bleibt festzuhalten, dass der Verfassungsentwurf des Europäischen Konvents gegenüber den verbreiteten Finalitätsvisionen der europäischen Integration eine politisch geradezu wohltuende Bedachtsamkeit zum Ausdruck bringt, die schärfer denn je die verschiedenen Hoheitsgebiete und Rechtskreise unterhalb der supranationalen Ebene wahrnimmt und aus den Überschneidungen vor allem von nationalen und supranationalen Machtsphären ein mehrstufiges Gebilde der Koordinierung, Kooperation und Integration zusammenfügt. Der Begriff der »Erreichung einer immer stärkeren Konvergenz des Handelns der Mitgliedstaaten « (Art. I-39) umschreibt mit einer treffenden Unbestimmtheit die mögliche Geschwindigkeit, Regelungstiefe und Zielrichtung der europäischen Integration. Die Europäische Union bleibt hinsichtlich ihrer politischen Konturen unscharf, und entsprechend vermag auch ihre demokratische Gestalt nicht über die Weichzeichnung eines gewaltenteiligen Handlungssystems auf der Basis der Volkssouveränität hinauszuwachsen. Es gibt in dem Verfassungsentwurf funktionale Elemente der Demokratie, aber es gibt kein normativ kohärentes Leitbild demokratischer Herrschaft.

Dennoch ist das Offenhalten der Entwicklungsdynamik und der Finalität nicht ausschließlich als ein taktisches Ausweichmanöver oder als eine inhaltliche Modellierungsschwäche zu interpretieren, sondern auch als ein demokratisches Potenzial, das an 
manchen Punkten der Entscheidungsverfahren und der Zieldefinitionen partizipative Gestaltungsmöglichkeiten eröffnet. Unter den normativen Gesichtspunkten einer deliberativen Demokratie ist es besser, einen geringen Integrationsgrad auf der Basis der Inklusion aller Beteiligten und Betroffenen zu erlangen, als zielstrebig eine hohe Integrationsdichte anzustreben, die aus sachlichen Gründen auf Einwände und abweichende Positionen keine Rücksicht nimmt.

Freilich liegt es nicht an der konzeptionellen Modellierung der Europäischen Union allein, ob die europäische Integration als >demokratisches Projekt< gelingen kann. Es liegt auch an den Rahmenbedingungen politischer Selbstorganisation im 2I. Jahrhundert. In einem Zeitalter der harten Spannungen zwischen globaler Vereinheitlichung und kleinteiliger Diversifikation stößt ein Integrationstypus wie die Europäische Union an strukturelle Grenzen seiner Entwicklungsfähigkeit als demokratischer Herrschaftsverband. Die Modernisierungstheorien resümieren seit Ende des 20. Jahrhunderts einhellig: »Großstaatsbildungen stehen nicht auf der Tagesordnung unseres Jahrhunderts, und es ist nicht zu erkennen, wieso das im kommenden Jahrhundert [...] sich ändern sollte.«(Lübbe I994: I9). Wir befinden uns in einem »Zeitalter der Komplexität«, das trotz aller globalen Homogenisierungsschübe und weltumspannender Vernetzung heftig diversifiziert, lokalisiert, fragmentiert, separiert.

»Die menschliche Gemeinschaft ist $\mathrm{zu}$ groß geworden, um noch ein politisches Gemeinwesen zu bilden. Die Bürger stellen immer weniger eine Gesamtheit dar, in der kollektive Souveränität zum Ausdruck kommen könnte; sie sind lediglich juristische Personen mit Rechten und Pflichten, sie befinden sich in einem abstrakten Raum mit zunehmend ungewissen territorialen Grenzen.« (Guéhenno I996: I3) 
Unter diesen Ausgangsbedingungen hat die europäische Integration keine Chance, als systemkonformes Nachfolgemodell des Nationalstaats in erweiterten Größendimensionen Profil gewinnen zu können. Die Auflösung des Prinzips der Nationalstaatlichkeit in eine höhere Ordnung nach gleichem Muster repräsentiert nicht mehr den zeitgemäßen Ersatz für überkommene Formen der Demokratie. Die Integrationsimpulse der friedenspolitischen Aussöhnung unter ehemals tief verfeindeten europäischen Nationalstaaten sind erfolgreich abgearbeitet. Nun stehen Prozesse einer neuen europäischen Selbstfindung in der Epoche globaler Vernetzung und großflächiger weltpolitischer Konfliktlinien auf der Tagesordnung. Diese Selbstfindung zehrt nur zum geringen Teil von den institutionellen Vorgaben eines staatsähnlichen Herrschaftsverbandes. Sie lebt zum größeren Teil von der demokratischen Verständigung über kollektive Werte, Ziele, Verfahren und Organisationsformen. Die Europäische Union muss sich also mehr denn je als ein von europäischen Traditionsbeständen zehrender Kommunikationsraum und als eine demokratische Diskursgemeinschaft verstehen. Das demokratische Versprechen liegt darin, großräumige Strategien der demokratisch legitimierten Handlungskoordination zu entwickeln, ohne dem Trugbild der konventionellen Staatlichkeit auf höherer Ebene zu erliegen. Dieses demokratische Projekt stellt eine anspruchsvolle modelltheoretische Herausforderung dar, zu der die europäische Verfassung noch keine schlüssige Konstruktion, sondern vorerst nur einige tragfähige Bausteine beizutragen vermag. 


\section{Literatur}

Derrida, Jacques/Habermas, Jürgen (2003): Unsere Erneuerung. Nach dem Krieg: Die Wiedergeburt Europas«, in: Frankfurter Allgemeine Zeitung vom 31.05.2003.

Deubner, Christian (2003): »Differenzierte Integration: Übergangserscheinung oder Strukturmerkmal der künftigen Europäischen Union?«, in: Aus Politik und Zeitgeschichte, B I-2, S. 24-32.

Erklärung von Laeken zur Zukunft der Europäischen Union (200I), online unter: http://europa.eu.int/futurum/docu ments/offtext/doci5I20I_de.htm, besucht am I5.I2. 2003.

Europäischer Konvent (2003): Entwurf eines Vertrags über eine Verfassung für Europa, dem Europäischen Rat auf seiner Tagung in Thessaloniki am 20. Juni 2003 überreicht, CONV $820 / 03$.

Frankenberg, Günter (200I): »Die Rückkehr des Vertrages. Überlegungen zur Verfassung der Europäischen Union«, in: Lutz Wingert/Klaus Günther (Hg.): Die Öffentlichkeit der Vernunft und die Vernunft der Öffentlichkeit. Festschrift für Jürgen Habermas, Frankfurt a.M., S. 507-538.

Giering, Claus (1997): »Vertiefung durch Differenzierung - Flexibilisierungskonzepte in der aktuellen Reformdebatte«, in: Integration, Heft 2, S. 72-83.

Giscard d'Estaing, Valéry (2002): Eröffnungsrede vor dem Konvent zur Zukunft Europas am 26. Februar, Dokumente des Konvents auf der Internetseite, SN I565/O2.

Grimm, Dieter (200I): Die Verfassung und die Politik. Einsprüche in Störfällen, München.

Guéhenno, Jean-Marie (1996): Das Ende der Demokratie, München. 
Günther, Carsten A. (2002): »Der Verfassungsvertrag - ein Modell für die Europäische Union?«, in: Zeitschrift für Parlamentsfragen, Heft 2, S. 347-360.

Habermas, Jürgen, (I994): »Staatsbürgerschaft und nationale Identität. Überlegungen zur europäischen Zukunft«, in: Nicole Dewandre/Jacques Lenoble (Hg.): Projekt Europa. Postnationale Identität: Grundlage für eine europäische Demokratie?, Berlin, S. II-29.

Hummer, Waldemar (2002): »Vom Grundrechte-Konvent zum Zukunfts-Konvent. Semantische und andere Ungereimtheiten bei der Beschickung des >Konvents zur Zukunft Europas «", in: Zeitschrift für Parlamentsfragen, Heft 2, S. 323-347.

Lübbe, Hermann (1994): Abschied vom Superstaat. Vereinigte Staaten von Europa wird es nicht geben, Berlin.

Maurer, Andreas (2003): »Less Bargaining - More Deliberation. The Convention Method for Enhancing EU Democracy«, in: Internationale Politik und Gesellschaft, Heft I, S. I67-I90.

Preuß, Ulrich K. (I994): »Europäische Einigung und die integrative Kraft von Verfassungen«, in: Jürgen Gebhardt/Rainer Schmalz-Bruns (Hg.): Demokratie, Verfassung und Nation. Die politische Integration moderner Gesellschaften, Baden-Baden, S. $27 \mathrm{I}-287$.

Preuß, Ulrich K. (2000): »Bürgerschaft in der Europäischen Union. Ein Paradigma für transnationale Demokratie?«, in: Ulrich Menzel (Hg.): Vom Ewigen Frieden und vom Wohlstand der Nationen. Dieter Senghaas zum 6o. Geburtstag, Frankfurt a.M., S. 243-260.

Richter, Emanuel (1983): Leitbilder des europäischen Föderalismus. Die Entwicklungsgeschichte der Idee eines europäischen Bundesstaats bis zum Beginn des 20. Jahrhunderts, Diss. Bonn.

Richter, Emanuel (I999): Das republikanische Europa. Aspekte einer nachholenden Zivilisierung, Opladen. 
Richter, Emanuel (2003): »Ein republikanischer Aufbruch für Europa? Demokratietheoretische Anmerkungen zum >Europäischen Konvent««, in: Berliner Debatte Initial, I4 Jg., Heft I, S. I6-33.

Scharpf, Fritz W. (I999): »Demokratieprobleme in der europäischen Mehrebenenpolitik«, in: Wolfgang Merkel/Andreas Busch (Hg.): Demokratie in Ost und West. Für Klaus von Beyme, Frankfurt a.M., S. 672-694.

Schmalz-Bruns, Rainer (I999): »Deliberativer Supranationalismus. Demokratisches Regieren jenseits des Nationalstaats«, in: Zeitschrift für Internationale Beziehungen, 6. Jg., Heft 2, S. $185-244$.

Schmitter, Philippe C. (2000): How to democratize the European Union ... and why bother?, Lanham.

Shaw, Jo (2000): »Process and Constitutional Discourse in the European Union«, in: Journal of Law and Society, Vol. 27, No. I, March, S. 4-37.

Thaysen, Uwe (2003): »Der deutsche Föderalismus zwischen zwei Konventen. Zur Reform des deutschen Bundesstaates um die Jahrtausendwende«, in: Aus Politik und Zeitgeschichte, B 29/30, S. 14-23.

Vertrag von Amsterdam (1998): Texte des EU-Vertrages und des EG-Vertrages, herausgegeben von Thomas Läufer, Bonn.

Waschkuhn, Arno (1995): Was ist Subsidiarität? Ein sozialphilosophisches Ordnungsprinzip: Von Thomas von Aquin bis zur »Civil Society«, Opladen.

Weiler, Joseph H. H. (I996): »European Neo-constitutionalism: in Search of Foundations for the European Constitutional Order«, in: Political Studies, Vol. XLIV, S. 5I7-533. 


\section{Von Normen und Werten:}

\section{Religion, Recht und Politik im}

\section{modernen Islam ${ }^{\mathrm{I}}$}

GUdRUN KRÄMER

$\mathrm{Zu}$ den bekanntesten Elementen der zeitgenössischen Diskussion um Islam, Recht und Politik zählt die Formel, der Islam sei »Religion und Staat« (al-islam din wa-daula) oder, etwas weiter gefasst und zugleich historisch früher belegt, der Islam sei »Religion und Welt« (al-islam din wa-dunya). Die Formel wird vielfach als Aussagesatz verstanden (dass es ursprünglich und über lange Zeit so war, selbst wenn diese Einheit sich heute nur selten verwirklicht findet) oder zumindest als normative Aussage (dass es so sein müsse, selbst wenn die Einheit in Geschichte und Gegenwart nicht wirklich die Norm abgegeben hat). Tatsächlich aber handelt es sich bei der viel gebrauchten Formel um ein Postulat (dass es so sein sollte, unabhängig davon, ob die Einheit in Geschichte und Gegenwart, von der kurzen Ära der prophetischen Führung im frühen 7. Jahrhundert n. Chr. abgesehen, je 
realisiert wurde), und am besten versteht man sie als Kampfbegriff in einer aktuellen Auseinandersetzung: Sie beinhaltet eine klare Absage an den Säkularismus, die sich mit gleicher Schärfe nach innen und nach außen richtet - nach innen gegen die Kritiker einer solchen Verbindung von religiöser Überzeugung und öffentlicher Ordnung in den eigenen Gesellschaften, nach außen gegen >den Westen Normen und Werten von der Toleranz über die Aufklärung bis hin zur säkularen Ordnung (vergessen werden in diesem Zusammenhang häufig die sozialistische Staatenwelt einschließlich der Sowjetunion und deren Nachfolgestaaten, die meist faktisch unter den Westen subsumiert werden).

Dass >im Islam< Religion, Recht und Politik eng und unauflöslich miteinander verknüpft sind und sein müssen, stellt zumindest in den Gesellschaften des Mittleren Ostens von Marokko bis Pakistan keine bloße Minderheitenposition dar. So denken beachtliche Teile der politischen Öffentlichkeit, die sich der breiten, nicht immer klar nach außen abgrenzbaren »islamischen Strömung « zurechnen lassen. ${ }^{2}$ Die »Islamisten « (unter denen Fundamentalisten im landläufigen Sinn des Wortes eine bedeutende, aber keineswegs die alles beherrschende Rolle spielen) sind sicherlich die lautesten und auffälligsten Fürsprecher einer Einheit von Religion, Recht und Politik. Sie geben in der Diskussion auf jeden Fall den Ton an, beeinflussen in nicht wenigen Staaten der Region auch das gesellschaftliche Leben und die Rechts- und Verfassungsordnung. Aber sie stoßen zugleich auf Kritik und Widerstand, der zum Teil seinerseits religiös argumentiert, um aus den normativen Quellen in dieser Frage ganz andere Schlüsse zu ziehen, zum Teil dezidiert säkularistisch auftritt, ohne die islamische Tradition zur Abstützung eigener Positionen zu bemühen. ${ }^{3}$ 


\section{Islam als Text}

An der Formel »Der Islam ist Religion und Staat« ist jeder einzelne Bestandteil klärungsbedürftig. Es beginnt mit dem Begriff »Islam«: Darüber, was Islam bedeutet, und ob es überhaupt legitim und sinnvoll ist, bei der Analyse gesellschaftlicher und kultureller Verhältnisse in muslimischen Gesellschaften auf »den Islam« zurückzugreifen, wird in der Wissenschaft heftig gestritten; gelegentlich erreicht die Debatte sogar eine breitere Öffentlichkeit. Grundsätzlich sollte - will man sich nicht des Essentialismus und plumpen Kulturalismus (in unserem Zusammenhang besser bekannt als »Orientalismus « $)^{4}$ schuldig machen zwischen verschiedenen Dimensionen islamischen Denkens und muslimischen Handelns unterschieden werden: Islam als historisch eingebetteter, da von Menschen (ganz überwiegend Männern) erarbeiteter normativer Tradition; der orts-, zeit- und milieuabhängigen Praxis von Musliminnen und Muslimen in Geschichte und Gegenwart, die keineswegs zwingend und durchgängig durch die normative Tradition normiert sein muss; und schließlich ebenso vielfältigen Vorstellungen über eine srechte< islamische Ordnung und Lebensweise.

Im vorliegenden Fall aber, wo es um das Verhältnis von Religion, Recht und Politik geht, ist klar, was mit >Islam < vorrangig gemeint ist: die normative Tradition, die im Wesentlichen durch Texte begründet wird und in Texten regelrecht festgeschrieben ist - dem Koran als nach muslimischem Verständnis direkter göttlicher Rede und der Sunna als von der göttlichen Offenbarung inspirierter prophetischer Rede und Praxis (daher im Deutschen häufig übersetzt als »Prophetentradition«). Beide Texte gelten Muslimen als heilig und daher weitgehend unantastbar: Über den Status des Koran als Gotteswort öffentlich zu diskutieren, ihn gar mit literaturwissenschaftlichen Methoden kritisch zu untersuchen, ist im aktuellen politischen Klima zu- 
mindest in der arabischen Welt so gut wie unmöglich. (Vgl. Bobzin 1999; Seidensticker 2000; Wild 1996)5 Weniger tabubeladen, wenn auch keineswegs risikofrei, ist der Umgang mit der Sunna als für spätere Generationen verbindlicher (wenigstens in Teilen auch rechtsverbindlicher) Rede und Praxis des Propheten. (Vgl. Brown 1996) Sowohl Koran wie Sunna erheben den Anspruch auf Wahrheit. Beide sind sie ihrer Komposition und Struktur nach jedoch hoch kompliziert und - was islamischen Gelehrten im Allgemeinen bekannt war und nach wie vor bekannt ist, von Islamisten aber gerne übersehen wird - in jedem Punkt auslegungsbedürftig, selbst dort, wo ihre Aussagen auf den ersten Blick klar und eindeutig erscheinen mögen. Das gilt für dogmatische ebenso wie für rechtsrelevante Fragen: Wenn im Koran von dem »Thron « oder der »Hand « Gottes die Rede ist, dann treten die Theologen auf den Plan, um der Gefahr eines anthropomorphistischen Verständnisses (oder eben Gottesbildes) entgegenzutreten, und wenn in Sure 5,38 geschrieben steht, dem Dieb und der Diebin seien die Hände abzuschlagen, werden die Juristen aktiv, um den Tatbestand des Diebstahls genauer (und das heißt in diesem Fall: möglichst restriktiv) zu definieren. (Mit dem biblischen Gebot »Du sollst nicht töten« ist es im Grundsatz nicht anders).

Koran und Sunna bilden das Fundament, auf das nicht nur Fundamentalisten ihren Glauben bauen. Sie stiften einen Bezugsrahmen und bieten zugleich ein Repertoire an Aussagen, Weisungen, Bildern und Metaphern, auf das Muslime zurückgreifen, wenn sie sich eine Vorstellung von islamischer Lehre machen. Aber es bleibt die Notwendigkeit der Auslegung, die nicht ohne Auswahl und Gewichtung der unterschiedlichen normativen Referenzen auskommt, die Koran und Sunna bereithalten. Ohne Exegese geht es nicht. Das stellt, wenn diese Thematik hier auch nicht vertieft werden kann, mit großer Dringlichkeit die Frage nach religiöser Autorität und religiösen Autori- 
täten, die in der Vergangenheit stets aktuell war und selten einheitlich beantwortet wurde, in der Gegenwart jedoch angesichts expandierender Bildungsmöglichkeiten und immer dichterer Kommunikation, wo immer mehr Menschen religiöses Wissen erlangen und aus diesem Wissen eigene Deutungsmacht beanspruchen, neue Aktualität gewonnen hat. ${ }^{6}$

\section{Islam und Staat}

Islam, darüber sind sich die meisten Muslime einig, ist mehr als das bloße Bekenntnis zu dem Einen Gott und seinem Gesandten Muhammad: Der Glaube ruft nach Taten. Er begründet eine bestimmte Lebensführung, in der sich die religiösen Werte in innerweltliches Handeln übersetzen; religiöse Ethik kann und darf nicht ohne gesellschaftliche Wirkung bleiben. Das muss in der einen oder anderen Weise auch auf Politik abstrahlen, die immer auf gewissen Werten beruhen und bestimmte Weltbilder reflektieren wird. (Das gilt im Übrigen ebenso für Buddhismus, Judentum und Christentum, aber auch für den historischen Materialismus oder jede andere Form der atheistischen oder agnostischen Weltanschauung.) Islamisten gehen jedoch weiter: Sie postulieren, dass sich die von Gott geforderte rechte Lebensführung nicht auf rein individueller Ebene verwirklichen lässt, sondern nur im Rahmen einer »islamischen Ordnung « (nizam islami), in der die göttlichen Gebote und Verbote öffentlich wirksam durchgesetzt werden.7 Der Islam verlangt nach ihrer Überzeugung die »Anwendung der Scharia« als von Gott verfügter allumfassender Rechts- und Werteordnung. Die Anwendung der Scharia aber setzt ihrerseits eine islamische Staatsgewalt voraus. Verglichen mit anderen Formen, Islam zu verstehen und zu leben (die gleichfalls davon ausgehen, dass Glaube und Handeln in erkennbarer Weise miteinander verknüpft sein müssen und alle 
Muslime beispielsweise die Pflicht haben, mehrmals täglich das Ritualgebet $\mathrm{zu}$ vollziehen, im Ramadan zu fasten, Almosen zu geben und nach Möglichkeit zumindest einmal im Leben nach Mekka zu pilgern), fällt auf, wie sehr die im engeren Sinn theologische Frage nach dem Heil hier überlagert wird durch die Konzentration auf diesseitiges Handeln, auf individuelle Praxis, Recht und öffentliche Ordnung und in letzter Konsequenz auf den Aspekt der Macht. Diese Fixierung auf die Macht ist in der innermuslimischen Diskussion auch vielfach (kritisch) angemerkt worden. (Vgl. Krämer I994a)

So unverzichtbar der islamische Staat nach Auffassung der Islamisten für ein wahrhaft islamisches Leben auch ist, sehen sie seine konkrete Form doch nicht unbedingt durch das historische Vorbild des Kalifats vorgegeben. Zumindest gilt das für die Mehrheit der sunnitischen Islamisten, während Schiiten im Rahmen der sog. Imamatstheorien spezifische Vorstellungen religiöser und politischer Autorität entwickelt haben, die in wesentlichen Punkten von sunnitischen Vorstellungen abweichen. ${ }^{8}$ Zwar soll der Koran (in dem vom Kalifat, nebenbei gesagt, nicht die Rede ist) einem verbreiteten Slogan zufolge als »Verfassung « des islamischen Staates dienen (»Der Koran ist unsere Verfassung«, al-qur an dusturuna). Tatsächlich enthalten weder Koran noch Sunna klare Weisungen für die Gestaltung der politischen Ordnung; in diesem Sinn gibt es daher auch keine verbindliche islamische politische Theorie. Unter Sunniten dominiert heute die Auffassung, Koran und Sunna schrieben den Muslimen in politischen Dingen einige allgemeine Richtlinien und Werte vor: das Beratungsprinzip shura, das Partizipation, wenn nicht Demokratie begründen soll, die Verantwortlichkeit der Regierenden, die Unabhängigkeit der Justiz - allesamt Grundsätze einer "guten Regierungsführung «, good governance, die internationale Organisationen seit Jahren einfordern und die hier gewissermaßen islamisch formuliert, legitimiert und abgesichert werden. ${ }^{9}$ 
Die in Koran und Sunna festgelegten und von Muslimen lediglich zu >entdeckenden< islamischen Grundsätze und Grundwerte müssen, so geht die Argumentation weiter, den wechselnden Zeitumständen und Bedürfnissen angepasst und in je angemessener Weise umgesetzt werden. Das kann im Rahmen eines wieder belebten Kalifats geschehen; es ist aber auch in einer islamischen Republik oder Monarchie möglich. Hier verbindet sich Festigkeit in den Grundsätzen mit Flexibilität in der Anwendung.

Politik dient aus dieser Sicht als Mittel zum Zweck, und der Zweck besteht in der Realisierung einer auf die Scharia gegründeten islamischen Ordnung, die man - mit allem, was das impliziert - als >Tugendstaat< verstehen kann. In dieser Vorstellung spiegelt sich, auch das wird rasch deutlich, ein eigenartig unpolitisches Politikverständnis, in dem die zentralen Kategorien von Macht, Interesse und Konkurrenz auffällig unterbelichtet bleiben, wenn sie nicht völlig ausgeblendet werden. An ihrer Stelle stehen religiös-moralische Kategorien wie richtig und falsch (haqq und batil), zulässig und unzulässig (halal und haram), gut und verwerflich (ma ruf und munkar) ${ }^{\mathrm{IO}}$ und das gleichfalls auf religiös-moralischer Grundlage konstruierte Gemeinwohl (almaslaha al-amma), an denen sich Wert und Berechtigung politischer Überzeugungen, Verfahren und Entscheidungen messen lassen sollen: Ein moralischer Diskurs ersetzt so weitgehend die politische Analyse. ${ }^{\text {II }}$

\section{Islam und Recht oder: Die 'Anwendung der Scharia،}

Die konkrete Gestaltung der politischen Ordnung ist aus dieser Sicht zweitrangig. Was zählt, ist die Rechts- und Werteordnung des islamischen Gemeinwesens. Dementsprechend rücken 
Form, Funktion und Wandlungsfähigkeit der Scharia in den Vordergrund, die in Wissenschaft und Öffentlichkeit lebhaft und äußerst kontrovers diskutiert werden. Die Vielzahl der Fragen, die sich bei genauerer Betrachtung stellen, kann hier nur angeschnitten werden: Sie betreffen unter anderem das Verhältnis von Ethik, Moral und Recht, das von muslimischen Juristen in anderer (im Wortsinn differenzierterer) Weise gesehen wird als von der Mehrzahl der zeitgenössischen Islamisten, die schlicht deren Identität behaupten. ${ }^{22}$ Tatsächlich liegt die besondere Attraktivität des Rufs nach einer »(integralen) Anwendung der Scharia « nicht zuletzt in der Erwartung, sie könne die Werte (Ethik, Moral, Anstand, Gerechtigkeit) verwirklichen, die in der eigenen Lebenswelt so heftig vermisst werden. ${ }^{\mathrm{I3}}$ Die zunächst akademisch anmutende Frage, ob die Scharia bzw. das islamische Juristenrecht (shura) überhaupt als >Recht< im modernen, juristischen Sinne verstanden werden könne, oder ob sie nicht vielmehr reine Pflichtenlehre sei (so in der ersten Hälfte des 20. Jahrhunderts der bedeutende Islamwissenschaftler Joseph Schacht, dem u.a. Baber Johansen widersprochen hat), zielt in eine ähnliche Richtung. Die sorgfältige Analyse zeigt, dass im islamischen shura - obgleich religiös fundiert - Ethik, Moral und Recht ebenso wenig zusammenfallen wie in anderen Rechtstheorien und -ordnungen. (Vgl. Schacht I935; Johansen I988; knapp und verständlich auch Scholz 200I)

Fundamental für jedes Verständnis islamischen Rechts ist das Verhältnis zwischen göttlicher Norm- und Rechtssetzung (shar, shari $\left.{ }^{i} a\right)$ auf der einen Seite und menschlicher Rechtsfindung (shura) auf der anderen: Nach islamischer Lehre ist die Scharia göttliches Recht in dem Sinn, dass sie in ihren Grundzügen ebenso wie in bestimmten Einzelpunkten von Gott (bzw., was meist weniger deutlich formuliert wird, seinem Gesandten Muhammad) für alle Zeiten unverrückbar festgelegt wurde, und zwar entweder im Koran oder in der von göttlicher Offenbarung 
geleiteten prophetischen Tradition, die gerade in Rechtsdingen als einander ergänzende normative Quellen gelten. Koran und Sunna aber sind, wie oben ausgeführt, Texte und daher auslegungsbedürftig. Ausgelegt wurden und werden sie durch Theologen und Juristen, die nach eigenem Verständnis nicht eigenständig Rechtsnormen entwickeln, diese vielmehr lediglich im heiligen Text »entdecken« oder aus dem heiligen Text »ableiten« (der Fachterminus lautet istinbat). Auch die sog. eigenständige Rechtsentwicklung (ijtihad), die in den Debatten um eine Erneuerung des Islam und der muslimischen Gesellschaften seit dem I8. Jahrhundert eine so zentrale Rolle spielt, wo immer wieder die »Öffnung« des angeblich im ıo. Jahrhundert geschlossenen »Tors des Ijtihad« gefordert wurde, bleibt an die normativen Quellen gebunden. Frei ist sie lediglich von der Bindung an eine bestimmte Rechtsschule (madhhab) mit ihren spezifischen Methoden und Doktrinen, die islamisches Recht und islamische Jurisprudenz über Jahrhunderte prägten. (Vgl. Kamali I99I; Hallaq ı997)

Damit ist wiederum das Thema »Festigkeit und Flexibilität« berührt, denn während die göttliche Setzung im Prinzip ewig gültig und unhinterfragbar ist (jedoch unausweichlich durch Menschen ermittelt wird), kann ihre menschliche Deutung keinen Anspruch auf Unfehlbarkeit erheben. Sie bleibt stets wandelbar und revidierbar. Kritik an Gottes Gesetz und Willen kann es nach muslimischer Überzeugung nicht geben, Kritik an menschlicher Auslegung sehr wohl. Allerdings wird zumindest in islamistischen Kreisen selten gründlicher über die Konsequenz aus dieser Einsicht nachgedacht; allzu häufig wird schlicht die Eindeutigkeit göttlicher Normen postuliert, die »in Koran und Sunna « klar und unmissverständlich nachzulesen und dann nur noch in die Praxis umzusetzen seien. Eine Reflexion darüber, was etwa die »Öffnung des Tors des Ijtihad« für das Verständnis menschlicher Vernunft und Freiheit bedeutet und in 
welchen Foren und Gremien sie stattfinden könnte, um gesellschaftliche Wirkung zu entfalten, fehlt allzu häufig. ${ }^{\text {I4 }}$

Schließlich geht es um die Reichweite islamrechtlicher Normen (zunächst gleichgültig, ob sie als Scharia im Sinne göttlicher Normsetzung oder shura im Sinne menschlicher Rechtsfindung bezeichnet werden), genauer gesagt darum, ob sie menschliches Verhalten auf individueller und kollektiver Ebene tatsächlich so flächendeckend reglementieren, wie von vielen Muslimen (und das heißt keineswegs nur Islamisten) behauptet, oder aber ob sie, wie von anderen angenommen, lediglich allgemeine Normen, Werte und Leitlinien vorgeben, die im Einklang mit variierenden Lebensumständen und Erwartungen wiederum flexibel umgesetzt werden müssen. Hierzu haben Gelehrte der klassischen Zeit mehr (und zugleich Komplizierteres und Interessanteres) gesagt, als vielen Zeitgenossen bewusst: Im Mittelpunkt standen dabei Überlegungen zum Gemeinwohl (al-maslaha al-amma), das in Beziehung zu Einzelbestimmungen der Scharia bzw. des shura gesetzt wurde. ${ }^{15}$ Das Beharren auf allgemeinen Normen und Werten wie Gerechtigkeit, Freiheit, Gleichheit, Verantwortung und Partizipation/shura (die gegebenenfalls sogar konkrete Vorschriften der Scharia und des tradierten fiqh überlagern oder aufheben sollen), als Kennzeichen einer gleichermaßen authentischen wie zeitgemäßen »islamischen Ordnung «, verdient auf jeden Fall Aufmerksamkeit, wenn man sich mit dem Verhältnis von Islam, Recht und Politik beschäftigt. (Vgl. Krämer I999a, bes. Kap. III, VI)

\section{Islam ist nicht gleich Islam}

So strittig einzelne Aspekte des Verhältnisses von Islam, Recht und Politik sind - und zwar unter Muslimen strittig - und so kontrovers sie ohne Zweifel bleiben werden, steht man doch 
nicht ohne Ergebnisse da. Sie lassen sich in einer Reihe von Un-Gleichungen ausdrücken: Islam ist nicht gleich Islam - das wird all denen einleuchten, die auf die offenkundige Vielfalt islamischer Denk- und Lebensformen blicken, und jene stören, die Islam in erster Linie als normative Tradition verstehen, deren notwendige Einheitlichkeit sie betonen. Islam ist nicht gleich Islamismus - das wird diejenigen überzeugen, die sich an die Realitäten halten, und jene irritieren, die im Einklang mit dem islamistischen Credo im Islam Religion und Politik zwingend und unauflöslich miteinander verbunden glauben. Islamismus ist nicht gleich Gewalt - das wird auf den Widerspruch derer stoßen, die Islamismus eng definieren und auf bestimmte (militante) Gruppierungen beschränken, die sie politisch bekämpfen.

Wenn Islam sich aber - auf einheitlicher normativer Quellenbasis - in unterschiedlichen Formen manifestiert und daher stets plural gedacht werden muss, wird man in politischen Fragen keine Einheitlichkeit erwarten dürfen. Die normativen Quellen formulieren keine spezifisch islamische politische Doktrin. Damit fällt auch jede Argumentation, im Islam seien Religion und Staat in vorgegebener Weise miteinander verbunden: Weder lässt sich behaupten, sie müssten unauflöslich miteinander verknüpft - noch aber, sie müssten notwendig voneinander getrennt sein. Sowohl die theokratische wie die säkulare Lösung bilden lediglich extreme Möglichkeiten politischer Gestaltung; sie sind Idealtypen, die in Vergangenheit und Gegenwart kaum je rein anzutreffen waren. Das gilt für das frühe Kalifat der Umayyaden ebenso wie für das späte der Osmanen, und für die Islamische Republik Iran ebenso wie für die Türkische Republik. ${ }^{\mathrm{I}}$

Dass Muslime in einem säkularen Staat leben können, muss wissenschaftlich nicht erst bewiesen werden. Das zeigt die Praxis nicht nur der muslimischen Diaspora in Westeuropa, Amerika und Australien, sondern auch der muslimischen Mehrheitsge- 
sellschaften der Türkei oder Usbekistans, wo die säkulare Ordnung allerdings von Staats wegen durchgesetzt wurde und gegen einigen Widerstand aufrechterhalten wird. Die Frage lautet zugleich jedoch, ob Muslime eine säkulare Ordnung selbst dort bejahen, wo eine sislamische Alternative< besteht. (Vgl. hierzu Johansen I996) ${ }^{\text {I7 }}$ Sie ist nicht allgemein zu beantworten, sondern nur mit Blick auf konkrete Personen, Gruppen und Gemeinschaften. In jedem Fall setzt dies voraus, dass Muslime zwar nicht ihren Glauben daran aufgeben, der Islam sei (die) religiöse Wahrheit - daran werden sie, wie die meisten Anhänger einer monotheistischen Glaubensgemeinschaft, vermutlich festhalten -, wohl aber den Anspruch auf Überlegenheit über alle anderen religiösen und weltanschaulichen Überzeugungen und die an diesen Überlegenheitsanspruch geknüpften rechtlichen und sozialen Konsequenzen von der rechtlichen Diskriminierung von Andersgläubigen und Agnostikern bis zum Verbot des Religionswechsels von Muslimen (»Apostasie«). Im Sinne echter Pluralität müsste die religiöse und rechtliche Anerkennung über den Kreis der Juden und Christen als Anhängern einer monotheistischen »Buchreligion« (ahl al-kitab) hinaus auf religiöse Bekenntnisse ausgedehnt werden, die im Islam als Heiden und Götzendiener abgewertet werden. Als legitim anerkannt werden müsste selbst der >bekennende< Atheismus. Eine »Anwendung der Scharia ist solange undenkbar, wie sie Prinzipien des tradierten shura enthält, die diese umfassende Anerkennung und rechtliche Gleichstellung gerade nicht zulassen. Ob eine derart radikal überholte Rechtsordnung noch als >Scharia< wahrgenommen würde, sei dahingestellt. Ausgeschlossen ist keine dieser Entwicklungen. Ausgemacht ebenso wenig. 


\section{Anmerkungen}

I Ein erster Abdruck dieses Beitrags erschien unter dem Titel Der Islam ist Religion und Staat in Schluchter (2003).

2 Die Terminologie ist in der Literatur wenig einheitlich; der in der Öffentlichkeit gängige Begriff »Fundamentalismus« wird von den Fachwissenschaftlern allerdings überwiegend als abwertend und generell unangemessen abgelehnt. Ausführlicher zu Definitionen von Islamismus, Fundamentalismus und politischem Islam in Krämer (I999a), insbes. Kap. I.

$3 \mathrm{Zu}$ säkularistischen Positionen in der arabischen Welt vgl. am Beispiel Ägyptens Steppat (I99I) sowie die Arbeiten von Flores, besonders Flores (I993).

4 Die so genannte Orientalismus-Debatte, die sich an Edward Saids 1978 erschienenem Buch »Orientalism« entzündete, das außerordentlich lebhafte, zum Teil offen polemische Kontroversen auslöste und vor allem (wenn auch keineswegs ausschließlich) eine jüngere Generation von Regional-, Kultur- und Islamwissenschaftlern beeindruckte, kann hier nicht eingehend behandelt werden. Beispielhaft für einen orientalismuskritischen Ansatz ist die Studie von Al-Azmeh (I996). Meine Position hierzu ist sehr knapp zusammengefasst in dem Vortrag »On Difference and Understanding« (Krämer 2000a).

5 Das meiste Aufsehen erregte international der Fall des ägyptischen Literatur- und Islamwissenschaftlers Nasr Hamid Abu Zaid, der in den goer Jahren wegen seiner literaturkritischen Arbeiten über den Koran der Apostasie beschuldigt, rechtskräftig verurteilt, von seiner Frau zwangsgeschieden und aus der Universität verdrängt wurde; er fand in Europa Asyl. Zumindest eines seiner Werke ist ins Deutsche übersetzt: Islam und Politik. Kritik eines religiösen Diskurses. 
6 Aus unterschiedlicher Perspektive vgl. hierzu Arjomand (I984), Berkey (200I), Skovgaard-Petersen (I997) oder auch Eickelman/Anderson (1999).

7 Dieser Punkt ist besonders deutlich herausgearbeitet bei Ayubi (I99I).

$8 \mathrm{Zu}$ den klassischen schiitischen Imamatslehren und der unter schiitischen Gelehrten umstrittenen - Doktrin von der »Herrschaft« oder »Vormundschaft des Rechtsgelehrten (velayat-e faqih) «, die von Ayatollah Khomeini entwickelt und in der Islamischen Republik Iran zumindest in Teilen umgesetzt wurde, vgl. Halm (I988) und Halm (I994). Außerhalb Irans übernahm die libanesische Hizbollah zunächst Grundzüge dieser Doktrin, um sich schrittweise jedoch von ihr abzuwenden - ein Beispiel für die Adaptations- und Lernfähigkeit auch solcher islamistischer Bewegungen, die gemeinhin als »radikal«, wenn nicht »extremistisch « eingestuft werden, vgl. Rosiny (I996). Zur Adaptations- und Lernfähigkeit islamistischer Bewegungen vgl. auch Krämer (I994b) und, noch breiter angelegt, Eickelman/Piscatori (1996).

9 Zum Folgenden eingehender Krämer (1999a) und Krämer (2000b); von der prinzipiellen Vereinbarkeit plural-demokratischer und (bestimmter) islamistischer Ordnungsvorstellungen geht Ahmad S. Moussalli (I995) aus.

IO Das gesellschaftspolitisch relevante koranische Gebot, »das Gute zu gebieten und das Verwerfliche zu verhindern« (alamr bil-ma'rufwan-nahy ${ }^{\text {a }}$ an al-munkar), das alle Abstufungen von Bürgersinn und gesellschaftlicher Verantwortung ganz allgemein bis hin zu umfassender Zensur und repressivem Vigilantentum umfassen kann, ist von Michael Cook (2000) umfassend untersucht worden. Zum Gemeinwohl nochmals unten. 
II Ein gutes Beispiel bietet der Aufsatz eines bekannten (nichtislamistischen) tunesischen Sozialwissenschaftlers: Bouhdiba (I998).

I2 Diese Sicht beschränkt sich allerdings nicht auf islamistische Muslime; sie prägt nicht selten auch die Darstellung dezidiert nicht-islamistischer Autoren; vgl. etwa die Beiträge in dem von Bouhdiba (I998) herausgegebenen Sammelband (vgl. Anm. II).

I3 Zum >Mythos Scharia< vgl. Sivan (I995: 218ff.); knapp auch: Krämer (I999b).

I4 Grundzüge eines liberalen islami(sti)schen Ansatzes, in dem diese Fragen zumindest ansatzweise gestellt werden, hat beispielhaft Leonard Binder (I998) analysiert. Ein gutes Beispiel einer solchen liberalen, auf die normativen Quellen gestützten Deutung, die sich selbst als Ijtihad versteht, bietet der in Kuala Lumpur lehrende Jurist Mohammad Hashim Kamali (I997).

I5 Dazu eingehend Hallaq (I997: I62-206) und auch Kamali (I99I).

I6 Aus sehr unterschiedlicher Perspektive vgl. hierzu Lapidus (I975); Sonn (I987) oder auch Schulze (I992).

I7 Der Zentralrat der Muslime in Deutschland - eine von mehreren miteinander konkurrierenden muslimischen Dachorganisationen - verabschiedete im Februar 2002 eine (bemerkenswerte) Islamische Charta, in der er die »vom Grundgesetz garantierte gewaltenteilige, rechtsstaatliche und demokratische Grundordnung « einschließlich des Rechts auf Religionswechsel bejahte (Punkt II), die deutsche Rechtsordnung anerkannte (Punkt Io und I3) und einen klerikalen Gottesstaat explizit ablehnte (Punkt I2). Ob die im Zentralrat vertretenen Muslime an anderem Ort und in einem anderen gesellschaftlichen Rahmen eine andere Rechts- 
und Verfassungsordnung für richtig befinden würden, ist diesem Text nicht zu entnehmen, für die öffentliche Ordnung in der Bundesrepublik Deutschland jedoch weitgehend unerheblich.

\section{Literatur}

Abu Zaid, Nasr Hamid (1996): Islam und Politik. Kritik eines religiösen Diskurses, Frankfurt a.M.

Arjomand, Said Amir (1984): The Shadow of God and the Hidden Imam. Religion, Political Order, and Societal Change in Shicite Iran from the Beginning to 1890 , Chicago [u.a.].

Ayubi, Nazih (I99I): Political Islam: Religion and Politics in the Arab World, London.

Al-Azmeh, Aziz (1996): Die Islamisierung des Islam. Imaginäre Welten einer politischen Theorie, Frankfurt a.M.

Berkey, Jonathan P. (200I): Popular Preaching and Religious Authority in the Medieval Islamic Near East, Seattle [u.a.].

Binder, Leonard (1998): Islamic Liberalism. A Critique of Development Ideologies, Chicago [u.a.].

Bouhdiba, Abdelwahab (1998): »Political Thought«, in: Ders. (Hg.): The Individual and Society in Islam (Different Aspects of Islamic Culture), Paris, S. 273-293.

Bobzin, Hartmut (1999): Der Koran. Eine Einführung, München.

Brown, Daniel W. (I996): Rethinking tradition in modern Islamic thought, Cambridge.

Cook, Michael (2000): Commanding Right and Forbidding Wrong in Islamic Thought, Cambridge.

Eickelman, Dale F./Piscatori, James (1996): Muslim Politics, Princeton. 
Eickelman, Dale F./Anderson, John W. (Hg.) (1999): New Media in the Muslim World. The Emerging Public Sphere, Bloomington.

Flores, Alexander (1993): »Secularism, Integralism and Political Islam. The Egyptian Debate«, in: Middle East Report, No. I83, S. 32-38.

Hallaq, Wael B. (1997): A History of Islamic Legal Theories, Cambridge.

Halm, Heinz (1988): Die Schia, Darmstadt.

Halm, Heinz (1994): Der schiitische Islam. Von der Religion zur Revolution, München.

Johansen, Baber (I988): »Die sündige, gesunde Amme. Moral und gesetzliche Bestimmung (hukm) im islamischen Recht«, in: Die Welt des Islams 28, S. 264-282.

Johansen, Baber (1996): »Staat, Recht und Religion im sunnitischen Islam - Können Muslime einen religionsneutralen Staat akzeptieren?«, in: Der Islam in der Bundesrepublik Deutschland, Münster (= Essener Gespräche zum Thema Staat und Kirche 20), S. 12-60.

Kamali, Mohammad Hashim (I99I): Principles of Islamic Jurisprudence, Cambridge.

Kamali, Mohammad Hashim (1997): Freedom of Expression in Islam, Cambridge.

Krämer, Gudrun (I994a): »Die Korrektur der Irrtümer: Innerislamische Debatten um Theorie und Praxis der islamischen Bewegungen «, in: Cornelia Wunsch (Hg.): XXV. Deutscher Orientalistentag, Vorträge, München 8.-13.4.1991, Stuttgart, S. I83-191.

Krämer, Gudrun (I994b): »The Integration of the Integrists: a comparative study of Egypt, Jordan and Tunisia«, in: Ghassan Salamé (Hg.): Democracy Without Democrats? The Renewal of Politics in the Muslim World, London, New York, S. 200-226. 
Krämer, Gudrun (I999a): Gottes Staat als Republik. Reflexionen zeitgenössischer Muslime zu Islam, Menschenrechten und Demokratie, Baden-Baden.

Krämer, Gudrun (I999b): »Law and Order: The Application of the Shari a in the Middle East«, in: Middle Eastern Lectures 3, S. 57-68.

Krämer, Gudrun (2000a): »On Difference and Understanding. The Use of Abuse of the Study of Islam«, in: ISIM (International Institute for the Study of Islam in the Modern World), Leiden, Newsletter 5, S. 6-7.

Krämer, Gudrun (2000b): »Good Counsel to the King: the Islamist Opposition in Saudi Arabia, Jordan and Morocco«, in: Joseph Kostiner (Hg.): Middle East Monarchies: the Challenge of Modernity, Boulder, S. 257-287.

Krämer, Gudrun (2003): »Der Islam ist Religion und Staat«, in: Wolfgang Schluchter (Hg): Fundamentalismus, Terrorismus, Krieg, Weilerswist.

Lapidus, Ira M. (I975): »The Separation of State and Religion in the Development of Early Islamic Society«, in: International Journal of Middle East Studies 6, S. 363-385.

Moussalli, Ahmad S. (I995): »Modern Islamic Fundamentalist Discourses on Civil Society, Pluralism and Democracy«, in: Augustus Richard Norton (Hg.): Civil Society in the Middle East, Bd. I, Leiden [u.a.], S. 79-II9.

Rosiny, Stephan (1996): Islamismus bei den Schiiten im Libanon, Berlin.

Saids, Edward W. (1978): Orientalism, London [u.a.].

Schacht, Joseph (I935): »Zur soziologischen Betrachtung des islamischen Rechts«, in: Der Islam 22, S. 207-238.

Schluchter, Wolfgang (2003): Fundamentalismus, Terrorismus, Krieg, Weilerswist. 
Scholz, Peter (200I): »Scharia in Tradition und Moderne - Eine Einführung in das islamische Recht«, in: Jura. Juristische Ausbildung 23, 8, S. 525-534.

Schulze, Reinhard (I992): »Islam und Herrschaft. Zur politischen Instrumentalisierung einer Religion«, in: Michael Lüders (Hg.): Der Islam im Aufbruch?, München, S. 94-I29.

Seidensticker, Tilman (2000): »Koran«, in: Udo Tworuschka (Hg.): Heilige Schriften. Eine Einführung, Darmstadt, S. III-Izо. Sivan, Emmanuel (1995): Mythes politiques arabes, Paris.

Skovgaard-Petersen, Jakob (1997): Defining Islam for the Egyptian State. Muftis and Fatwas of the Dar al-Ifta, Leiden [u.a.].

Sonn, Tamara (1987): »Secularism and National Stability in Islam«, in: Arab Studies Quarterly 9, 3, S. 284-305.

Steppat, Fritz (199I): »Säkularisten und Islamisten. Ein Kategorisierungsversuch in Ägypten«, in: Asien, Afrika, Lateinamerika I9, S. 699-704.

Wild, Stefan (Hg.) (I996): The Qur'an as Text, Leiden [u.a.]. 



\section{Zu den Herausgebern und Autoren}

Ernst-Otto Czempiel, Dr. phil., em. Professor für Internationale Politik und Außenpolitik an der Johann Wolfgang Goethe-Universität Frankfurt a.M., Mitbegründer und Mitglied der Hessischen Stiftung Friedens- und Konfliktforschung.

Jürgen Kocka, Dr. phil., Professor für Geschichte der industriellen Welt an der Freien Universität Berlin, seit 200I Präsident des Wissenschaftszentrums Berlin für Sozialforschung (WZB).

Helmut König, Dr. phil., Professor für Politische Wissenschaft an der Rheinisch-Westfälischen Technischen Hochschule Aachen.

Gudrun Krämer, Dr. phil., Professorin für Islamwissenschaft an der Freien Universität Berlin.

Herfried Münkler, Dr. phil., Professor für Theorie der Politik am Institut für Sozialwissenschaften der Humboldt-Universität zu Berlin. 
August Pradetto, Dr. phil., Professor für Politikwissenschaft am Institut für Internationale Politik der Helmut-Schmidt-Universität - Universität der Bundeswehr Hamburg.

Emanuel Richter, Dr. phil., Professor für Politische Systeme am Institut für Politische Wissenschaft der Rheinisch-Westfälischen Technischen Hochschule Aachen.

Manfred Sicking, Dr. phil., Leiter des Fachbereichs Wirtschaftsförderung/Europäische Angelegenheiten der Stadt Aachen und Lehrbeauftragter am Institut für Politische Wissenschaft der Rheinisch-Westfälischen Technischen Hochschule Aachen.

Christian Tomuschat, Dr. jur., Professor für öffentliches Recht, insbesondere Völker- und Europarecht, an der Juristischen Fakultät der Humboldt-Universität zu Berlin. 


\section{Weitere Titel zum Thema:}

Ulrich Beck, Natan Sznaider,

Rainer Winter (Hg.)

Globales Amerika?

Die kulturellen Folgen der

Globalisierung

2003, 344 Seiten,

kart., $25,80 €$,

ISBN: $3-89942-172-8$

Markus Kaiser (Hg.)

Auf der Suche nach Eurasien

Politik, Religion und

Alltagskultur zwischen

Russland und Europa

Januar 2004, 398 Seiten,

kart., $25,80 €$,

ISBN: 3-89942-131-o

Roger Behrens

Die Diktatur der Angepassten

Texte zur kritischen Theorie

der Popkultur

2003, 298 Seiten,

kart., $24,80 €$,

ISBN: 3-89942-115-9

Martin Ludwig Hofmann

Monopole der Gewalt

Mafiose Macht, staatliche

Souveränität und die

Wiederkehr normativer Theorie

2003, 274 Seiten,

kart., $25,80 €$,

ISBN: 3-89942-170-1
Klaus E. Müller (Hg.)

Phänomen Kultur

Perspektiven und Aufgaben der

Kulturwissenschaften

2003, 238 Seiten,

kart., $25,80 €$,

ISBN: 3-89942-117-5

Markus Kaiser (Hg.)

\section{WeltWissen}

Entwicklungszusammenarbeit in der Weltgesellschaft

2003, 384 Seiten,

kart., $25,80 €$,

ISBN: 3-89942-112-4

Sibylle Niekisch

\section{Kolonisation und Konsum}

Kulturkonzepte in Ethnologie und Cultural Studies

2002, 110 Seiten,

kart., $13,80 €$,

ISBN: 3-89942-101-9

Andreas Ackermann,

Klaus E. Müller (Hg.)

Patchwork: Dimensionen multikultureller

Gesellschaften

Geschichte, Problematik und

Chancen

2002, 312 Seiten,

kart., $25,80 €$,

ISBN: 3-89942-108-6

Leseproben und weitere Informationen finden Sie unter: www.transcript-verlag.de 